MODELING AND OPTIMIZATION OF A BIOETHANOL PRODUCTION FACILITY

\author{
A Thesis \\ by \\ KERRON JUDE GABRIEL
}

\begin{abstract}
Submitted to the Office of Graduate Studies of Texas A\&M University in partial fulfillment of the requirements for the degree of MASTER OF SCIENCE
\end{abstract}

August 2011

Major Subject: Chemical Engineering 
Modeling and Optimization of a Bioethanol Production Facility Copyright 2011 Kerron Jude Gabriel 


\title{
MODELING AND OPTIMIZATION OF A BIOETHANOL PRODUCTION FACILITY
}

\author{
A Thesis \\ by \\ KERRON JUDE GABRIEL
}

\begin{abstract}
Submitted to the Office of Graduate Studies of
Texas A\&M University

in partial fulfillment of the requirements for the degree of

MASTER OF SCIENCE
\end{abstract}

\begin{abstract}
Approved by:
Chair of Committee, Mahmoud El-Halwagi

Committee Members, M. Sam Mannan

Guy Curry

Head of Department, Michael Pishko
\end{abstract}

August 2011

Major Subject: Chemical Engineering 


\author{
ABSTRACT \\ Modeling and Optimization of a Bioethanol Production Facility. \\ (August 2011) \\ Kerron Jude Gabriel, B.S., University of the West Indies, Trinidad \\ Chair of Advisory Committee: Dr. Mahmoud El-Halwagi
}

The primary objective of this work is to identify the optimal bioethanol production plant capacity and configuration based on currently available technology for all the processing sections involved. To effect this study, a systematic method is utilized which involves the development of a superstructure for the overall technology selection, process simulation and model regression of each processing step as well as equipment costing and overall economic evaluation. The developed optimization model is also designed to incorporate various biomass feedstocks as well as realistic maximum equipment sizing thereby ensuring pragmatism of the work. For this study, the criterion for optimization is minimum ethanol price.

The secondary and more interesting aim of this work was to develop a systematic method for evaluating the economics of biomass storage due to seasonal availabilities. In essence, a mathematical model was developed to link seasonal availabilities with plant capacity with subsequent integration into the original model developed. Similarly, the criterion for optimization is minimum ethanol price. 
The results of this work reveal that the optimal bioethanol production plant capacity is $\sim 2800$ MT biomass/day utilizing Ammonia Fiber Explosion pretreatment technology and corn stover as the preferred biomass feedstock. This configuration provides a minimum ethanol price of $\$ 1.96 /$ gal. Results also show that this optimal pretreatment choice has a relatively high sensitivity to chemical cost thereby increasing the risk of implementation. Secondary to this optimal selection was lime pretreatment using switchgrass which showed a fairly stable sensitivity to market chemical cost.

For the storage economics evaluation, results indicated that biomass storage is not economical beyond a plant capacity of $\sim 98 \mathrm{MMgal} / \mathrm{yr}$ with an average biomass shortage period of 3 months. The study also showed that for storage to be economical at all plant capacities, the storage scheme employed should be general open air land use with a corresponding biomass loss rate as defined in the study of $0.5 \%$ per month. 


\section{DEDICATION}

I would like to dedicate my academic work to my family but especially to my mother, Judy Perichan - Gabriel who has always encouraged me to never settle for mediocrity and to always strive for excellence in every undertaken task. She will never be forgotten and her words and inspiration will live with me forever. 


\section{ACKNOWLEDGEMENTS}

There are many people who have helped me in my graduate studies whom I wish to thank. First is my advisor, Dr. El-Halwagi, for the guidance, support and patience he has shown me throughout my coursework and research. I also wish to thank Dr. Mannan and Dr. Curry for serving on my committee and for their assistance during the course of this research.

I would also like to thank my family for their unwavering support and love throughout this entire journey and my former co-workers at Cambridge Chemical Technologies Inc. for teaching me and greatly enriching my professional engineering capabilities. Finally, I wish to extend my thanks to my officemates, Eric Pennaz and Mohamed Noureldin, and to my many friends here at Texas A\&M University for their inspiration and support throughout this program. 


\section{NOMENCLATURE}
A
Pre-exponential factor
$A_{o}$
"A" parameter for pre-exponential factor
$A_{1}$
"A" parameter for pre-exponential factor
$A^{\text {evp }}$
Total Heat transfer area of evaporator
$A_{i j, \text { evp }}^{\text {heat }}$
Total heat transfer area of evaporator for source $i$, technology $j$
$A_{i j, d}^{c o n d}$
Heat transfer area of distillation condenser for source $i$, technology $j$
$A_{i j, p}^{h e a t}$
Heat transfer area for pretreatment HEX for source $\mathrm{i}$, technology $\mathrm{j}$
$A_{i j, d}^{r e b}$
Heat transfer area of distillation reboiler for source $\mathrm{i}$, technology $\mathrm{j}$
$A_{i j, \text { air }}^{\text {cool }}$
Heat transfer area of air cooler for source $i$, technology $j$
$A_{\text {sales }}$
Annual sales
$A_{C r}$
Annual credits
$A_{D}$
Annual straight line depreciation
$A_{F C}$
Annualized capital investment
$A_{O C}$
Annual operating cost
$A_{\text {tax }}$
Annual tax
$A_{\text {cash flow }}$
Annual cash flow
$C_{o}$
Concentration of acid used for pretreatment
$C_{a}$
Effective acid concentration after biomass neutralization
$c_{i}^{l i n}$
Y-intercept of ith line for linearized function 


\begin{tabular}{|c|c|}
\hline$C^{\text {strip }}$ & Cost of stripping column \\
\hline$C^{\text {dist }}$ & Cost of distillation column \\
\hline$C^{e v p}$ & Cost of evaporator \\
\hline$C_{i}^{b i o}$ & Cost of biomass for source i \\
\hline$C_{i}^{\text {gate }}$ & Cost of biomass at gate for source $\mathrm{i}$ \\
\hline$C^{\text {elect }}$ & Cost of electricity \\
\hline$C^{\text {acid }}$ & Cost of acid \\
\hline$C^{\mathrm{H}_{2} \mathrm{O}}$ & Cost of process water \\
\hline$C^{C W}$ & Cost of cooling water \\
\hline$C^{s t m}$ & Cost of steam \\
\hline$C^{e n z}$ & Cost of enzyme \\
\hline$C^{N G}$ & Cost of natural gas \\
\hline$C^{\text {etoh }}$ & Cost of ethanol \\
\hline$c_{i j}^{a c i d}$ & Concentration of acid for source $i$, technology $j$ \\
\hline $\mathrm{C}_{p, \mathrm{H}_{2} \mathrm{O}}$ & Specific heat capacity of water \\
\hline$C L_{i j}$ & Cellulose loading to hydrolysis for source $i$, technology $j$ \\
\hline$C r_{i j}^{b i o}$ & Credits for biomass for source $i$, technology $j$ \\
\hline$C r_{i j, \text { evp }}^{L P S}$ & Credits for recovered LPS from evaporator for source $i$, technology $j$ \\
\hline $\mathrm{Cr}_{i j, \text { evp }}^{\mathrm{H}_{2} \mathrm{O}, \mathrm{r}}$ & Credits for recovered water from evaporator for source $i$, technology $j$ \\
\hline$C r_{i j, e v p}^{\text {elect }}$ & Credits for cogeneration electricity for source $i$, technology $j$ \\
\hline
\end{tabular}


$\mathrm{Cr}_{i j, d}^{\mathrm{H}_{2} \mathrm{O}, \mathrm{r}} \quad$ Credits for recovered water from distillation for source $\mathrm{i}$, technology $\mathrm{j}$

$C r_{i j} \quad$ Credits for source $\mathrm{i}$, technology $\mathrm{j}$

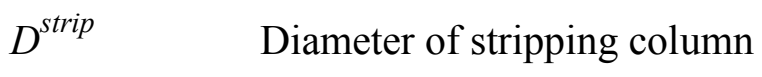

$D_{i j, s}^{c o l} \quad$ Diameter of stripping column for source $\mathrm{i}$, technology $\mathrm{j}$

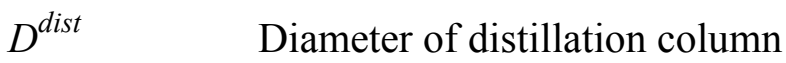

$D_{i j, d}^{c o l} \quad$ Diameter of distillation column for source $\mathrm{i}$, technology $\mathrm{j}$

$E_{i}^{\text {mill }} \quad$ Energy requirement for milling biomass for source i

[Enzyme] Enzyme concentration

$E_{A} \quad$ Activation energy

$E L_{i j, h} \quad$ Enzyme loading to hydrolyser for source i, technology $\mathrm{j}$

$E L_{i j, f} \quad$ Enzyme loading to fermenter for source $\mathrm{i}$, technology $\mathrm{j}$

FPU Enzyme activity (Filter paper units)

$F_{\text {etoh }}^{\text {strip }} \quad$ Flowrate of ethanol to stripping column

$F_{g l u}^{f e r m} \quad$ Flowrate of glucose to fermenter

$\mathrm{F}_{\text {ferm }}^{\mathrm{CO}_{2}} \quad$ Flowrate of carbon dioxide from fermenter

$F_{x y l}^{f e r m} \quad$ Flowrate of xylose to fermenter

$F_{L P S}^{\text {strip }} \quad$ Flowrate of MPS to stripping column

$F_{\mathrm{H}_{2} \mathrm{O}}^{\text {strip }} \quad$ Flowrate of water to stripping column

$F_{\text {cont }}^{\text {strip }} \quad$ Flowrate of contaminants to stripping column

$F_{\text {etoh }}^{\text {strip }} \quad$ Flowrate of ethanol to stripping column 
$F_{H_{2}}^{\text {dist }}$

$F_{\text {etoh }}^{\text {dist }}$

$F_{M P S}^{e v p}$

$F_{\mathrm{H}_{2} \mathrm{O}}^{\text {evp }}$

$F_{\text {cont }}^{\text {evp }}$

$F_{L P S, r}^{e v p}$

$F_{i}^{b i o}$

$F_{i, j}^{b i o}$

$F_{i}^{\max }$

$F_{i j, p}^{a c i d}$

$F_{i j, p}^{\mathrm{H}_{2} \mathrm{O}}$

$F_{i j, p}^{H P S}$

$F_{i j, p}^{L P S}$

$F_{i j, p}^{L P S \max }$

$F C_{i j, p}^{\text {heat }}$

$F_{i j, f}^{x y l}$

$F_{i j, h}^{b i o}$

$F_{i j, n}^{\mathrm{H}_{2} \mathrm{O}}$

$F C_{i j, p}^{\text {react }}$

$F_{i j, n}^{\text {lime }}$

Flowrate of water to distillation column

Flowrate of ethanol to distillation column

Flowrate of MPS to evaporator

Flowrate of water to evaporator

Flowrate of contaminants to evaporator

Flowrate of recovered LPS from evaporator

Flowrate of biomass for source $\mathrm{i}$

Flowrate of biomass for source $i$, technology $j$

Maximum flowrate of biomass for source i

Flowrate of acid for source $\mathrm{i}$, technology $\mathrm{j}$

Flowrate of water to pretreatment for source $i$, technology $j$

Flowrate of HPS to pretreatment for source $i$, technology $j$

Flowrate of LPS to pretreatment for source $i$, technology $j$

Max flowrate of LPS to pretreatment for source $i$, technology $j$

Fixed capital cost of pretreatment heater for source $\mathrm{i}$, technology $\mathrm{j}$

Flowrate of xylose to fermentation for source $i$, technology $j$

Flowrate of biomass to hydrolysis for source $i$, technology $j$

Flowrate of water to neutralization for source $i$, technology $j$

Fixed capital cost for pretreatment reactor for source $i$, technology $j$

Flowrate of lime to neutralization for source $i$, technology $j$ 
$F_{i j, n}^{g y p s u m} \quad$ Flowrate of gypsum from neutralization for source $\mathrm{i}$, technology $\mathrm{j}$

$F_{i j, n}^{a c i d} \quad$ Flowrate of acid to neutralization for source $\mathrm{i}$, technology $\mathrm{j}$

$F C_{i j, n}^{\text {react }} \quad$ Fixed capital cost of neutralization reactor for source $\mathrm{i}$, technology $\mathrm{j}$

$F_{i j, h}^{\mathrm{H}_{2} \mathrm{O}} \quad$ Flowrate of water to hydrolysis for source i, technology $\mathrm{j}$

$F_{i j, h}^{b i o} \quad$ Flowrate of biomass to hydrolysis for source i, technology j

$F_{i j, f}^{g l u} \quad$ Flowrate of glucose to fermenter for source i, technology j

$F_{i j, b}^{b i o} \quad$ Flowrate of biomass to burn for source $\mathrm{i}$, technology $\mathrm{j}$

$F_{i j, f}^{x y l} \quad$ Flowrate of xylose to fermenter for source i, technology j

$F_{i j, f}^{\mathrm{H}_{2} \mathrm{O}} \quad$ Flowrate of water to fermenter for source i, technology $\mathrm{j}$

$F_{i j, \text { loss }}^{\mathrm{H}_{2} \mathrm{O}} \quad$ Flowrate of lost water for source i, technology $\mathrm{j}$

$F_{i j, h}^{\mathrm{H}_{2} \mathrm{O}} \quad$ Flowrate of water to hydrolyser for source i, technology j

$F C_{i j, h}^{\text {react }} \quad$ Fixed capital cost of hydrolyser for source i, technology $\mathrm{j}$

$F_{i j, s}^{g l u} \quad$ Flowrate of glucose to stripping column for source $\mathrm{i}$, technology $\mathrm{j}$

$F_{i j, s}^{x y l} \quad$ Flowrate of xylose to stripping column for source i, technology $\mathrm{j}$

$F_{i j, s}^{\text {tol }} \quad$ Flowrate of xylitol to stripping column for source $\mathrm{i}$, technology $\mathrm{j}$

$F_{i j, s}^{\text {etoh }} \quad$ Flowrate of ethanol to stripping column for source $\mathrm{i}$, technology $\mathrm{j}$

$F_{i j, f}^{\mathrm{CO}_{2}} \quad$ Flowrate of carbon dioxide from fermenter for source $\mathrm{i}$, technology $\mathrm{j}$

$F_{i j, s}^{\mathrm{H}_{2} \mathrm{O}} \quad$ Flowrate of water to stripping column for source i, technology $\mathrm{j}$

$F_{i j, s}^{L P S} \quad$ Flowrate of LPS to stripping column for source $\mathrm{i}$, technology $\mathrm{j}$ 
$F_{i j, s}^{c o n t}$

$F C_{i j, f}^{\text {react }}$

$F_{i j, S}^{L P S}$

$F_{i j, d}^{\mathrm{H}_{2} \mathrm{O}}$

$F_{i j, \text { evp }}^{\mathrm{H}_{2} \mathrm{O}}$

$F_{i j, d}^{e t o h}$

$F C_{i j, s}^{c o l}$

$F_{i j, \text { evp }}^{M P S}$

$F_{i j, \text { evp }}^{\mathrm{H}_{2} \mathrm{O}}$

$F_{i j, \text { evp }}^{\text {cont }}$

$F_{i j, \text { evp }}^{L P S, r}$

$F C_{i j, \text { evp }}^{\text {heat }}$

$F_{i j \text {,waste }}^{\mathrm{H}_{2} \mathrm{O}}$

$F_{i j, e v p}^{\mathrm{H}_{2} \mathrm{O}, \mathrm{r}}$

$F C_{i j, \text { evp }}^{\text {turbine }}$

$F C_{i j, d}^{c o l}$

$F_{i j, d}^{C W}$

$F C_{i j, d}^{\text {cond }}$

$F_{i j, d}^{H P S}$

Flowrate of contaminant to stripping column for source $i$, technology $j$

Fixed capital cost of fermenter for source $i$, technology $j$

Flowrate of LPS to stripping column for source $\mathrm{i}$, technology $\mathrm{j}$

Flowrate of water to distillation column for source $i$, technology $j$

Flowrate of water to evaporator for source $i$, technology $j$

Flowrate of ethanol to distillation column for source $i$, technology $j$

Fixed capital cost of stripping column for source $i$, technology $j$

Flowrate of MPS to evaporator for source i, technology $\mathrm{j}$

Flowrate of water to evaporator for source $i$, technology $j$

Flowrate of contaminant to evaporator for source $i$, technology $j$

Flowrate of recovered LPS from evaporator for source $\mathrm{i}$, technology $\mathrm{j}$

Fixed capital cost of evaporator for source $i$, technology $j$

Flowrate of water waste for source $i$, technology $j$

Flowrate of recovered water from evaporator for source $i$, technology $j$

Fixed capital cost of MPS turbine source $i$, technology $\mathrm{j}$

Fixed capital cost of distillation column

Flowrate of cooling water to distillation column for source $\mathrm{i}$, technology $\mathrm{j}$

Fixed capital cost of condenser for source $i$, technology $j$

Flowrate of HPS to distillation for source $i$, technology $j$ 


\begin{tabular}{|c|c|}
\hline$F C_{i j, d}^{r e b}$ & Fixed capital cost of reboiler for source $i$, technology $j$ \\
\hline$F_{i j, \text { sieve }}^{\text {etoh }}$ & Flowrate of ethanol to sieve beds for source i, technology $j$ \\
\hline$F_{i j, \text { sieve }}^{H_{2} O}$ & Flowrate of water to sieve beds for source $i$, technology $j$ \\
\hline$F_{i j, d}^{H_{2} O, r}$ & Flowrate of recovered water from distillation for source $i$, technology $j$ \\
\hline$F C_{i j, \text { air }}^{\text {cool }}$ & Fixed capital cost of air cooler for source $i$, technology $j$ \\
\hline$F_{i j, \text { sales }}^{\text {etoh }}$ & Flowrate of ethanol to sales for source $i$, technology $j$ \\
\hline$F C_{i j, \text { sieve }}$ & Fixed capital cost of sieve beds for source $i$, technology $j$ \\
\hline$F C$ & Total fixed capital cost \\
\hline$F C_{i j}$ & Fixed capital cost for source $i$, technology $j$ \\
\hline$F_{i j, h}^{e n z}$ & Flowrate of enzyme to hydrolyser for source i, technology j \\
\hline$\Delta H_{v}^{H P S}$ & Heat of vaporization for HPS \\
\hline$\Delta H_{v}^{L P S}$ & Heat of vaporization for LPS \\
\hline$\Delta H_{c, i}$ & Heat of combustion of biomass for source $i$ \\
\hline HEX & Heat exchanger \\
\hline HPS & High pressure steam \\
\hline$H^{H P S}$ & Enthalpy of HPS \\
\hline$H^{M P S}$ & Enthalpy of MPS \\
\hline$i$ & Index variable for biomass source \\
\hline I & Maximum for index variable $i$ \\
\hline$I R$ & Interest rate \\
\hline
\end{tabular}


Index variable for pretreatment technology

$J \quad$ Maximum for index variable $j$

Rate constant

$k_{f}$

Rate constant for fast reacting xylan

$k_{2}$

Rate of degradation for xylose

$k$

$$
k_{A}
$$

$k_{1}$

$k_{2}$

Rate constant for slow reacting xylan

$k_{A}$

"k" parameter for pre-exponential factor

" $\mathrm{k}$ " parameter for pre-exponential factor

$k_{o}$

" $\mathrm{k}$ " parameter for pre-exponential factor

"k" parameter for pre-exponential factor

$k_{g l u}$

Rate constant for glucose conversion

$k_{\text {tol }}$

Rate constant for xylitol production

$k_{x y l}$

Rate constant for xylose conversion

$L C_{i j} \quad$ Labor cost for source $\mathrm{i}$, technology $\mathrm{j}$

LPS Low pressure steam

MPS Medium pressure steam

$M W_{\text {lime }} \quad$ Molecular weight for lime

$M W_{\text {acid }} \quad$ Molecular weight of acid

$M W_{\text {gypsum }} \quad$ Molecular weight of gypsum

$m_{i}^{l i n} \quad$ Gradient of ith line for linearized function

$m_{i}^{t} \quad$ Transportation cost factor for source $\mathrm{i}$ 


\begin{tabular}{|c|c|}
\hline$M_{s}$ & Mass biomass stored \\
\hline$\dot{m}_{H}$ & Harvesting rate of biomass \\
\hline$\dot{m}_{P}$ & Production rate of biomass \\
\hline$M_{s}^{o}$ & Initial mass stored at start of winter period \\
\hline$\dot{m}_{a c c}$ & Accumulation rate of biomass \\
\hline$N A$ & Neutralizing ability of biomass \\
\hline$n$ & Exponent for effective acid concentration \\
\hline$O C_{i j, S}^{L P S}$ & Operating cost of LPS to stripping column for source $i$, technology $j$ \\
\hline$O C^{b i o}$ & Operating cost for biomass source i \\
\hline$O C_{i}^{\text {mill }}$ & Operating cost of milling biomass for source $\mathrm{i}$ \\
\hline$O C_{i j, p}^{a c i d}$ & Operating cost for acid for source $i$, technology $j$ \\
\hline$O C_{i j, p}^{\mathrm{H}_{2} \mathrm{O}}$ & Operating cost for water for source $i$, technology $j$ \\
\hline$O C_{i j, p}^{L P S}$ & Operating cost of LPS to pretreatment for source $i$, technology $j$ \\
\hline$O C_{i j, h}^{\mathrm{H}_{2} \mathrm{O}}$ & Operating cost of water to hydrolysis for source i, technology j \\
\hline$O C_{i j, h}^{e n z}$ & Operating cost of hydrolyser enzyme for source $i$, technology $j$ \\
\hline$O C_{i j, d}^{C W}$ & Operating cost of cooling water to distillation for source $i$, technology $j$ \\
\hline$O C_{i j, d}^{H P S}$ & Operating cost of HPS for distillation for source $i$, technology $j$ \\
\hline$O C_{i j, \text { air }}^{\text {cool }}$ & Operating cost of air cooler for source $i$, technology $j$ \\
\hline$O P_{\text {days }}$ & Operating days \\
\hline$O C^{o m}$ & Operating and maintenance costs \\
\hline
\end{tabular}


$O C_{i j} \quad$ Operating cost for source $\mathrm{i}$, technology $\mathrm{j}$

$P_{I}^{\text {strip }} \quad$ Parametric cost coefficient for stripping column costing

$P_{2}^{\text {strip }} \quad$ Parametric cost coefficient for stripping column costing

$P_{3}^{\text {strip }} \quad$ Parametric cost coefficient for stripping column costing

$P_{1}^{\text {dist }} \quad$ Parametric cost coefficient for distillation column costing

$P_{2}^{\text {dist }} \quad$ Parametric cost coefficient for distillation column costing

$P_{3}^{\text {dist }} \quad$ Parametric cost coefficient for distillation column costing

$P_{1}^{e v p} \quad$ Parametric cost coefficient for evaporator costing

$P_{1}^{\text {cond }} \quad$ Parametric cost coefficient for condenser costing

$P_{1}^{r e b} \quad$ Parametric cost coefficient for reboiler costing

$P_{l}^{\text {turb }} \quad$ Parametric cost coefficient for steam turbine costing

$P_{l}^{\text {air }} \quad$ Parametric cost coefficient for air cooler costing

$P_{1}^{\text {sieve }} \quad$ Parametric cost coefficient for sieve bed costing

$P S_{i j} \quad$ Number of processing steps

plife Plant life

$Q_{\text {cond }}^{\text {dist }} \quad$ Duty of distillation column condenser

$Q_{\text {reb }}^{\text {dist }} \quad$ Duty of distillation column reboiler

$Q_{\text {cool }}^{\text {evp }} \quad$ Duty required for cooling recovered water from evaporator

$Q_{i j, \text { evp }}^{\text {cool }} \quad$ Duty required for cooling recovered water from evaporator

$Q_{i j, d}^{\text {cond }} \quad$ Duty of distillation column condenser 


\begin{tabular}{|c|c|}
\hline$Q_{i j, d}^{r e b}$ & Duty of distillation column reboiler \\
\hline $\mathrm{R}$ & Gas constant \\
\hline$r$ & Rotting rate of biomass \\
\hline$S L$ & Solid loading \\
\hline$S L_{i j}$ & Solid loading for source $\mathrm{i}$, technology $\mathrm{j}$ \\
\hline $\mathrm{T}$ & Temperature \\
\hline$t^{p}$ & Time of pretreatment \\
\hline$t^{h}$ & Time of hydrolysis \\
\hline$t^{f}$ & Time of fermentation \\
\hline$T_{j}$ & Pretreatment temperature for technology $\mathrm{j}$ \\
\hline$T_{a m b}$ & Ambient temperature \\
\hline$\Delta T_{l m}^{h e a t}$ & Log mean temperature difference for heaters \\
\hline$\Delta T_{l m}^{c o n d}$ & Log mean temperature difference for condenser \\
\hline$\Delta T_{l m}^{r e b}$ & Log mean temperature difference for reboiler \\
\hline$\Delta T^{a i r}$ & Temperature difference for air cooler \\
\hline$\Delta T_{l m}^{a i r}$ & Log mean temperature difference for air cooler \\
\hline$t_{i j}^{p}$ & Pretreatment time for source $i$, technology $j$ \\
\hline$t_{i j}^{h}$ & Hydrolysis time for source i, technology j \\
\hline$t_{i j}^{f}$ & Fermentation time Flowrate for source $i$, technology $j$ \\
\hline$t_{i j}^{n}$ & Neutralization time for source $\mathrm{i}$, technology $\mathrm{j}$ \\
\hline$T^{C W}$ & Cooling water temperature \\
\hline
\end{tabular}




\begin{tabular}{|c|c|}
\hline$T C I$ & Total capital investment \\
\hline$T R^{\text {corp }}$ & Corporate tax rate \\
\hline$t_{\text {har }}$ & Harvesting period for biomass \\
\hline$t_{\text {win }}$ & Winter period of region \\
\hline$U^{\text {heat }}$ & Overall heat transfer coefficient for heaters \\
\hline$U^{\text {cond }}$ & Overall heat transfer coefficient for condenser \\
\hline$U^{r e b}$ & Overall heat transfer coefficient for reboiler \\
\hline$U^{\text {air }}$ & Overall heat transfer coefficient for air cooler \\
\hline$V_{i j, n}^{r e a c t}$ & Volume of neutralization reactor for source $i$, technology $j$ \\
\hline$V_{i j, h}^{r e a c t}$ & Volume of hydrolyser for source $i$, technology $j$ \\
\hline$V_{i j, f}^{r e a c t}$ & Volume of fermenter for source $i$, technology $j$ \\
\hline$V_{i j, p}^{r e a c t}$ & Volume of pretreatment reactor for source $i$, technology $j$ \\
\hline$v^{\text {etoh }}$ & Specific density of ethanol \\
\hline$W C I$ & Working capital investment \\
\hline$x$ & Enzyme loading exponent \\
\hline$X^{x}$ & Fractional conversion of xylan \\
\hline$X_{f}^{x o}$ & Fractional composition of fast reacting xylan \\
\hline$X_{s}^{x o}$ & Fractional composition of slow reacting xylan \\
\hline$X^{\text {poly }}$ & Fractional conversion of polysaccharide \\
\hline$X_{R}^{g l u}$ & Fraction conversion of glucose to ethanol \\
\hline$X_{R}^{x y l}$ & Fractional conversion of xylose to ethanol \\
\hline
\end{tabular}




\begin{tabular}{|c|c|}
\hline$X_{R}^{\text {tol }}$ & Fractional conversion of xylose to xylitol \\
\hline$x_{\text {etoh }}^{\text {dist }}$ & Mass fraction of ethanol \\
\hline$X_{i j, p}^{x}$ & Fractional conversion of xylose in pretreatment for source $i$, technology $j$ \\
\hline$X_{i}^{x o}$ & Fractional composition of xylan in biomass for source $\mathrm{i}$ \\
\hline$X_{i}^{g o}$ & Fractional composition of glucan in biomass for source $i$ \\
\hline$X_{i j, h}^{g}$ & Fractional conversion of glucan in hydrolyser for source $i$, technology $j$ \\
\hline$X_{\text {loss }}^{\text {enz }}$ & Fractional enzyme loss \\
\hline$X_{i j, f}^{g}$ & Fractional conversion of glucose in fermenter for source $i$, technology $j$ \\
\hline$X_{i j, f}^{x}$ & Fractional conversion of xylose in fermenter for source $i$, technology $j$ \\
\hline$X_{i j, f}^{t o l}$ & Fractional conversion to xylitol \\
\hline$X_{\text {rec,s }}^{\text {etoh }}$ & Fractional recovery of ethanol in stripping column \\
\hline$x_{i j, d}^{e t o h}$ & Mass fraction of ethanol \\
\hline$X_{\text {rec, } d}^{\text {etoh }}$ & Fractional recovery of ethanol in distillation \\
\hline$y$ & Predicted value \\
\hline$y^{*}$ & Experimental value \\
\hline$\eta_{b}$ & Boiler efficiency \\
\hline$\rho_{\mathrm{H}_{2} \mathrm{O}}$ & Density of water \\
\hline$\rho_{i}^{b i o}$ & Density of biomass \\
\hline$\rho_{\text {acid }}$ & Density of acid \\
\hline$\rho_{\text {lime }}$ & Density of lime \\
\hline$\rho_{f}^{e n z}$ & Density of fermenting enzyme \\
\hline
\end{tabular}




\section{TABLE OF CONTENTS}

Page

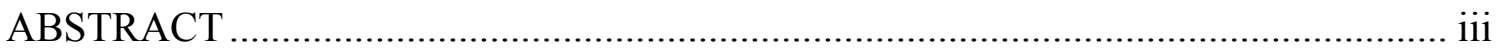

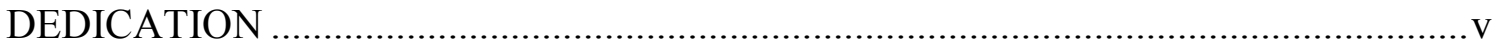

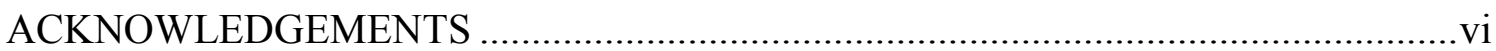

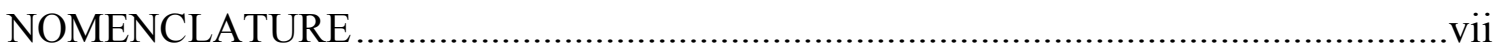

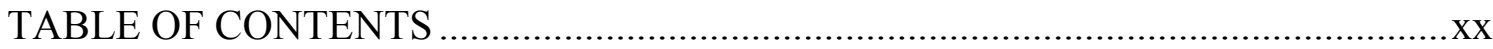

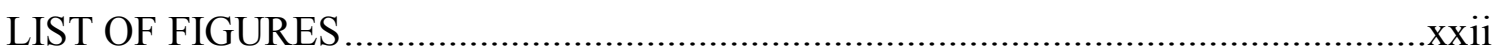

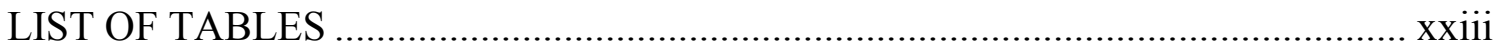

1. INTRODUCTION

2. BACKGROUND

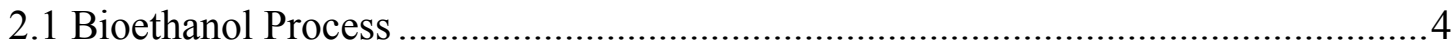

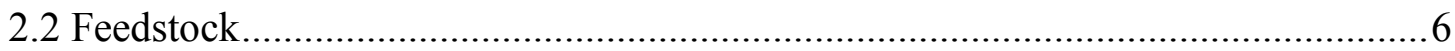

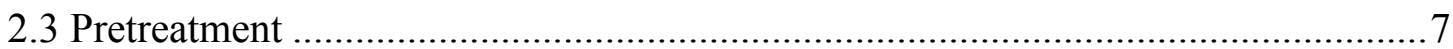

2.4 Enzymatic Hydrolysis ...............................................................................

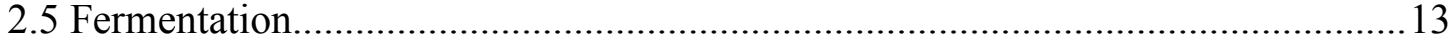

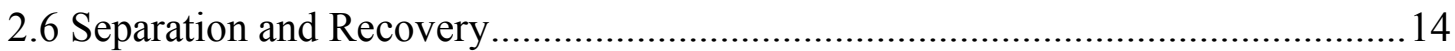

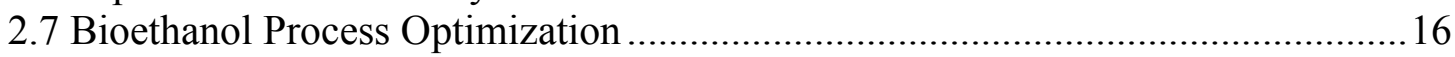

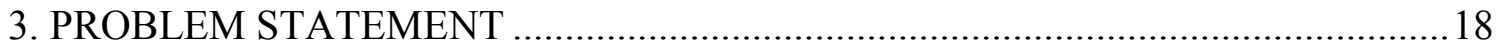

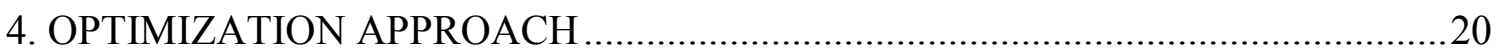

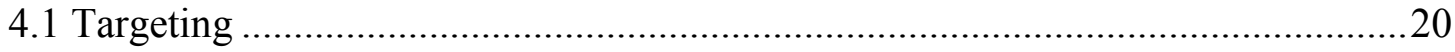

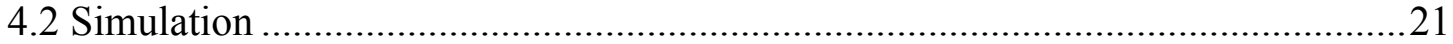

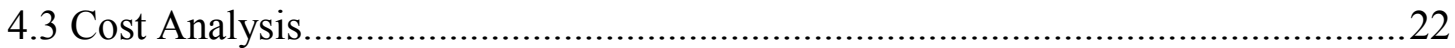

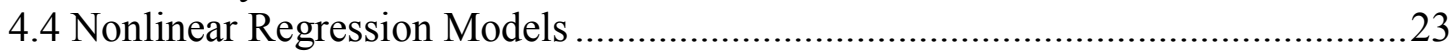

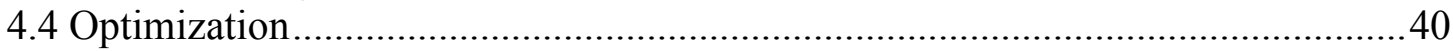

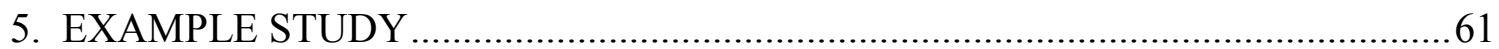

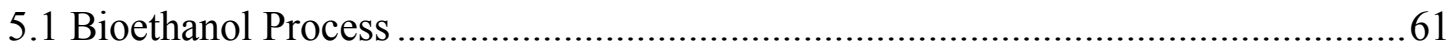

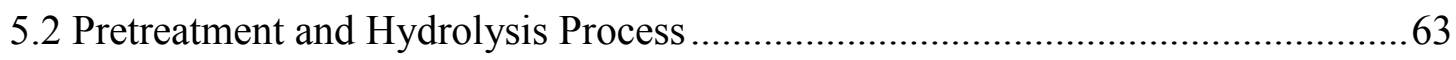




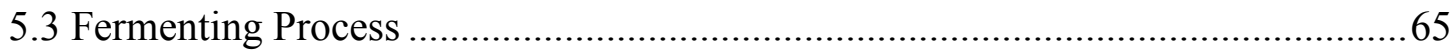

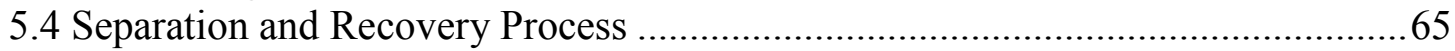

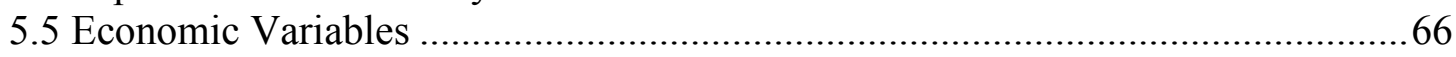

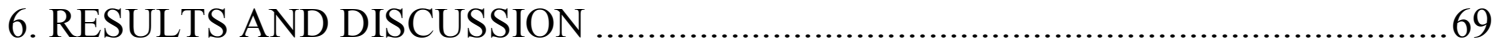

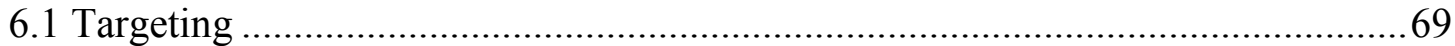

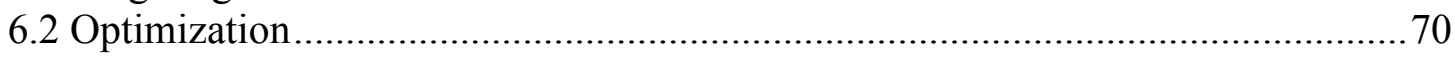

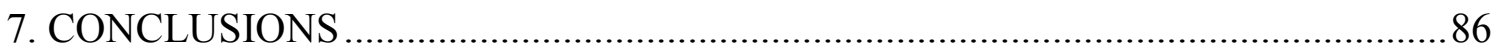

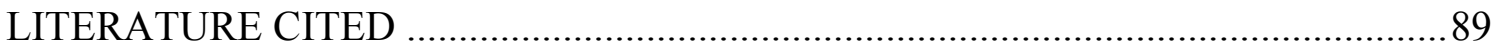

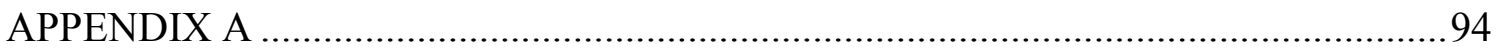

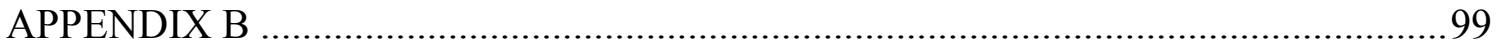

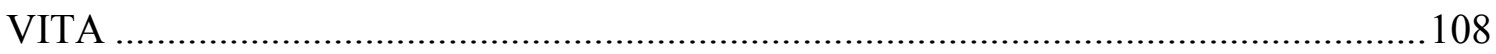




\section{LIST OF FIGURES}

Figure 1 Schematic of bioethanol production process. 5

Figure 2 Glucan conversion of AFEX pretreated corn stover...................................26

Figure 3 Polysaccharide conversion of lime pretreated corn stover. ............................28

Figure 4 Glucan conversion of aqueous ammonia pretreated corn stover. ..................... 31

Figure 5 Polysaccharide conversion of hydrothermally pretreated corn stover...............32

Figure 6 Model for fermentation at $2 \mathrm{~g} / \mathrm{L}$ enzyme concentration. ................................34

Figure 7 Superstructure for optimization problem............................................ 41

Figure 8 Superstructure for case study I...................................................... 71

Figure 9 Effect of plant capacity on ethanol price. ................................................ 72

Figure 10 Effect of plant capacity on enzyme loading ........................................ 75

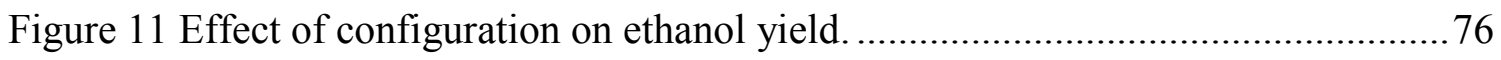

Figure 12 Effect of chemical cost on ethanol price................................................. 78

Figure 13 Effect of storage on ethanol cost..................................................... 84

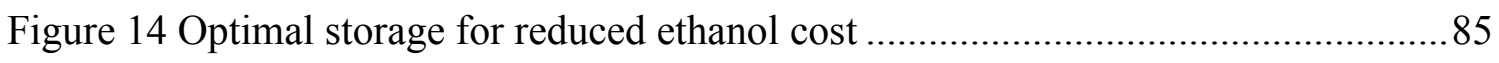

Figure 15 Overall bioethanol production plant configuration....................................94

Figure 16 Ammonia fiber explosion pretreatment. .............................................. 95

Figure 17 Aqueous ammonia recirculation and percolation pretreatment. ....................96

Figure $18 \mathrm{pH}$ controlled hot water pretreatment. ............................................... 97

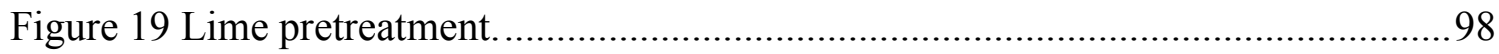




\section{LIST OF TABLES}

Table 1 Model parameters for AFEX pretreated corn stover. .27

Table 2 Model parameters for AFEX pretreated switchgrass. .27

Table 3 Model parameters for lime pretreated corn stover. .29

Table 4 Model parameters for lime pretreated switchgrass. 29

Table 5 Model parameters for aqueous ammonia pretreated corn stover. 30

Table 6 Prediction model parameters for hydrothermally pretreated corn stover. 32

Table 7 Prediction model parameters for stripper mass balance .36

Table 8 Parametric cost coefficients for stripper costing. 37

Table 9 Prediction model parameters for distillation column duties. 38

Table 10 Parametric coefficients for distillation column costing. 38

Table 11 Prediction model parameters for evaporator.

Table 12 Chemical compositions of biomass used. 62

Table 13 Design parameters for pretreatment and hydrolysis .64

Table 14 Design parameters for fermentation process. 65

Table 15 Design parameters of separation and recovery process. 66

Table 16 Plant utility costs.

Table 17 Chemicals cost. .67

Table 18 Biomass gate cost.

Table 19 Minimum biomass cost contribution.

Table 20 Optimal conditions for selected configuration. .73 


\section{INTRODUCTION}

The United States continues to be heavily dependent on foreign oil. According to the US Energy information administration their importation represents $51 \%$ of the current use of crude oil and refined products. To reduce this dependence on foreign oil which in itself continues to slowly dwindle, the US government proposed mandates such as the "Energy Independence and Security Act of 2007" "1 which by law, requires an increase in the amount of renewable fuels to 36 billion gallons by the year 2022 .

Previous to this only ethanol production had been mandated with the "Energy Policy act of 2005 " which required a production increase to 15 billion gallons by the year 2015 . Such requirements have driven the renewable fuel industry to delve into scientifically unchartered territory to devise bio-processing routes that are more technologically efficient and versatile.

The support for the increased use of biofuels does not simply hinge on the need to reduce foreign oil dependence or the potential security risks that may follow, but also on the vast environmental benefits that accompany the use of such "home grown" fuels. The use of biofuels as opposed to the conventional fossil fuels can result in a reduction in carbon dioxide emissions which is one of the major gases touted as a contributor to global warming. Their production is also considered carbon neutral due to the growing process of the biomass requiring approximately the same amount of emitted carbon

This thesis follows the style of the Biotechnology Progress Journal. 
dioxide during combustion. Other advantages include the ease of using current infrastructure for fuel distribution as well as its ability to reduce knocking in engines.

There are currently numerous routes for converting biomass sources into biofuels though economics defines the development and use of such technology. For bioethanol production facilities, the overall economics are heavily dependent on feedstock cost, chemical cost, plant capacity and selected technology or processing associated costs. The latter economic factor is normally critical to the overall design of a bioethanol facility since its performance would dictate the overall production of valuable end product. In most cases the development of a bioethanol facility hinges on the proper selection of technology that ensures the highest and most cost effective performance. This selection process is not evidently intuitive since there are many possible technology routes that are difficult to economically evaluate for every possible plant capacity. This leads the design engineer to follow industrial standards that may be suboptimal or not even worth implementing.

This thesis therefore focuses on the overall selection of technology and feedstock choice that would evidently be the most economically optimal processing route. To achieve this task, literature reviews were done to gather data on the many available processing routes currently utilized in the industry as well as those not commercially available. Next, a superstructure depicting all the possible routes is developed and an optimization model is formulated to solve the technology and feedstock selection problem. The model includes all relevant economic contributors like equipment cost, feedstock cost and overall processing costs. An economic analysis is then performed to 
determine the minimum ethanol selling price. The optimization model is then applied to a realistic case study where feedstock cost varies and seasonal availability requires the use of biomass storage. The data generated is then used to identify the optimal plant capacity and storage conditions for a typical bioethanol facility. 


\section{BACKGROUND}

\subsection{Bioethanol Process}

The concept of a biorefinery in many regards follows that of an oil refinery. In essence the technologies and processing routes used are well integrated and designed to extract the maximum amount of valuable product from the feedstock. In the oil refining industry, facilities are designed to be able to accept feedstocks with ranging qualities. This design principle helps to buffer the plant economics in situation where feedstock cost and availability constantly fluctuates. These concepts as well as many other principles for design of an oil refinery have been as a direct result of the plethora of research and development that have been conducted for the industry. In the case of the biorefinery, its level of advancement in terms of standards and technology is still dwarfed by the petroleum industry and as such plant design can be a harrowing process. In essence, the lack of sound processing data for different valuable chemicals from biomass sources results in most biorefineries being built with few major valuable chemicals and very little room for diversity unlike its oil refinery counterpart. Technology continues to be improved and research continues to delve in providing ways to meet the procedural standards of the petroleum industry. ${ }^{2-11}$

One common conversion route for biomass is the production of ethanol. ${ }^{12}$ This processing route is one of the most researched and involves the use of digestive and fermenting steps to access and convert sugars respectively into ethanol. The initial process utilized corn as the feedstock of choice though its competing demand as a food 
source resulted in numerous negative economical and social impacts consequently switching the focus of ethanol production to non-food sources such as lignocellulosic materials. This alteration in the process resulted in the need to devise innovative and economically attractive ways of maximizing the extraction of reducing sugars from the lignocellulosic material ${ }^{2}$ - a process not easily done by the previous routes.

The conversion process for biomass to ethanol is illustrated in Figure 1 which describes the typical scheme for which numerous ethanol production plants have been designed. In this scheme there are many different technologies for pretreatment, hydrolysis and fermentation, the latter being quite similar to earlier processes though with enzyme modifications to account for the increased levels of pentose (C5) sugars. As ethanol is currently the major source of biofuels to date, emphasis would be placed on optimizing the entire processing route to achieve maximum production from lignocellulosic material.

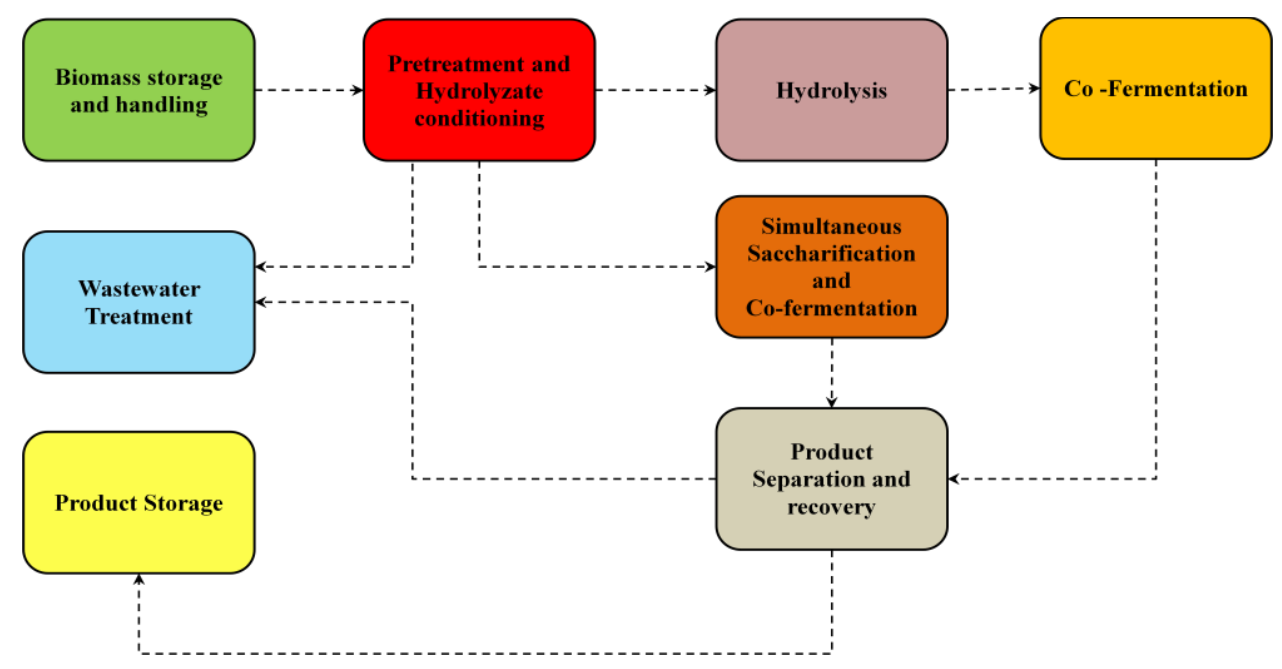

Figure 1 Schematic of bioethanol production process. 


\subsection{Feedstock}

The location of a biorefinery is typically dependent on the feedstock that can be supplied to the process. As such, there are a numerous choices depending on the economics and quality of the feedstock. The latter is crucial to the process since the maximum production of the value added product is hinged on the chemical content of the feed. This is evident in producing ethanol from lignocellulosic material which has relatively high lignin contents. This lignin content is the fibrous portion of the biomass that forms its structural backbone and encapsulates the valuable cellulose and hemicellulosic material. As indicated in pretreatment process research, ${ }^{13}$ lignin presents a major hindrance in the enzymatic hydrolysis of lignocellulosic material. Therefore high lignin content biomass requires a more intense pretreatment section to allow enzymes to access the sugars.

Other notable considerations when selecting the feedstock to a bioethanol production facility would be availability and local delivered cost to the plant. The former factor would simply affect the overall capacity of the plant which subsequently affects the ability for the plant to meet demand locally and regionally. The latter factor on the other hand directly affects the cost of the final ethanol product which in all intent should be competitive when compared to other available fuels on the market. Considering that these characteristics of the feedstock varies with location, it is clear that careful feed selection has be undergone when deciding on the location of the proposed bioethanol plant. 
The indirect effects of feedstock selection rely on the long term consequences on the local and regional economy. To further elucidate, some biomass feedstocks require that they be grown and maintained like many other food sources - requiring nutrients,

extensive land area and weed control. ${ }^{14}$ This creates an economical problem between the growth of food sources and energy crops. On a long term scale, if the return on investment is higher for the energy crop, then farmers would be more inclined to switch out of the food business and into the energy crop business. This leads to possible dwindling supply of food sources which eventually has a negative trickledown effect of increasing food prices. Consequently careful selection of a bioethanol plant's feedstock must be one to ensure that attractive economics for the plant coincide with few negative socioeconomic effects.

\subsection{Pretreatment}

The pretreatment step in bioethanol production is the most crucial step when processing biomass. This step represents a physiochemical, chemical or thermochemical breakdown of the biomass so that the effect of the lignin is reduced and as such, enzymatic hydrolysis is improved. To achieve this, there are many pretreatment techniques that have been developed by the scientific community, some of which are currently commercial. In many cases, the techniques developed are difficult for scale up and lack the necessary data for a proper economic analysis therefore this study focuses on those that are practical, show great potential and are well documented in the literature. For this study the pretreatment routes chosen were: 
Ammonia Fiber Explosion (AFEX)

$>$ Dilute acid

Aqueous ammonia

Lime

$\mathrm{pH}$ controlled hot water

Apart from the effectiveness of the pretreatment technique to improve enzymatic hydrolysis, the cost of achieving the highest performance should not be as high as to negatively impact the economics of the overall conversion process. The latter is usually the key variable to optimize when selecting a pretreatment process.

\section{$\underline{\text { Ammonia fiber explosion }}$}

Ammonia fiber explosion is a physiochemical process that uses liquid ammonia to disrupt the structural makeup of the biomass. In this process, biomass is treated with the liquid ammonia at moderate temperatures. Pretreatment of less than thirty (30) minutes is then followed by a rapid decrease in operating pressure thereby allowing the ammonia to flash vaporize. This drop in pressure causes the biomass to literally explode since liquid ammonia that may have seeped into the micro pores of the biostructure now tries to escape. Consequently, the process increases available surface area, lignin solubilization and cellulosic decrystallization therefore greatly improving the enzymatic hydrolysis of cellulosic and hemicellulosic material.

There are many advantages for using AFEX pretreatment from a processing and by extension, economical standpoint. As identified ${ }^{15}$, one of the most important 
advantages over other pretreatment options is that the entire AFEX process does not require neutralization or a conditioning step subsequent to the process. Another key advantage is that all the ammonia is recovered in the process which helps to reduce the overall chemical cost for the process.

\section{Dilute acid}

In the biomass structure, the cellulose is normally encapsulated by a lignin hemicellulosic network. As such the pretreatment process is used to break this network up so as to access as much of the cellulose as possible as well as the hemicellulose. In the acid pretreatment process, the biomass is subjected to a dilute concentration of sulfuric acid ( 0.6 to $1.2 \mathrm{wt} \%)$ at relatively high temperatures $\left(140\right.$ to $\left.180^{\circ} \mathrm{C}\right)$. In essence this thermochemical process easily and quickly breaks down the lignin hemicellulosic network by easily dissolving the hemicellulose (xylan) and converting it into its monomeric constituent. The acid pretreatment also helps to disrupt the ligninhemicellulose-cellulose ${ }^{16}$ interactions thereby improving the enzymatic digestibility of the cellulose.

The two main advantages for using dilute acid pretreatment is the fact that the process requires little acid as compared with its concentrated acid pretreatment process counterpart. The chemical cost as well as equipment cost for the process is reduced due to the low required operating acid concentration. Another major advantage for the process is the high reported level of conversion of hemicellulose to pentose (C5) sugars which greatly improves the overall ethanol production. 


\section{$\underline{\text { Aqueous ammonia }}$}

Similar to other pretreatment processes, aqueous ammonia is used to disrupt the lignin structure thereby making cellulose and hemicellulose more available for enzyme digestibility. This pretreatment process is slightly better than acid pretreatment in the sense that the cost of aqueous ammonia is shown to be one fourth that of sulfuric acid as well as the high volatility of the chemical makes it ideal for simple flash recovery. This pretreatment method also has the advantage of operating under a continuous basis, a process termed ammonia recycle percolation (ARP). This continuous based operation eliminates the need for scheduling as well as reduces required equipment cost.

$\underline{\text { Lime }}$

This pretreatment process uses calcium hydroxide as the pretreatment agent to aid in the disruption of the lignin-hemicellulose-cellulose interactions. This chemical choice has been shown ${ }^{17}$ to be less effective than other stronger alkaline solutions though the low cost as compared to that of other stronger alkalis like sodium and potassium hydroxide as well as sulfuric acid illustrates is potential. The use of calcium hydroxide is also easily recoverable by carbonation and subsequent thermal decomposition. Once a bioethanol plant is fully integrated, the carbon dioxide from the fermentation process can easily be used to recover the calcium hydroxide and consequently reduce the overall chemical cost for pretreatment. 
$\mathrm{pH}$ controlled hot water

This hydrothermal process is one of the most advantageous compared to the others previously discussed since evidently there is no need for any costly chemicals such as lime, ammonia or sulfuric acid. The process also does not require a neutralization or recovery step associated with other chemical processes. It has also been shown that this pretreatment process maximizes the solubilization of the hemicellulose as liquid soluble oligosaccharides while minimizing the formation of monomeric sugars. $^{18}$

\subsection{Enzymatic Hydrolysis}

This step is a simple but well researched process that involves the breakdown of polysaccharides into their simple sugar constituents. To achieve this, the process requires the use of specific enzymes that hydrolyze or add water, to the macromolecules thereby creating molecules that are smaller and easier for the fermenting enzymes to convert to ethanol. This step in converting biomass to ethanol has been used for many years with great efficiency when utilizing corn as the feedstock. The high cellulose (glucan) content in corn made the process simple since the enzymes were simply cellulases or cellulose hydrolyzing enzymes. The overall process is usually carried out at a low temperature $\left(50^{\circ} \mathrm{C}\right)$ so as not to denature the fragile enzymes. The abbreviated reaction for the hydrolysis of cellulose is shown below by Equation 1:

$$
\mathrm{C}_{6} \mathrm{H}_{10} \mathrm{O}_{5}+\mathrm{H}_{2} \mathrm{O} \stackrel{\text { cellulase }}{\longrightarrow} \mathrm{C}_{6} \mathrm{H}_{12} \mathrm{O}_{6}
$$


With the need to switch to non-food feedstock like lignocellulosic material, the role of the hydrolyzing enzymes also changed to adapt to the need to digest the hemicellulosic portion (xylan) of the biomass. The reduced cellulose content in lignocellulosic biomass as compared to corn required that all the potential reducing sugar sources be expended as physically and economically possible. In essence, the hemicellulosic portion (xylan) of the biomass had to be hydrolyzed into its simple sugar (xylose). This resulted in numerous attempts to biologically alter the original strain of cellulases into strains that could efficiently and effectively achieve the conversion of hemicellulose into xylose. The overall reaction as similar to that of cellulose hydrolysis is shown below in Equation 2:

$$
\mathrm{C}_{5} \mathrm{H}_{8} \mathrm{O}_{4}+\mathrm{H}_{2} \mathrm{O} \stackrel{\text { xylanase }}{\longrightarrow} \mathrm{C}_{5} \mathrm{H}_{10} \mathrm{O}_{5}
$$

In the hydrolysis reaction, the enzymes bind to the biomass to achieve the conversion. This approach while effective can result in a significant amount of the enzymes being lost during the separation process that precedes the fermentation step. The eventual cost of the hydrolyzing enzymes for a poorly designed process consequently increases and in many cases can tip the scales of economic viability for the entire bio-processing route. Recent studies have shown though ${ }^{19}$ that the use of centrifugation followed by ultra-filtration can recover up to $66 \%$ of the total hydrolyzing enzyme thereby making this process more economically inline to provide a fairly inexpensive ethanol product. Other studies ${ }^{20}$ have shown that the use of polysorbate surfactants such as Tween 20 can be used to prevent irreversible bonding of enzymes to the biomass thereby reducing the overall loss. 


\subsection{Fermentation}

Fermentation from a general stand point is the process of converting carbohydrates to alcohols and carbon dioxide using yeast enzymes under anaerobic conditions. The process of fermentation has been around for many years through the early uses to make beer, wine and many other alcoholic beverages. This reaction although simple, has tremendously evolved over the years to aid in the capitalization on creating ethanol from lignocellulosic material.

This final step in the conversion of biomass into ethanol, like the hydrolyzing step, has changed dramatically to incorporate the introduction of pentose or C5 sugars. In early fermenting processes where corn was the feedstock to the bio-processing scheme, the only available reducing sugar was glucose. Considering the years of research and operation of glucose fermenting processes, this step was considered to be the fastest and most economical - evident by the thriving alcoholic beverage industry. The reduction of available glucose from lignocellulosic material and introduction of reducing sugars that are foreign to regular fermenting enzymes created a problem for this processing step. To overcome this issue, there has been extensive research ${ }^{21}$ to biologically engineer new yeast strains that are able to ferment or convert xylose into ethanol efficiently and effectively while still maintaining their ability to rapidly convert

glucose as well. As shown below the overall conversion of both glucose and xylose have the same theoretical yield of 0.5111 kilogram of ethanol per kilogram of sugar:

$$
\mathrm{C}_{6} \mathrm{H}_{12} \mathrm{O}_{6} \stackrel{\text { enzyme }}{\longrightarrow} 2 \mathrm{C}_{2} \mathrm{H}_{5} \mathrm{OH}+2 \mathrm{CO}_{2}
$$




$$
3 \mathrm{C}_{5} \mathrm{H}_{10} \mathrm{O}_{5} \stackrel{\text { enzyme }}{\longrightarrow} 5 \mathrm{C}_{2} \mathrm{H}_{5} \mathrm{OH}+5 \mathrm{CO}_{2}
$$

The theoretical yield of xylose though does not include the practical conversion of some of the sugars to xylitol, a hydrogenated form of the sugar. This byproduct is an alcohol that in many cases is being used as a sugar substitute for diabetic patients and other health conscious individuals.

\subsection{Separation and Recovery}

Once the fermentation step achieves maximum conversion of sugars into the desired ethanol product, there is need to recover the ethanol from the dilute broth. This process is one of the most energy intensive sections of the process due to the high water content of the fermentation broth. The basic scheme for ethanol recovery from the broth would incorporate the use of various separating techniques depending on the content and flowrate of the broth stream as well as the degree of recovery and purity required for the ethanol. For this study the preferred scheme incorporated the use of a stripping column following by a distillation column and subsequently, molecular sieve beds. This scheme proved to ensure a $99.9 \mathrm{wt} \%$ overall recovery of ethanol with an end purity of $99 \mathrm{wt} \%$. Other possible schemes would replace the molecular sieve beds with extractive distillation columns. The aforementioned technique is quite effective and in many cases less costly than molecular sieve bed drying though for this study the ease of operation and simulation of the sieve beds tipped the scales in the final selection. 
The premise behind using a stripping column prior to a distillation column is not an intuitive selection choice though from an overall operability and economic standpoint, its implementation does create positive results. One main advantage is that the stripper provides the first line of pre-separation of remaining sugars and unknown high molecular weight byproducts as well as any particulates that may have been carried over from the hydrolysis section. These compounds may cause fouling in a conventional distillation column thereby requiring intricate and possible expensive design of the distillation units. By introducing the stripping column first, the subsequent distillation columns can be conventionally and inexpensively designed.

Other considerations for using the stripping column preceding the distillation column are evident only with intimate knowledge of the overall processing flow sheet. This scheme decision actually ensures that the water leaving the bottoms of the distillation column can be easily recycled back to the front end of the process since it would only contain water and trace amounts of ethanol. Another attractive factor for the scheme decision was the convenience in being able to supply the stripping column with steam from the waste water evaporator. The latter is used to concentrate the sugars and remaining contaminants present in the fermentation broth while recovering water to be recycled to the rest of the processing units. 


\subsection{Bioethanol Process Optimization}

The biorefinery processing scheme has significantly developed over the past decades with earlier conceptual designs being commercialized to date. Earlier bioethanol plants that utilized corn as a feedstock continue to go bankrupt due to the high feed cost as well as a mandate to switch to the use of lignocellulosic materials. To continually garner improvements in technology and efficiency for the bioethanol industry many innovative processing routes have been developed to tackle this mandated switch of feedstock. This has lead to a plethora of experimental and costing data that can aid in developing rigorous optimization models to tackle the problem of optimal bioprocessing route.

Research $^{22}$ has focused on optimizing bio-processing routes based on multiple objectives such as minimal waste and the conventional minimum ethanol price. The optimization model presented also searches through many different routes that would lead to the production of multiple value added chemicals. This multi product optimization has served useful to the scientific community though more so to the bioethanol industry since optimal routes would represent a mathematical model and not an experience based model that defines the best way forward for the industry.

One of the major costs of the biorefinery in general is the cost of feed. There are many researchers that focus on finding ways to reduce this cost through mathematical

optimization techniques. Some researchers ${ }^{23}$ have presented a mathematical solution to this problem through integrated biomass supply analysis and logistics (IBSAL). This approach exploits the different ways that biomass can be baled and transported to a 
biorefinery at some optimal cost. The approach in essence identifies the most optimal baling and transportation scheme for a biorefinery so as to minimize the overall delivered cost of biomass and consequently the end ethanol price.

For this study focus was placed on removing the typical black box that is placed for each unit operation associated within the biorefinery. In most optimization models that investigate the optimal selection of a bio-processing route, target values are used to represent the overall performance of the unit operation. This approach while convenient, does not allow for the optimal operating conditions of each unit to be found. In essence, a target value may be suboptimal due to the required operating cost to attain that theoretical value. This work seeks to find those optimal operating parameters that provide the economic tradeoff between extent and cost of performance. 


\section{PROBLEM STATEMENT}

Evident by currently ongoing research work, experimental data and industrial best practices alone cannot be used to make accurate decisions when selecting bioprocessing routes that are economically optimal. As such, this work aims to provide an optimization tool for which the optimal bioethanol plant configuration can be determined by using economics as the guide point. The effort achieves this by marrying experimental data, current industrial plant configurations as well proper cost estimate data to develop a mathematical optimization model to determine all required objectives. The given route decisions are simplified as follows:

- A selection of biomass feedstocks $[\mathrm{i} \mid \mathrm{i}=1,2, \ldots, \mathrm{I}]$

- A selection of pretreatment technologies $[\mathrm{j} \mid \mathrm{j}=1,2, \ldots, \mathrm{J}]$ along with their corresponding hydrolysis unit

- A common fermentation process

- A common ethanol separation and recovery process

By using optimization and integration techniques, a systematic approach for determining the optimal processing route is attained.

The layout for determining the optimal process configuration begins with the first node of the route - biomass selection. The chosen biomass feedstock is screened based on cost, availability and chemical content. To ensure that the optimization model reflects realistic values, the biomass flowrate is constrained to the maximum available for that plant location. For the next selection node, each pretreatment technology is developed 
from experimental data accessed from literature along with relevant costing and maximum capacity constraints, similar to those applied to the plant feedstock. The remaining route-common nodes are constructed from industrial best practices with open variables that are allowed to change based on the conditions of the previous node selections. Once all nodes are represented mathematically the overall model is optimized to minimize the annual cash flow thereby determining the minimum ethanol selling price. This objective allows for the optimal process configuration to be selected based on economical attractiveness while still maintaining realistic operational and capacity limits. 


\section{OPTIMIZATION APPROACH}

\subsection{Targeting}

Targeting is a useful technique that explores the economic viability or material efficiency of a process or process unit under maximum theoretical data. It is used to determine whether a given process is worth exploring. ${ }^{24}$ For proper targeting of a bioethanol plant, every unit operation is assumed to perform at $100 \%$ conversion or separation and recovery. This approach is applied to all the routes with the optimization model.

The key target for the bioethanol facility would be end production of ethanol. The theoretically optimal biomass source can be determined by simply performing targeting calculations based on its chemical composition. The overall cellulose and hemicellulose determines the total amount of ethanol that can be produced.

To obtain maximum ethanol production from a particular biomass, the pretreatment, hydrolysis and fermentation unit operations must all operate at their theoretical best. In essence the pretreatment section simply influences the ability of the hydrolysis section to operate close to theoretical therefore only the chemical reactions in the hydrolysis and fermentation section need be targeted. The chemical reactions taking place in the hydrolysis section are given by Equations 1 and 2 .

This reaction represents the breakdown of the polysaccharide into its constituent reducing sugars. These reducing sugars are then digested to produce ethanol via the fermentation reaction given by Equations 3 and 4 . 
It should be noted that fermentation of xylose results in the production of a byproduct called xylitol. For targeting purposes, it would be assumed that the production of this byproduct is minimized. The maximum ethanol yield per unit of biomass coupled with the cost of the biomass and selling price of ethanol would give a quick indication of the economic viability of using that specific biomass feedstock.

Applying this targeting approach to a list of biomass feedstocks can elucidate a theoretical comparison of the potentials of each source.

The only changing condition for the model in this work is the choice of pretreatment. Therefore the final targeting approach would involve using maximum experimental conversions available in literature for each pretreatment option. This would serve as the final screening for all the processing routes to determine overall economic viability.

\subsection{Simulation}

For this study, the energy and material flows are allowed to vary due to other varying parameters in the optimization model. Considering this factor, simulating an entire bio-processing configuration offers little information for the overall optimization model. Therefore in the case of this work, simulation software would be used to provide material and energy flow data for each unit operation. This simulation data would then be used to develop non-linear mathematical models that accurately describe or track the material and energy flows. For this effort, the simulation software that would be used is ASPEN ${ }^{2}$. 
ASPEN ${ }^{\circledR}$ simulation software was designed particularly to deal with issues in the petrochemical industry. Consequently its use in the biochemical industry is still slowly being developed. To date there has been no revamp by the designers of ASPEN ${ }^{\circ}$ to account for the many compounds that are associated with biomass conversion reactions - simple data bank changes though have been introduced. To account for the material and energy balances associate with these compounds, simple hand calculations were used in lieu of ASPEN ${ }^{\circ}$. The data for the bio-reactions were obtained from literature and are well documented in the reference section of this work.

\subsection{Cost Analysis}

To obtain capital cost estimates, ASPEN ICARUS Process Evaluator, Super Pro Designer and literature data were used. In the former two cases a cost function for each piece of equipment was obtained either directly from the software or indirectly by plotting costs of different equipment sizes. Other equipment costs not available from both evaluators were obtained from literature. To ensure fair comparison among cost estimates, all values were updated to 2010 US dollars.

To account for operating costs associated with the process, commodity prices of the various chemicals used are obtained from the ICIS static pages. Cost of steam and other non-chemical operating expenses are obtained from literature or governmental databases in the case of labor costs. 
To account for carbon dioxide emissions a cap and trade system is normally implemented. For this work this approach was not applied due to the policies and regional cap values not being well established to date. Instead the process is assumed to operate at the cap value and as such no credits are received from reduction in GHG emissions. This approach is very conservative since in the near future, the cap and trade system once established, would present an avenue for significant savings for the biofuels industry.

\subsection{Nonlinear Regression Models}

The core of this optimization problem relies on the ability to characterize each unit operation mathematically so as to develop an overall model that reflects a configuration based on the optimal choice of operating parameters. To obtain these mathematically characteristic models, experimental values are extracted from literature and a non-linear regression model is derived to predict the values. In some cases these models predict the experimental data within $\pm 5 \%$ error while in other cases the predictions are not as accurate. In cases where non-linear models are overly complicated to the point that an optimal solution may be hindered, experimental data was represented as a group of linear equations. These linear equations are then incorporated into the model via the convex hull formulation. The general optimization formulation to determine the non-linear model is as follows:

$$
\min \left\|y-y^{*}\right\|_{2}^{2}
$$


The non-linear models for each group of experimental data was first predicted based on the shape and characteristics of the experimental graphs then tested using the above optimization formulation for the least possible \% error. The following subsections are the resulting models for various unit operations within the overall bio-processing configuration.

Due to the availability of experimental data, the pretreatment and hydrolysis process are lumped together resulting in some regression models being based on pretreatment time, hydrolysis time, enzyme loading or a combination of all three parameters.

\section{$\underline{\text { Acid pretreatment }}$}

The kinetic model for this pretreatment route was not developed in this study but was provided in literature. ${ }^{16}$ The addition of this model is simply to provide completeness for this section and to illustrate the complexity associated with the optimization of this processing choice. This model evaluates the conversion of xylan (hemicellulose) into xylose via a biphasic kinetic model based on the Equation 6:

$$
\text { Xylan } \stackrel{k_{f}, k_{s}}{\longrightarrow} \text { Xylose } \stackrel{k_{2}}{\longrightarrow} \text { byproducts }
$$

The $k_{f}$ and $k_{s}$ values represent the rate constant for fast and slow decomposing xylan in the biomass respectively while the $k_{2}$ constant represents the decomposition of xylose. These rate constants are assumed to have Arrhenius-type temperature dependence with a pre-exponential factor dependent upon the effective acid concentration: 


$$
\begin{aligned}
& k=A \cdot \exp \left[-E_{A} / R T\right] \\
& A=A_{o} C_{a}^{n}
\end{aligned}
$$

The effective acid concentration is dependent on the neutralizing ability $(N A)$ of the biomass. In essence the biomass is not exposed to the full acid concentration due to compositional characteristics. The effective acid concentration is given by Equation 9 below:

$$
C_{a}=C_{o}-[S L /(100-S L)] * N A / 10
$$

With the given parameters for the activation energy, pre-exponential factor, reactor solid loading $(S L)$ and neutralizing ability for a particular biomass, the percent conversion of xylan is given by Equation 10 below:

$X^{x}=\frac{k_{f} \cdot X_{f}^{x o}}{\left(k_{2}-k_{f}\right)}\left[\exp \left(-k_{f} t^{p}\right)-\exp \left(-k_{2} t^{p}\right)\right]+\frac{k_{f} X_{s}^{x o}}{\left(k_{2}-k_{s}\right)}\left[\exp \left(-k_{s} t^{p}\right)-\exp \left(-k_{2} t^{p}\right)\right]$

This kinetic model for acid pretreatment is used for the analysis of corn stover, switchgrass and poplar in this study. 


\section{$\underline{\text { AFEX pretreatment }}$}

\section{Corn stover}

The experimental data used to develop these non-linear models were obtained from literature. ${ }^{15}$ For this data set, the pretreatment conditions were predetermined therefore the predicted model was based on the hydrolysis time and enzyme loading. The predicted model for this set of experimental data is given as follows:

$$
\begin{aligned}
& X^{\text {poly }}=A\left[1-\exp \left(-k t^{h}\right)\right] \\
& A=A_{o}+A_{1}\left[1-\exp \left(-k_{A} F P U\right)\right] \\
& k=k_{o}+k_{1}(F P U)^{x}
\end{aligned}
$$

Figure 2 shows an application of the prediction model when applied to glucan conversion in corn stover. This model also works for the conversion of xylan.

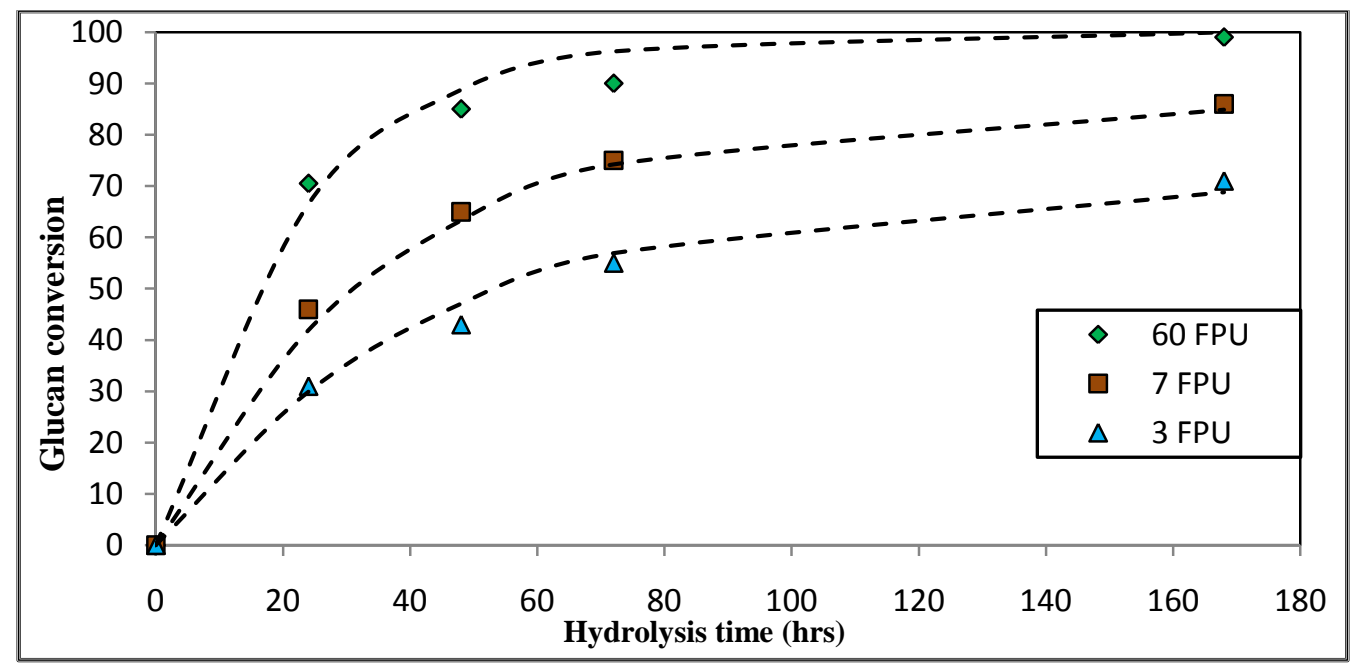

Figure 2 Glucan conversion of AFEX pretreated corn stover.

Adapted from experimental data ${ }^{15}$ 
For this pretreatment route the corresponding parameter values for cellulose and hemicellulose conversion are shown in Table 1.

Table 1 Model parameters for AFEX pretreated corn stover.

\begin{tabular}{ccccccc} 
Polysaccharide & $\mathrm{A}_{\circ}$ & $\mathrm{A}_{1}$ & $\mathrm{k}_{\mathrm{A}}$ & $\mathrm{k}_{\mathrm{o}}$ & $\mathrm{k}_{1}$ & $\mathrm{x}$ \\
\hline Glucan & 48.6 & 51.4 & 0.1824 & 0 & 0.018 & 0.2263 \\
Xylan & 40.4 & 36.6 & 0.0754 & 0 & 0.031 & 0.0492 \\
\hline
\end{tabular}

Switchgrass

The experimental data used to develop these non-linear models were obtained from literature. ${ }^{25}$ For this data set, the pretreatment conditions and enzyme loading were predetermined therefore the predicted model was based on the hydrolysis time only. The predicted model for this set of experimental data is given as follows:

$$
X^{p o l y}=A\left[1-\exp \left(-k t^{h}\right)\right]
$$

The parameter values that correspond to this prediction model are shown in Table 2.

Table 2 Model parameters for AFEX pretreated switchgrass.

\begin{tabular}{ccc} 
Polysaccharide & A & k \\
\hline Glucan & 100 & 0.018 \\
Xylan & 71.2 & 0.028 \\
\hline
\end{tabular}




\section{$\underline{\text { Lime pretreatment }}$}

Corn stover

The experimental data used to develop a prediction model for lime pretreatment of corn stover was obtained from literature. ${ }^{26}$ For this model development, a linearized model was used since the originally predicted non-linear model was outside of the desired $\%$ error margin. The available data were obtained under set pretreatment conditions therefore the model is characterized by overall hydrolysis time. The model is represented as:

$$
X^{\text {poly }}=m_{i}^{l i n} t^{h}+c_{i}^{l i n}
$$

Similarly, Figure 3 shows an application of the model to the experimental data obtained.

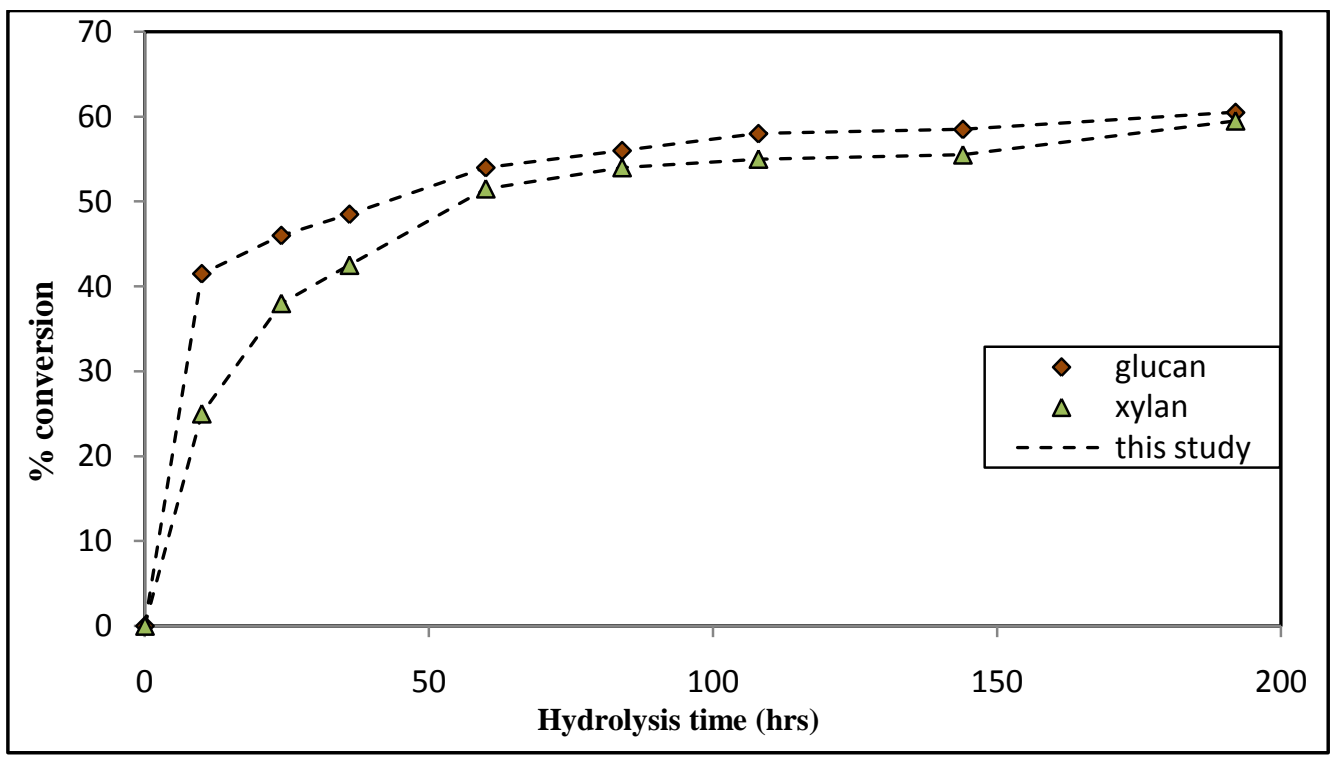

Figure 3 Polysaccharide conversion of lime pretreated corn stover.

Adapted from experimental data ${ }^{26}$ 
The linear model parameters for both glucan and xylan conversion are given in Table 3 .

Table 3 Model parameters for lime pretreated corn stover.

\begin{tabular}{lcccc} 
& \multicolumn{2}{c}{ Glucan } & \multicolumn{2}{c}{ Xylan } \\
\cline { 2 - 5 } Time $(\mathrm{hr})$ & $m_{i}^{\text {lin }}$ & $c_{i}^{\text {lin }}$ & $m_{i}^{\text {lin }}$ & $c_{i}^{\text {lin }}$ \\
\hline $0--10$ & 4.150 & 0.0 & 2.5 & 0.0 \\
$10--24$ & 0.321 & 38.3 & 0.929 & 15.7 \\
$24--36$ & 0.208 & 41.0 & 0.375 & 29.0 \\
$36--60$ & 0.229 & 40.3 & 0.375 & 29.0 \\
$60--84$ & 0.083 & 49.0 & 0.104 & 45.3 \\
$84--108$ & 0.083 & 49.0 & 0.042 & 50.5 \\
$108--144$ & 0.014 & 56.5 & 0.014 & 53.5 \\
$144--192$ & 0.042 & 52.5 & 0.083 & 43.5 \\
\hline
\end{tabular}

Switchgrass

The experimental data used to develop a prediction model for lime pretreatment of switchgrass were obtained from literature. ${ }^{17}$ The prediction model used for this pretreatment route follows the same structure as represented by Equations 11, 12 and 13 . The corresponding parameters for the model are shown in Table 4.

Table 4 Model parameters for lime pretreated switchgrass.

\begin{tabular}{cccccc} 
Parameter & $\mathrm{A}_{\circ}$ & $\mathrm{A}_{1}$ & $\mathrm{k}_{\mathrm{A}}$ & $\mathrm{k}_{\mathrm{o}}$ & $\mathrm{k}_{1}$ \\
\hline Glucan & 0.0 & 78.4 & 0.2683 & 0.1071 & 0.0 \\
Xylan & 42 & 58 & 0.1188 & 0.0567 & 0.0 \\
\hline
\end{tabular}




\section{$\underline{\text { Aqueous ammonia pretreatment }}$}

The experimental data for this pretreatment route were obtained from literature. ${ }^{27}$ In contrast with the previous routes, this experimental data were obtained at a predetermined enzyme loading with the only variables being pretreatment and hydrolysis residence time. The predicted model for this data follows the same format as that for AFEX pretreatment though with different formulations for the $\boldsymbol{A}$ and $\boldsymbol{k}$ parameters.

These parameters are given by:

$$
\begin{aligned}
& A=A_{o}+A_{1}\left[1-\exp \left(-k_{A} t^{p}\right)\right] \\
& k=k_{o}+k_{1} t^{p}
\end{aligned}
$$

Figure 4 shows the application of the prediction model as compared to the experimental data. For this pretreatment route the corresponding parameter values for cellulose and hemicellulose conversion are shown in Table 5.

Table 5 Model parameters for aqueous ammonia pretreated corn stover.

\begin{tabular}{cccccc} 
Parameter & $\mathrm{A}_{\mathrm{o}}$ & $\mathrm{A}_{1}$ & $\mathrm{k}_{\mathrm{A}}$ & $\mathrm{k}_{\mathrm{o}}$ & $\mathrm{k}_{1}$ \\
\hline Glucan & 13.5 & 79.5 & 0.194 & 0.159 & $8.89 \mathrm{E}-5$ \\
Xylan & 12.9 & 59.5 & 0.189 & 0.159 & 0 \\
\hline
\end{tabular}




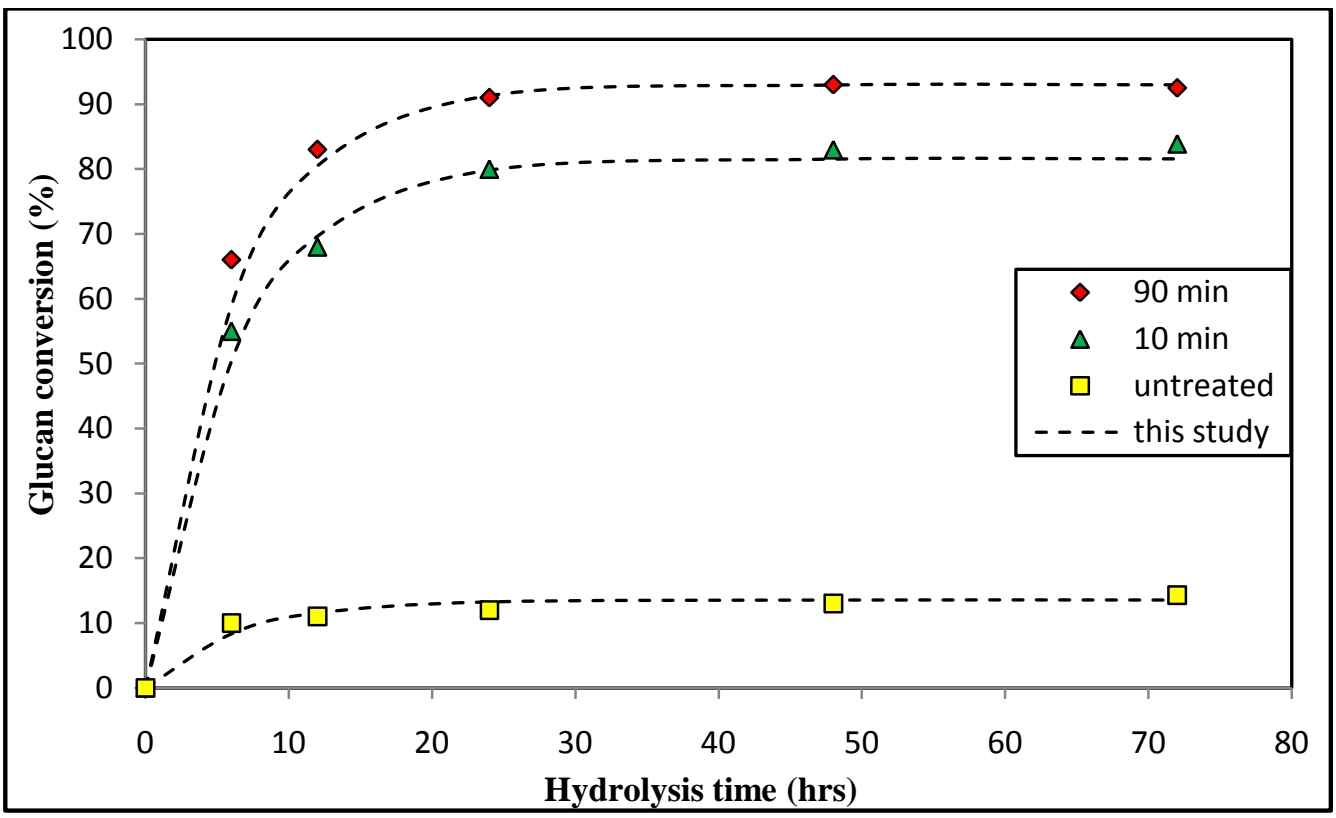

Figure 4 Glucan conversion of aqueous ammonia pretreated corn stover. Adapted from experimental data ${ }^{27}$

\section{$\underline{\text { Hydrothermal pretreatment }}$}

The experimental data used to develop this non-linear model were obtained from literature. ${ }^{28}$ For this data set, the hydrolysis conditions were predetermined therefore the predicted model was based on the pretreatment time. The predicted model for this set of experimental data is given as follows:

$$
X^{\text {poly }}=A_{o}+A_{1}\left[k_{1} /\left(k_{2}-k_{1}\right)\right]\left[\exp \left(-k_{1} t^{p}\right)-\exp \left(-k_{2} t^{p}\right)\right]
$$

For this model, an increased pretreatment time results in the degradation of the reducing sugars. The application of the model compared to the actual experimental data is shown in Figure 5 with the corresponding parameters for Equation 18 given in Table 6. 


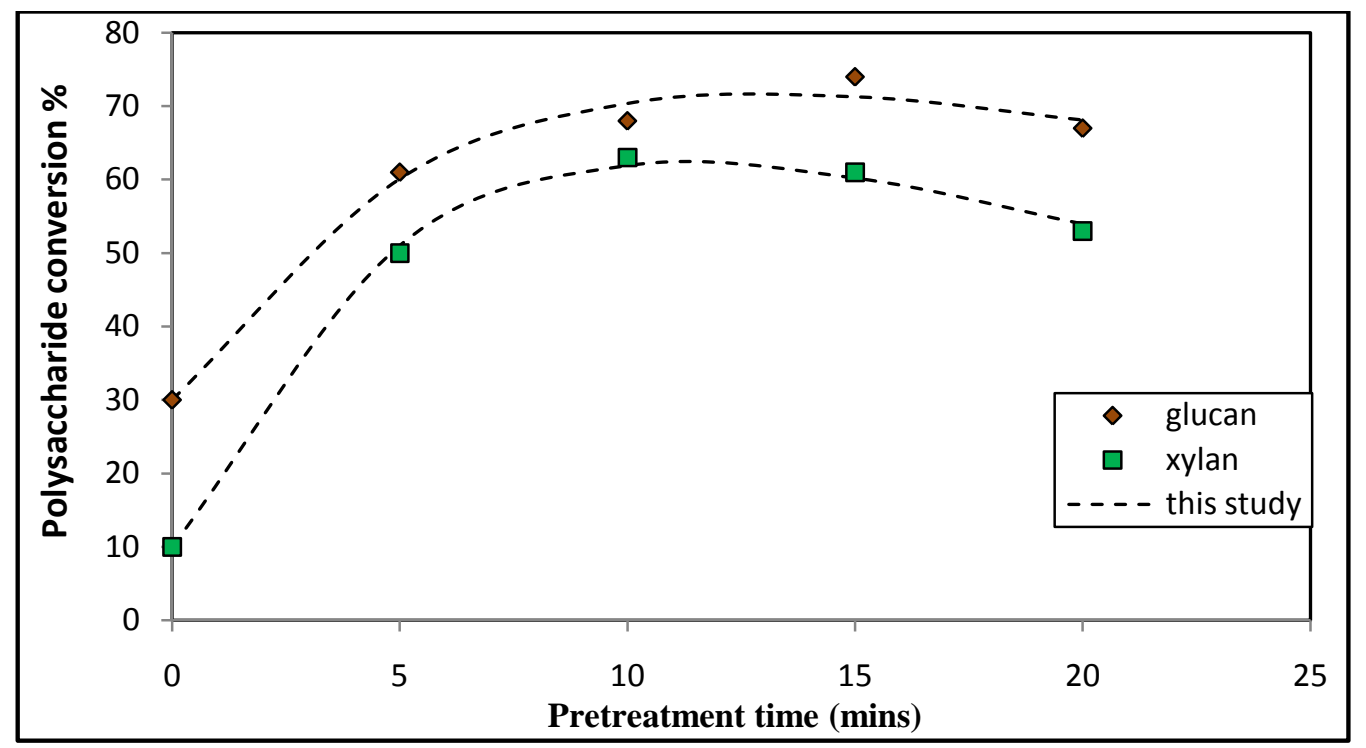

Figure 5 Polysaccharide conversion of hydrothermally pretreated corn stover. Adapted from experimental data ${ }^{28}$

Table 6 Prediction model parameters for hydrothermally pretreated corn stover.

\begin{tabular}{ccccc} 
Parameter & $\mathrm{A}_{\circ}$ & $\mathrm{A}_{1}$ & $\mathrm{k}_{1}$ & $\mathrm{k}_{2}$ \\
\hline Glucan & 30 & 70 & 0.1304 & 0.0396 \\
Xylan & 10 & 90 & 0.1471 & 0.0482 \\
\hline
\end{tabular}

Fermentation

The fermentation section is common to all processing routes by choice since the end product is ethanol and only one conversion route can be used. To ensure that the production of ethanol from biomass is economical, the fermenting microorganisms should be able to digest all sugars that are present. A possible microorganism capable of fermenting all cellulosic sugars such as glucose and xylose has been presented in 
literature. ${ }^{21}$ For the mathematical model representing the fermentation process, the experimental data from their results were used. The predicted model for the conversion of glucose into ethanol and xylose into ethanol and xylitol respectively are based on Equations 19 through 26:

$$
\begin{aligned}
& \mathrm{C}_{6} \mathrm{H}_{12} \mathrm{O}_{6} \stackrel{k_{g l u}}{\longrightarrow} 2 \mathrm{C}_{2} \mathrm{H}_{5} \mathrm{OH}+2 \mathrm{CO}_{2} \\
& 3 \mathrm{C}_{5} \mathrm{H}_{10} \mathrm{O}_{5} \stackrel{k_{x y l}}{\longrightarrow} 5 \mathrm{C}_{2} \mathrm{H}_{5} \mathrm{OH}+5 \mathrm{CO}_{2} \\
& \mathrm{C}_{5} \mathrm{H}_{10} \mathrm{O}_{5}+2 \mathrm{NAD}(\mathrm{P}) \mathrm{H} \stackrel{k_{\text {tol }}}{\longrightarrow} \mathrm{C}_{5} \mathrm{H}_{12} \mathrm{O}_{5}+2 \mathrm{NAD}(\mathrm{P})^{+}
\end{aligned}
$$

Prediction model:

$$
\begin{aligned}
& X_{R}^{g l u}=100\left[1-\exp \left(-k_{g l u} t^{f}\right)\right] \\
& X_{R}^{x y l}=100\left\{1-\exp \left[-\left(k_{x y l}+k_{\text {tol }}\right) t^{f}\right]\right\} \\
& X_{R}^{\text {tol }}=100\left[k_{\text {tol }} /\left(k_{x y l}+k_{\text {tol }}\right)\right]\left\{1-\exp \left[-\left(k_{x y l}+k_{\text {tol }}\right) t^{f}\right]\right\} \\
& F_{\text {etoh }}^{\text {strip }}=0.5111\left[X_{R}^{g l u} F_{g l u}^{\text {ferm }}+\left[k_{x y l} /\left(k_{x y l}+k_{\text {tol }}\right)\right] X_{R}^{x y l} F_{x y l}^{\text {ferm }}\right] \\
& F_{\text {ferm }}^{C O_{2}}=0.4889\left[X_{R}^{g l u} F_{g l u}^{f e r m}+\left[k_{x y l} /\left(k_{x y l}+k_{\text {tol }}\right)\right] X_{R}^{x y l} F_{x y l}^{f e r m}\right] \\
& k_{g l u}=0.5211[\text { Enzyme }]^{0.229} \\
& k_{x y l}=0.0106[\text { Enzyme }]^{0.4464} \\
& k_{\text {tol }}=0.0013[\text { Enzyme }]^{0.1373}
\end{aligned}
$$

Equations 22 and 23 represent the fractional conversion of polysaccharide into ethanol while Equation 24 represents the simultaneous fractional conversion of xylose 
into the xylitol by-product. The 0.5111 coefficient in Equation 25 represents the stoichiometric mass balance between glucose and xylose conversion to ethanol while the 0.4889 coefficient in Equation 26 represents the mass balance for conversion to carbon dioxide. Equations 25 and 26 represent the holistic relationship for ethanol and carbon dioxide flow based on glucose and xylose flow as well as reaction conversions. As noted for Equations 27 through 29, the reaction $\boldsymbol{k}$ values are based on the enzyme concentration used in the fermenting unit. By introducing this free variable, the optimization model is allowed to find the most inexpensive concentration that provides a tradeoff between cost of enzyme and cost of equipment. Figure 6 illustrates the application of the prediction model to the actual experimental data.

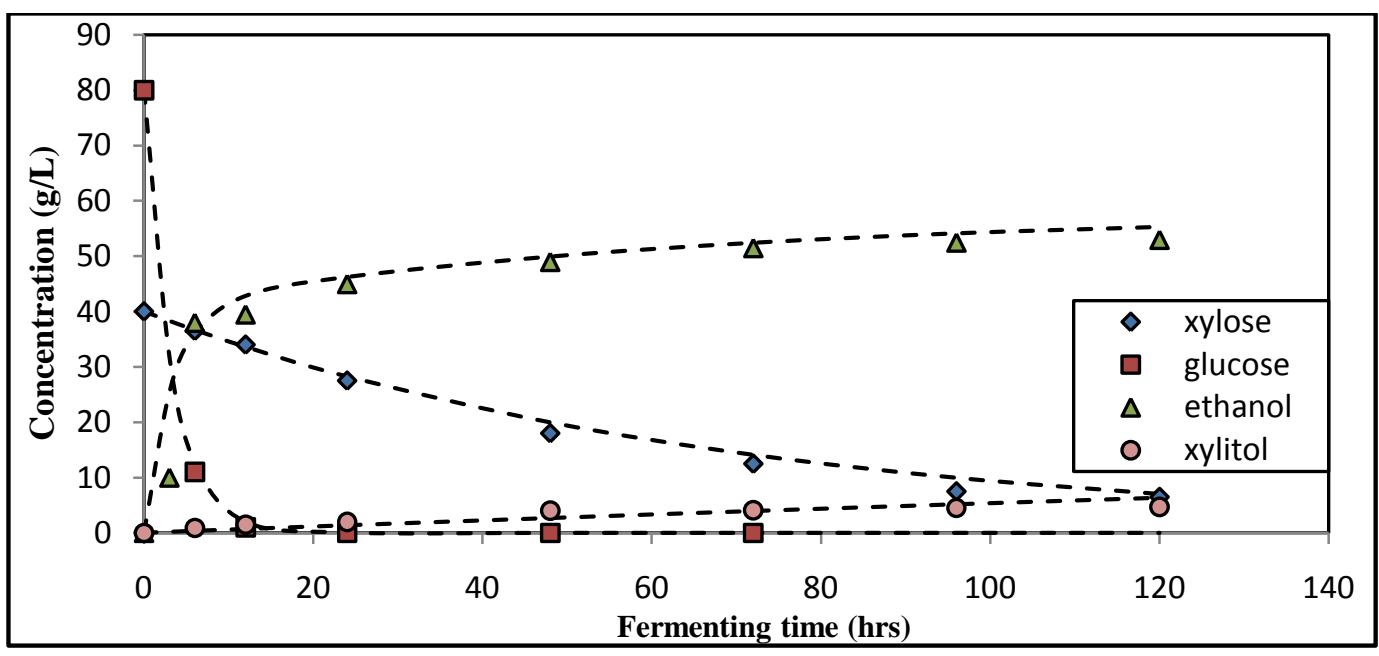

Figure 6 Model for fermentation at $2 \mathrm{~g} / \mathrm{L}$ enzyme concentration. Adapted from experimental data ${ }^{21}$ 


\section{$\underline{\text { Separation and recovery }}$}

The development of a model to track material and energy flows for this section of the model represents a crucial step in the overall model formulation. The reason for the importance of this model development resides in the fact that the concentrations and flows of the feed components to this unit operation change constantly throughout the iterations of the overall selection model. Hence this model has to be accurately designed since it also represents the desired product separation and recovery. For this model formulation, ASPEN ${ }^{\circledR}$ was used to obtain simulation data at various flow rates and concentrations of components. The selected property package for ethanol separation was SRK. Using this plethora of a data, a model is then generated to match within $\pm 1 \%$ error margin.

\section{Ethanol stripping}

The stripping column is used to separate the ethanol from the remaining sugars and particulates leaving the fermentation unit. This unit is designed to use low pressure steam recycled from the waste evaporator as the stripping vapor as well as to recover $99.99 \%$ of the incoming ethanol. To account for the required steam rate and outlet water rate to the distillation unit, based on the changing feed flow rate and composition, the following models were proposed and matched to the simulation data obtained from ASPEN ${ }^{\circ}$. These linear prediction models are given by Equations 30 and 31 with parameters given by Table 7: 


$$
\begin{aligned}
& F_{\text {LPS }}^{\text {strip }}=a_{1}^{\text {strip }} F_{\text {cont }}^{\text {strip }}+a_{2}^{\text {strip }} F_{\mathrm{H}_{2} \mathrm{O}}^{\text {strip }}+a_{3}^{\text {strip }} F_{\text {etoh }}^{\text {strip }}+a_{4}^{\text {strip }} \\
& F_{\mathrm{H}_{2} \mathrm{O}}^{\text {dist }}=a_{5}^{\text {strip }} F_{\text {cont }}^{\text {strip }}+a_{6}^{\text {strip }} F_{\mathrm{H}_{2} \mathrm{O}}^{\text {strip }}+a_{7}^{\text {strip }}
\end{aligned}
$$

Table 7 Prediction model parameters for stripper mass balance.

\begin{tabular}{clllllll} 
Parameter & $a_{1}^{\text {strip }}$ & $a_{2}^{\text {strip }}$ & $a_{3}^{\text {strip }}$ & $a_{4}^{\text {strip }}$ & $a_{5}^{\text {strip }}$ & $a_{6}^{\text {strip }}$ & $a_{7}^{\text {strip }}$ \\
\hline value & 0.0806 & 0.1852 & 0.2231 & 1.3468 & 0.1429 & 0.1879 & 1.1939 \\
\hline
\end{tabular}

Both models accurately predict the required steam flowrate and water rate within a maximum of $\pm 0.6 \%$ error. The range for the model covers a contaminant concentration from as low as $0 \mathrm{~g} / \mathrm{L}$ to $150 \mathrm{~g} / \mathrm{L}$ and an ethanol concentration as low as $3 \mathrm{~g} / \mathrm{L}$ to $80 \mathrm{~g} / \mathrm{L}$. For this model the contaminant refers to all the remaining sugars and other byproducts leaving the fermentation unit.

The size function of the stripping column was found to be dependent on the required steam flowrate to the unit and as such the model representing this relationship was found to be as follows with $\left(a_{8}^{\text {strip }}\right)$ as 0.04485 for this study:

$$
D^{\text {strip }}=a_{8}^{\text {strip }}\left(F_{M P S}^{\text {strip }}\right)^{0.5}
$$

In most cases when performing a cost estimate for equipment, the $6 \mid 10$ rule is used. For this optimization model a costing function was developed using ASPEN ICARUS Process evaluator. The costing function for the stripping column using ICARUS was found to be as follows with the corresponding parameter given by Table 8: 


$$
C^{\text {strip }}=P_{1}^{\text {strip }}\left(D^{\text {strip }}\right)^{2}+P_{2}^{\text {strip }} D^{\text {strip }}+P_{3}^{\text {strip }}
$$

Table 8 Parametric cost coefficients for stripper costing.

\begin{tabular}{cccc} 
Parameter & $P_{1}^{\text {strip }}$ & $P_{2}^{\text {strip }}$ & $P_{3}^{\text {strip }}$ \\
\hline value & 1388 & 25107 & 121222 \\
\hline
\end{tabular}

The range for this cost function was between $2 \mathrm{ft}$ and $12 \mathrm{ft}$ - typical minimum and maximum sizes for an industrial stripping column.

\section{$\underline{\text { Distillation }}$}

The distillation column receives feed from the top of the stripper which would contain only water and ethanol. Similar to the stripping unit, the distillation column is designed to recover $99.99 \%$ of incoming ethanol with an overhead product close to the azeotropic composition. The models generated for this unit operation would be those required for cost analysis. These models would represent the condenser and rebioler duties as well as the size and cost of the distillation column. For the distillation column duties, the following models are used with corresponding parameters given by Table 9:

$$
\begin{aligned}
& Q_{\text {cond }}^{\text {dist }}=a_{1}^{\text {dist }} F_{\text {etoh }}^{\text {dist }}+a_{2}^{\text {dist }} F_{\mathrm{H}_{2} \mathrm{O}}^{\text {dist }} \\
& Q_{\text {reb }}^{\text {dist }}=a_{3}^{\text {dist }} F_{\text {etoh }}^{\text {dist }}+a_{4}^{\text {dist }} F_{\mathrm{H}_{2} \mathrm{O}}^{\text {dist }}
\end{aligned}
$$


Table 9 Prediction model parameters for distillation column duties.

\begin{tabular}{ccccc} 
Parameter & $a_{1}^{\text {dist }}$ & $a_{2}^{\text {dist }}$ & $a_{3}^{\text {dist }}$ & $a_{4}^{\text {dist }}$ \\
\hline value & 1.4584 & 0.0729 & 1.4353 & 0.0768 \\
\hline
\end{tabular}

Similar to the stripping column, a sizing and corresponding costing function is developed for the distillation column for economic analysis purposes. The costing function also follows the same strategy as that used for the stripping column where the 6|10 rule is bypassed for a function developed from the ASPEN ICARUS process evaluator software. These functions are as follows with parameters given by Table 10:

$$
\begin{aligned}
& D^{\text {dist }}=a_{5}^{\text {dist }} x_{\text {etoh }}^{\text {dist }}\left(F_{\mathrm{H}_{2} \mathrm{O}}^{\text {dist }}+F_{\text {etoh }}^{\text {dist }}\right)^{0.546}+a_{6}^{\text {dist }}\left(F_{\mathrm{H}_{2} \mathrm{O}}^{\text {dist }}+F_{\text {etoh }}^{\text {dist }}\right)^{0.524} \\
& C^{\text {dist }}=P_{1}^{\text {dist }}\left(D^{\text {dist }}\right)^{2}+P_{2}^{\text {dist }} D^{\text {strip }}+P_{3}^{\text {dist }}
\end{aligned}
$$

For Equation 36, $\left(x_{\text {etoh }}^{\text {dist }}\right)$ represents the mass fraction of ethanol in the feed entering the distillation column while $\left(a_{5}^{\text {dist }}\right)$ and $\left(a_{6}^{\text {dist }}\right)$ are 0.0595 and 0.0166 respectively.

Table 10 Parametric coefficients for distillation column costing.

\begin{tabular}{cccc} 
Parameter & $P_{1}^{\text {dist }}$ & $P_{2}^{\text {dist }}$ & $P_{3}^{\text {dist }}$ \\
\hline value & 5618 & 4986 & 301887 \\
\hline
\end{tabular}


Similarly, the range of the cost function for the distillation column is set at $2 \mathrm{ft}$ to $12 \mathrm{ft}$ which is typical for industrial distillation columns.

Waste evaporator

The waste evaporator is used to recover water from the waste stream leaving the stripping column. This unit forms an integral part of the recovery section since the low pressure steam produced in the third effect is used for heating in various parts of the plant as well as for stripping steam in the ethanol stripping unit. Similar to previous units, models were developed to track the material and energy flows. The resulting models for medium pressure steam usage and produced low pressure steam are given by Equations 38 and 39 respectively:

$$
\begin{aligned}
& F_{M P S}^{e v p}=a_{1}^{e v p} * F_{H_{2} \mathrm{O}^{-}}^{e v p} a_{2}^{e v p} * F_{c o n t}^{e v p} \\
& F_{L P S, r}^{e v p}=a_{3}^{e v p} * F_{H_{2} \mathrm{O}^{-}}^{e v p} a_{4}^{e v p} * F_{c o n t}^{e v p}
\end{aligned}
$$

For convenience the heat transfer area for the evaporator was modeled as a function of the incoming water and contaminant flow. The fixed cost of the evaporator was modeled as a function of this area using various ICARUS cost values. The developed models are illustrated via Equations 40 and 41:

$$
\begin{aligned}
& A^{e v p}=a_{5}^{e v p} * F_{H_{2} O}^{e v p}-a_{6}^{e v p} * F_{c o n t}^{e v p} \\
& C^{e v p}=P_{1}^{e v p} *\left(A^{e v p}\right)^{0.65}
\end{aligned}
$$

For this study the parametric cost coefficient $P_{1}^{e v p}$ was 37304 while the maximum area per effect is $900 \mathrm{~m}^{2}$. 
The recovered water leaving the evaporator has to be cooled before returning it to the front end of the plant. As such the duty required for this cooling is modeled as a function of the water and contaminant flow to the evaporator. This duty model is represented by Equation 42 below with corresponding parameters given by Table 11:

$$
Q_{\text {cool }}^{e v p}=a_{7}^{e v p} * F_{H_{2} \mathrm{O}^{-}}^{e v p} a_{8}^{e v p} * F_{c o n t}^{e v p}
$$

Table 11 Prediction model parameters for evaporator.

\begin{tabular}{ccccccccc} 
Parameter & $a_{1}^{e v p}$ & $a_{2}^{e v p}$ & $a_{3}^{e v p}$ & $a_{4}^{e v p}$ & $a_{5}^{e v p}$ & $a_{6}^{e v p}$ & $a_{7}^{e v p}$ & $a_{8}^{e v p}$ \\
\hline value & 0.3891 & 0.3205 & 0.3364 & 0.3137 & 0.0570 & 0.0486 & 0.0585 & 0.0606 \\
\hline
\end{tabular}

\subsection{Optimization}

To develop the overall optimization model, all possible configurations and processing routes must first be represented. This is done using a superstructure which indicates the possible connections among feedstock, pretreatment, hydrolysis and separation and recovery choices. Figure 7 elucidates the concept of the superstructure utilized in this optimization model. 


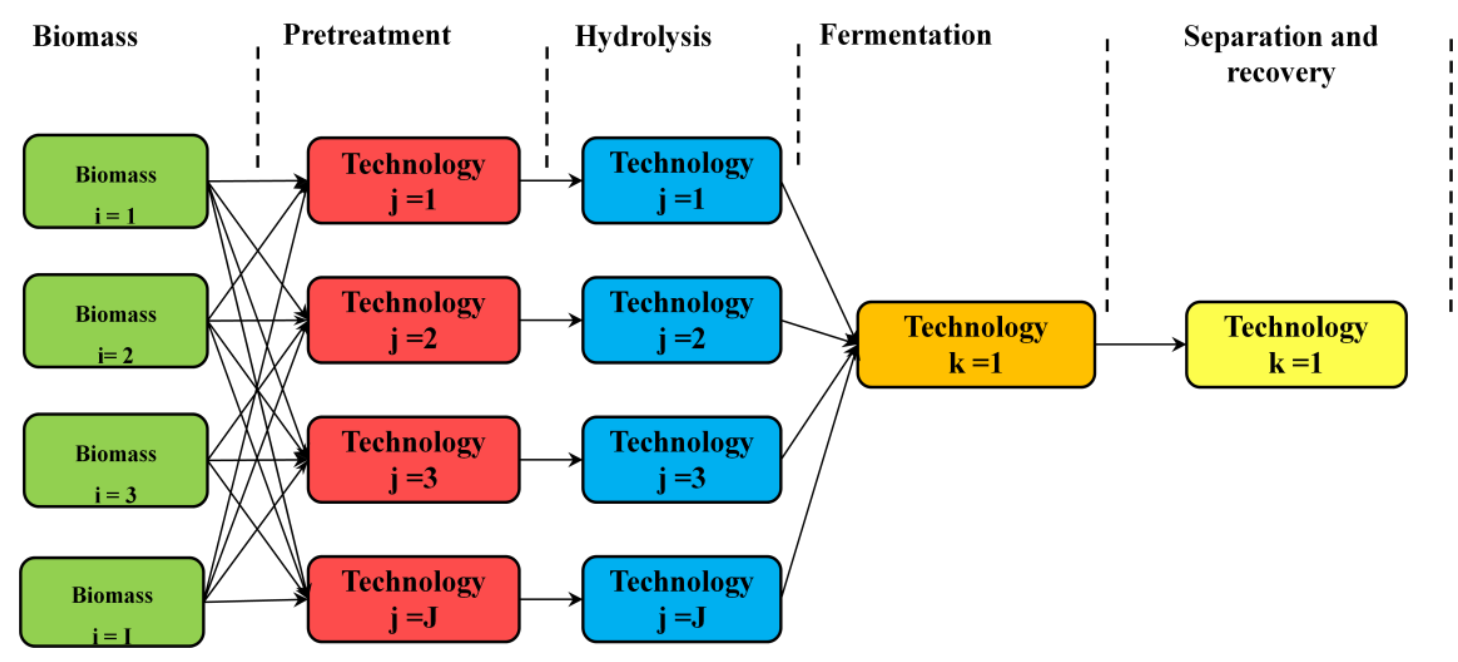

Figure 7 Superstructure for optimization problem.

Based on the superstructure and characteristic equations involved in the formulation, the model is classified as a Mixed Integer Non-linear programming problem (MINLP). There are many solvers that can solve this optimization problem though LINGO was the mathematical optimization software used to solve this numerical problem.

The model is formulated using flow rates of individual stream components as opposed to total flowrate and an introduction of mass fractions. This is done to prevent poor model scaling due to the ratio of the highest to lowest variable being several orders of magnitude. This approach also makes economical analysis calculations easier.

The biomass feed $(i)$ can be split to follow any initial pretreatment route $(j)$. The flow of all the split fractions $[\mathrm{kg} / \mathrm{hr}]$ though must add to the total flow from source $\boldsymbol{i}$ :

$$
F_{i}^{b i o}=\sum_{j=1}^{J} F_{i, j}^{b i o}
$$


The total flow of biomass $[\mathrm{kg} / \mathrm{hr}]$ from a particular source is limited by its availability in that region:

$$
F_{i}^{\text {bio }} \leq F_{i}^{\max }
$$

Feedstock cost $[\$ / \mathrm{kg}]$ is a function of the plant's biomass capacity:

$$
C_{i}^{b i o}=m_{i}^{t} F_{i}^{b i o}+C_{i}^{\text {gate }}
$$

Overall operating cost for feedstock in [\$/day] is given by Equation 46 below:

$$
O C^{b i o}=24 * \sum_{i=1}^{I} C_{i}^{b i o} * F_{i}^{b i o}
$$

The dry milling cost [\$/day] for the incoming biomass is based on the milling energy $[\mathrm{kWh} /$ tonne biomass $]$ and electrical cost $[\$ / \mathrm{kWh}]$ :

$$
O C_{i}^{\text {mill }}=2.4 \times 10^{-2} * E_{i}^{\text {mill } *} C^{\text {elect }} * F_{i}^{\text {bio }}
$$

Every pretreatment and subsequent hydrolysis option has a different configuration and as such the material and energy balances around each option would be different. To illustrate an entire configuration, the acid pretreatment route would be used as a basis. In this case the $\boldsymbol{j}$ index is $\mathbf{1}$ which represents the selection of acid pretreatment.

The water and acid requirements for the pretreatment section are determined as a function of the solids loading $\left(S L_{i j}\right)$ as well as the desired acid concentration $\left(c_{i j}^{a c i d}\right)$. The relationship is shown in Equation 47. Here the solids loading and acid concentration are in $[\mathrm{wt} \%]$ while the flowrate of biomass, acid and water are in $[\mathrm{kg} / \mathrm{hr}]$ :

$$
\begin{aligned}
& F_{i j, p}^{a c i d}=\left(1 / S L_{i j}-10^{-2}\right) * c_{i j}^{a c i d} * F_{i j}^{b i o} \\
& F_{i j, p}^{H_{2} O}=\left(1 / S L_{i j}-10^{-2}\right) *\left(100-c_{i j}^{a c i d}\right) * F_{i, j}^{b i o}
\end{aligned}
$$


The operating cost [\$/day] associated with purchase of chemicals for this pretreatment route is found by multiplying the flowrate of the chemicals by their respective costs $[\$ / \mathrm{kg}]$ :

$$
\begin{aligned}
& O C_{i j, p}^{a c i d}=24 * C^{a c i d} * F_{i j, p}^{a c i d} \\
& O C_{i j, p}^{\mathrm{H}_{2} \mathrm{O}}=24 * C^{\mathrm{H}_{2} \mathrm{O}} * F_{i j, p}^{\mathrm{H}_{2} \mathrm{O}}
\end{aligned}
$$

For the pretreatment process to be carried out at some optimized temperature, high pressure (HPS) and low pressure steam (LPS) are used as heating utilities. This heating requirement is represented by Equation 52 . Here the flow of steam is in $[\mathrm{kg} / \mathrm{hr}]$ :

$$
\left(F_{i j, p}^{a c i d}+F_{i j, p}^{H_{2} O}\right) * C_{p, H_{2} O} *\left(\mathrm{~T}_{\mathrm{j}}-\mathrm{T}_{\mathrm{amb}}\right)=F_{i j, p}^{H P S} * \Delta H_{v}^{H P S}+F_{i j, p}^{L P S} * \Delta H_{v}^{L P S}
$$

There is a maximum flow limit on the LPS due to thermodynamic limitations. In essence the LPS cannot preheat the incoming acid to over $100^{\circ} \mathrm{C}$. Hence the maximum flow of LPS varies with biomass flow. The operating cost [\$/day] of LPS for this preheater is given by Equation 54 based on the assumed cost of steam $[\$ / \mathrm{kg}]$ :

$$
\begin{aligned}
& F_{i j, p}^{L P S} \leq F_{i j, p}^{L P S \max } \\
& O C_{i j, p}^{L P S}=24 * C^{s t m} * F_{i j, p}^{L P S}
\end{aligned}
$$

To determine the LPS pre-heater cost, its area $\left[\mathrm{m}^{2}\right]$ is first found by dividing the LPS duty by the log mean temperature difference and overall heat transfer coefficient for the heat exchanger. The overall cost is then found by Equation 56 which includes the total installed cost lumped into the parametric cost coefficient $\left(P_{1}^{\text {heat }}\right)$ which is 2034 for this study: 


$$
\begin{aligned}
& A_{i j, p}^{\text {heat }}=F_{i j, p}^{L P S} * \Delta H_{v}^{L P S} /\left(U^{\text {heat }} * \Delta T_{l m}^{\text {heat }}\right) \\
& F C_{i j, p}^{\text {heat }}=P_{l}^{\text {heat }} *\left(A_{i j, p}^{\text {heat }}\right)^{0.89}
\end{aligned}
$$

For this process configuration, xylan conversion to xylose occurs in the pretreatment section as opposed to the hydrolysis section. As such the percent conversion of xylan to xylose is determined via Equations 7 through 10 in Section 4.4 using the respective data and represented as $X_{i j, p}^{x}[\%]$ in subsequent equations. The flow of xylose $[\mathrm{kg} / \mathrm{hr}]$ from the pretreatment section is found as the product of the initial concentration of xylan in the biomass, the biomass flowrate and conversion percent of xylan. The 0.88 factor is used to account for the water molecule that is added to the xylan to form xylose. The remaining biomass that is sent to the hydrolysis unit is found by the difference between the initial biomass flow $[\mathrm{kg} / \mathrm{hr}]$ and the converted xylan flow $[\mathrm{kg} / \mathrm{hr}]$. The water flow leaving the pretreatment section is found as the difference between the inlet flow and the water fraction used for xylose formation. This relationship is represented by Equation (59):

$$
\begin{aligned}
& F_{i j, f}^{x y l}=X_{i j, p}^{x} * X_{i}^{x o} * F_{i j}^{b i o} / 8800 \\
& F_{i j, h}^{b i o}=\left[1-\left(X_{i j, p}^{x} * X_{i}^{x o} / 10000\right)\right] * F_{i j}^{b i o} \\
& F_{i j, n}^{\mathrm{H}_{2} \mathrm{O}}=F_{i j, p}^{\mathrm{H}_{2} \mathrm{O}}-0.12 * F_{i j, f}^{x y l}
\end{aligned}
$$

From Equation 10 the pretreatment time $t_{i j}^{p}[\mathrm{~min}]$ is optimized to obtain the best conversion economically possible. This optimized time dictates the required volume of 
the pretreatment reactor which is also a function of the biomass flow [kg/hr], acid flow $[\mathrm{kg} / \mathrm{hr}]$ and water flow $[\mathrm{kg} / \mathrm{hr}]$. The overall fixed cost of the pretreatment reactor is then found as a function of its volume as shown in Equation 61 inclusive of the parametric cost coefficient $\left(P_{1, p}^{\text {react }}\right)$ which accounts for installed cost. For this study $\left(P_{1, p}^{\text {react }}\right)$ is 48326 :

$$
\begin{aligned}
& V_{i j, p}^{\text {react }}=t_{i j}^{p} / 60 *\left[F_{i j, p}^{\mathrm{H}_{2} \mathrm{O}} / \rho_{\mathrm{H}_{2} \mathrm{O}}+F_{i j}^{\text {bio }} / \rho_{i}^{\text {bio }}+F_{i j, p}^{\text {acid }} / \rho_{\text {acid }}\right] \\
& F C_{i j, p}^{\text {react }}=P_{l, p}^{\text {react }} *\left(V_{i j, p}^{\text {react }}\right)^{0.72}
\end{aligned}
$$

The material leaving the pretreatment section is then filtered with the remaining biomass being sent to the hydrolysis section and the filtrate to the neutralization section. The acidified xylose sugar stream is neutralized using calcium hydroxide. This reaction as shown in Equation 62 produces hydrated calcium sulfate also known as gypsum which is then separated via filtration leaving a clean sugar stream which is sent to the fermentation unit:

$$
\mathrm{CaO}+\mathrm{H}_{2} \mathrm{O}+\mathrm{H}_{2} \mathrm{SO}_{4} \longrightarrow \mathrm{CaSO}_{4} \cdot 2 \mathrm{H}_{2} \mathrm{O}
$$

The required lime and produced gypsum flow rates in $[\mathrm{kg} / \mathrm{hr}]$ are determined from the stoichiometric relationship illustrated in Equation 62 and are given by Equations 63 and 64 respectively:

$$
\begin{aligned}
& F_{i j, n}^{\text {lime }}=F_{i j, p}^{a c i d} * M W_{\text {lime }} / M W_{\text {acid }} \\
& F_{i j, n}^{\text {gypsum }}=F_{i j, p}^{a c i d} * M W_{\text {gypsum }} / M W_{\text {acid }}
\end{aligned}
$$


Using the neutralization residence time $\left(t_{i j}^{n}\right)[\mathrm{hrs}]$, the volume of the unit $\left[\mathrm{m}^{3}\right]$ is found as a function of the lime, acid and water flow $[\mathrm{kg} / \mathrm{hr}]$ to the unit. Similar to the pretreatment reactor cost, the neutralization unit fixed cost is found as a function of the unit's volume and parametric cost coefficient $\left(P_{1, n}^{\text {react }}\right)$ which is 5232 in this study:

$$
\begin{aligned}
& V_{i j, n}^{\text {react }}=t_{i j}^{n} *\left[F_{i j, p}^{\mathrm{H}_{2} \mathrm{O}} / \rho_{\mathrm{H}_{2} \mathrm{O}}+F_{i j, n}^{\text {acid }} / \rho_{\text {acid }}+F_{i j, n}^{\text {lime }} / \rho_{\text {lime }}\right] \\
& F_{i j, n}^{a c i d}=F_{i j, p}^{\text {acid }} \\
& F C_{i j, n}^{\text {react }}=P_{1, n}^{\text {react }} *\left(V_{i j, n}^{\text {react }}\right)^{0.6}
\end{aligned}
$$

For the hydrolysis section the water required in $[\mathrm{kg} / \mathrm{hr}]$ is given by Equation 68 and is based on the initial percent composition of cellulose $\left(X_{i}^{g o}\right)$ as well as the cellulose loading $\left(C L_{i j}\right)$ which is given as the weight percent of cellulose in the overall solid-liquid mixture:

$$
F_{i j, h}^{\mathrm{H}_{2} \mathrm{O}}=\left(X_{i}^{g o} / C L_{i j}-1\right) * F_{i j, h}^{b i o}
$$

The operating cost [\$/day] of this required process water is given by Equation 69 :

$$
\mathrm{OC}_{i j, h}^{\mathrm{H}_{2} \mathrm{O}}=24 * \mathrm{C}^{\mathrm{H}_{2} \mathrm{O}} * \mathrm{~F}_{i j, h}^{\mathrm{H}_{2} \mathrm{O}}
$$

Similar to the xylose flow from the pretreatment section, the glucose flow is found as the product of the biomass flow to the unit as well as the conversion percentage of glucan to glucose as given by Equations 22 and 27. A 0.9 factor is used to account for the addition of water to glucan in the hydrolysis process:

$$
F_{i j, f}^{g l u}=X_{i j, h}^{g} * X_{i}^{g o} / 9000 * F_{i j, h}^{b i o}
$$


The required enzyme flow $\left[\mathrm{m}^{3} / \mathrm{hr}\right]$ for the hydrolysis section is a function of the enzyme load $\left(E L_{i j, h}\right)$ in $[\mathrm{ml} / \mathrm{g}$ cellulose], the biomass flow $[\mathrm{kg} / \mathrm{hr}]$ and cellulose percent $\left(X_{i}^{g o}\right)$. The corresponding cost of hydrolyzing enzyme is that amount that is irrecoverable in the process $\left(X_{\text {loss }}^{e n z}\right)$. Hence the cost of enzyme is based on the required makeup with unit cost $\left(C^{e n z}\right)$ given in $\left[\$ / \mathrm{m}^{3}\right]$ :

$$
\begin{aligned}
& F_{i j, h}^{e n z}=10^{-5} * X_{i}^{g o} * E L_{i j, h} * F_{i j}^{b i o} \\
& \mathrm{OC}_{\mathrm{ij}, \mathrm{h}}^{\mathrm{enz}}=24 * C^{e n z} * F_{i j, h}^{e n z} * X_{\text {loss }}^{e n z}
\end{aligned}
$$

The unconverted biomass $\left(F_{i j, b}^{b i o}\right)$ that leaves the hydrolysis reactor is sent to the boiler to be used as fuel. This biomass flow would be the initial biomass flow to the system $\left(F_{i j}^{b i o}\right)$ less the glucan and xylan flow that was converted. The total water leaving the pretreatment and hydrolysis sections ends up in the fermentation unit after filtration and other processes. This water balance is represented by Equation 74 and incorporates a lost water term $\left(F_{i j, l o s s}^{\mathrm{H}_{2} \mathrm{O}}\right)$ which accounts for losses such as in the gypsum separation process:

$$
\begin{aligned}
& F_{i j, b}^{b i o}=F_{i j}^{b i o}-0.9 * F_{i j, f}^{g l u}-0.88 * F_{i j, f}^{x y l} \\
& F_{i j, f}^{\mathrm{H}_{2} \mathrm{O}}=\left(F_{i j, h}^{\mathrm{H}_{2} \mathrm{O}}-0.1 * F_{i j, f}^{g l u}\right)+\left(F_{i j, p}^{\mathrm{H}_{2} \mathrm{O}}-0.12 * F_{i j, f}^{x y l}\right)-F_{i j, l o s s}^{\mathrm{H}_{2} \mathrm{O}}
\end{aligned}
$$

The hydrolysis volume $\left[\mathrm{m}^{3}\right]$ would be a function of the residence time $\left(t_{i j}^{h}\right)[\mathrm{hrs}]$ which is a free variable to be optimized based on overall economics. The fixed cost, 
similar to the pretreatment and neutralization unit is found as a function of the unit volume and parametric cost coefficient $\left(P_{l, h}^{\text {react }}\right)$ which is 5232 for this study:

$$
\begin{aligned}
& V_{i j, h}^{\text {react }}=t_{i j}^{h} *\left[F_{i j, h}^{\mathrm{H}_{2} \mathrm{O}} / \rho_{\mathrm{H}_{2} \mathrm{O}}+F_{i j, h}^{b i o} / \rho_{i}^{\text {bio }}+F_{i j, h}^{e n z}\right] \\
& F C_{i j, h}^{\text {react }}=P_{l, h}^{\text {react }} *\left(V_{i j, h}^{\text {react }}\right)^{0.6}
\end{aligned}
$$

The unconverted biomass that is burnt represents a savings since the required natural gas for the boiler is reduced. The energy credit is represented by Equation 77 where $\left(\eta_{b}\right)$ represents the boiler efficiency, $\left(\Delta H_{c, i}\right)$ represents the heat of combustion of biomass [MMBTU/kg] and $\left(C^{N G}\right)$ represents the cost of natural gas [\$/MMBTU].

$$
C r_{i j}^{b i o}=24 * \eta_{b}{ }^{*} \Delta H_{c, i} * F_{i j, b}^{b i o} * C^{N G}
$$

For the fermentation reaction, the values of the conversion percent of glucose and xylose to ethanol $\left(X_{i j, f}^{g}, X_{i j, f}^{x}\right)$ and xylose to xylitol $\left(X_{i j, f}^{t o l}\right)$ are given by Equations 22, 23 and 24 respectively in Section 4.4. These conversion percentages are then used to find the overall component flows leaving the fermentation unit. These relationships are given by Equations 79 through 83:

$$
\begin{aligned}
& {[\text { enzyme }]=E L_{i j, f}} \\
& F_{i j, s}^{g l u}=\left(100-X_{i j, f}^{g}\right) / 100 * F_{i j, f}^{g l u} \\
& F_{i j, s}^{x y l}=\left(100-X_{i j, f}^{x}\right) / 100 * F_{i j, f}^{x y l} \\
& F_{i j, s}^{t o l}=X_{i j, f}^{t o l} / 100 * F_{i j, f}^{x y l}
\end{aligned}
$$




$$
\begin{aligned}
& F_{i j, s}^{e t o h}=0.5111\left[X_{i j, f}^{g} / 100 * F_{i j, f}^{g l u}+k_{x y l} /\left(k_{x y l}+k_{t o l}\right) * X_{i j, f}^{x} / 100 * F_{i j, f}^{x y l}\right] \\
& F_{i j, s}^{C O_{2}}=0.4889\left[X_{i j, f}^{g} / 100 * F_{i j, f}^{g l u}+k_{x y l} /\left(k_{x y l}+k_{t o l}\right) * X_{i j, f}^{x} / 100 * F_{i j, f}^{x y l}\right]
\end{aligned}
$$

For the water balance around the fermenter, it is assumed that little to no water is consumed and as such the inlet water flow is equal to the water flow to the ethanol stripping unit:

$$
F_{i j, f}^{\mathrm{H}_{2} \mathrm{O}}=F_{i j, s}^{\mathrm{H}_{2} \mathrm{O}}
$$

For capital cost estimates, the fermenter volume is calculated. It is represented as the residence time $\left(t_{i j}^{f}\right)$ in [hrs] multiplied by the volume flow of sugars and enzyme. For this calculation, the density of sugars is taken to be close to that of water. The corresponding fixed cost of the fermenter is calculated via Equation 85 which uses a similar parametric cost coefficient $\left(P_{l, f}^{\text {react }}\right)$ as that for the hydrolysis and neutralization reactor. For this study the coefficient is also 5232:

$$
\begin{aligned}
& V_{i j, f}^{\text {react }}=t_{i j}^{f} *\left[\left(F_{i j, f}^{g l u}+F_{i j, f}^{x y l}+F_{i j, f}^{\mathrm{H}_{2} \mathrm{O}}\right) / \rho_{\mathrm{H}_{2} \mathrm{O}}+E L_{i j, f} * F_{i j, f}^{\mathrm{H}_{2} \mathrm{O}} / 1000 * \rho_{f}^{\text {enz }}\right] \\
& F C_{i j, f}^{\text {react }}=P_{l, f}^{\text {react }} *\left(V_{i j, f}^{\text {react }}\right)^{0.6}
\end{aligned}
$$

The fermentation broth is sent to the ethanol stripping column as the first unit for product separation. For the separation process, low pressure stripping steam is used. This required flowrate of steam is a function of the unconverted sugars and byproduct $\left(F_{i j, s}^{c o n t}\right)$, ethanol flow $\left(F_{i j, s}^{e t o h}\right)$ as well as the flow of water to the unit $\left(F_{i j, s}^{\mathrm{H}_{2} \mathrm{O}}\right)$. The equation was 
developed using simulation data and explained in Section 4.4. The operating cost of this steam [\$/day] is also calculated as shown in Equation 87 below:

$$
\begin{aligned}
& F_{i j, s}^{L P S}=a_{1}^{s t r i p} * F_{i j, s}^{c o n t}+a_{2}^{s t r i p} * F_{i j, s}^{\mathrm{H}_{2} \mathrm{O}}+a_{3}^{\text {strip }} * F_{i j, s}^{e t o h}+a_{4}^{\text {strip }} \\
& O C_{i j, s}^{L P S}=24 * C^{s t m} * F_{i j, s}^{L P S}
\end{aligned}
$$

The diameter requirement of the stripping column [ $\mathrm{ft}]$ is found as a function of the required stripping steam flowrate $[\mathrm{kg} / \mathrm{hr}]$ and is explained in Section 4.4. This column size is kept within a certain range, typical of industrial standards represented by Equation 89:

$$
\begin{aligned}
& D_{i j, s}^{c o l}=a_{8}^{s t r i p} *\left(F_{i j, s}^{L P S}\right)^{0.5} \\
& 2 f t \leq D_{i j, s}^{c o l} \leq 12 f t
\end{aligned}
$$

The water flow $[\mathrm{kg} / \mathrm{hr}]$ in the overhead stream of the stripping column is found via Equation 90 which is also explained in Section 4.4. The corresponding water balance is done to determine the water flow to the waste evaporator $\left(F_{i j, \text { evp }}^{\mathrm{H}_{2} \mathrm{O}}\right)$ as given by Equation 91. This balance explains that the total water to the evaporator is equal to the water into the stripper from the fermenter $\left(F_{i j, s}^{\mathrm{H}_{2} \mathrm{O}}\right)$ plus the stripping steam flow $\left(F_{i j, s}^{L P S}\right)$ minus the flow of water to the distillation column from stripper's overhead stream $\left(F_{i j, d}^{\mathrm{H}_{2} \mathrm{O}}\right)$ :

$$
\begin{aligned}
& F_{i j, d}^{\mathrm{H}_{2} \mathrm{O}}=a_{5}^{\text {strip }} * F_{i j, s}^{c o n t}+a_{6}^{\text {strip }} * F_{i j, s}^{\mathrm{H}_{2} \mathrm{O}}+a_{7}^{\text {strip }} \\
& F_{i j, \text { evp }}^{\mathrm{H}_{2} \mathrm{O}}=F_{i j, s}^{\mathrm{H}_{2} \mathrm{O}}+F_{i j, s}^{L P S}-F_{i j, d}^{\mathrm{H}_{2} \mathrm{O}}
\end{aligned}
$$


The ethanol flow to the distillation column $[\mathrm{kg} / \mathrm{hr}]$ is simply the recovery fraction of the stripping unit $\left(X_{r e c, s}^{e t o h}\right)$ multiplied by the stripper inlet flow of ethanol $\left(F_{i j, s}^{e t o h}\right)$ :

$$
F_{i j, d}^{e t o h}=X_{r e c, s}^{e t o h} F_{i j, s}^{e t o h}
$$

The fixed cost of the ethanol stripping unit is found using the equation derived from ICARUS as outlined in Section 4.4:

$$
F C_{i j, s}^{c o l}=P_{1}^{s t r i p} *\left(D_{i j, s}^{c o l}\right)^{2}+P_{2}^{s t r i p} * D_{i j, s}^{c o l}+P_{3}^{\text {strip }}
$$

Similar to the stripping column, the evaporator medium pressure steam requirement is found using equations developed and illustrated in Section 4.4:

$$
F_{i j, \text { evp }}^{M P S}=a_{1}^{\text {evp }} * F_{i j, \text { evp }}^{\mathrm{H}_{2} \mathrm{O}}-a_{2}^{\text {evp }} * F_{i j, \text { evp }}^{\text {cont }}
$$

It was assumed that for the stripping column, none of the contaminating products exited with the ethanol overhead stream consequently being sent to the waste evaporator:

$$
F_{i j, \text { evp }}^{\text {cont }}=F_{i j, s}^{\text {cont }}
$$

The benefit of using this triple effect evaporating unit is its generation of low pressure steam in the final effect. This steam can then be used for heating in various parts of the plant. The condensed steam is not integrated back into the boiler feed water loop but is sent to the process water tank. Hence for every pound of medium pressure steam used for evaporation, approximately one pound of low pressure steam is produced as well as one pound of water is recovered in the system. Hence there is double credit to the plant economics: 


$$
\begin{aligned}
& F_{i j, \text { evp }}^{L P S, r}=a_{3}^{\text {evp }} * F_{i j, \text { evp }}^{\mathrm{H}_{2} \mathrm{O}} a_{4}^{\text {evp }} * F_{i j, \text { evp }}^{\text {cont }} \\
& C r_{i j, \text { evp }}^{L P S}=24 * C^{s t m} * F_{i j, \text { evp }}^{L P S, r}
\end{aligned}
$$

The fixed cost of the waste evaporator is found as a function of the heat transfer area $\left[\mathrm{m}^{2}\right]$. This area is calculated using the developed equation from Section 4.4 and is then used to calculate evaporator fixed cost as shown by Equation 99 below. The parametric cost coefficient $\left(P_{1}^{e v p}\right)$ was illustrated in Section 4.4 and for this study is taken as 37304 :

$$
\begin{aligned}
& A_{i j, \text { evp }}^{\text {heat }}=a_{5}^{\text {evp }} * F_{i j, \text { evp }}^{\mathrm{H}_{2} \mathrm{O}}-a_{6}^{\text {evp }} * F_{i j, \text { evp }}^{\text {cont }} \\
& F C_{i j, \text { evp }}^{\text {heeat }}=P_{1}^{\text {evp }} *\left(A_{i j, \text { evp }}^{\text {heat }}\right)^{0.65}
\end{aligned}
$$

Based on the unit configuration, water evaporated in the first effect is used for heating in the second effect and subsequent water evaporated in the second effect is used as heating for the third effect. These condensed water streams is cooled and recycled back to the front end of the plant thus representing a credit in overall water cost. The cooling required is found using Equation 100 as was developed and illustrated in Section 4.4:

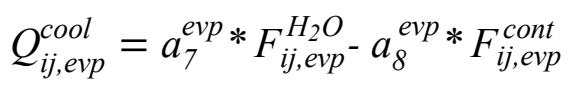

The evaporator unit was designed to concentrate the contaminant stream to 50 $\mathrm{wt} \%$ liquor which can be subsequently sent to the boiler for heat recovery credits or sold as an animal meal additive. For the evaporator it assumed that waste contaminants are not highly volatile and exit the evaporator in the waste stream: 


$$
F_{i j, \text { waste }}^{\mathrm{H}_{2} \mathrm{O}}=F_{i j, \text { evp }}^{\text {cont }}
$$

The recycled water flowrate $\left(F_{i j, e v p}^{\mathrm{H}_{2} \mathrm{O}, r}\right)$ is found via the water entering the unit $\left(F_{i j, \text { evp }}^{\mathrm{H}_{2} \mathrm{O}}\right)$ minus the recovered steam $\left(F_{i j, \text { evp }}^{L P S, r}\right)$ and waste water $\left(F_{i j \text {,waste }}^{\mathrm{H}_{2} \mathrm{O}}\right)$ :

$$
F_{i j, \text { evp }}^{\mathrm{H}_{2} \mathrm{O} r}=F_{i j, \text { evp }}^{\mathrm{H}_{2} \mathrm{O}}-F_{i j \text {,evp }}^{L P S, r}-F_{i j, \text { waste }}^{\mathrm{H}_{2} \mathrm{O}}
$$

The water recovery credit for the evaporator is calculated as a product of recovery water flow $\left(F_{i j, \text { evp }}^{\mathrm{H}_{2} \mathrm{O}, r}\right)$ and LPS recovered $\left(F_{i j, \text { evp }}^{L P S, r}\right)$ and the cost of process water for the plant $\left(\mathrm{C}^{\mathrm{H}_{2} \mathrm{O}}\right)$ given in $[\$ / \mathrm{kg}]$ :

$$
\mathrm{Cr}_{i j, \text { evp }}^{\mathrm{H}_{2} \mathrm{O}, r}=24 * C^{\mathrm{H}_{2} \mathrm{O}} *\left(F_{i j, \text { evp }}^{\mathrm{H}_{2} \mathrm{O}, \mathrm{r}}+F_{i j, \text { evp }}^{\mathrm{LPS}, \mathrm{r}}\right)
$$

The heating requirement for the bioethanol plant is substantial and as such, cogeneration of electricity poses some potential. As such, medium pressure steam used in the evaporator is generated by stepping down high pressure steam through a steam turbine. The generated electricity is normally in excess of that required thereby creating an electricity credit for the process. This is given in Equation 104 as the product of the difference in steam enthalpies $[\mathrm{kJ} / \mathrm{kg}]$, the MPS flowrate $[\mathrm{kg} / \mathrm{hr}]$ and the cost of electricity $[\$ / \mathrm{kWh}]$ along with conversion factors:

$$
C r_{i j, \text { evp }}^{\text {elect }}=24 *\left(H^{H P S}-H^{M P S}\right) * F_{i j, \text { evp }}^{M P S} / 3600 * C^{\text {elect }}
$$

The fixed cost of the steam turbine is a function of the power output and is given by Equation 104 which includes the installed cost of the unit in the parametric cost coefficient $\left(P_{l}^{\text {turb }}\right)$. For this study $\left(P_{l}^{\text {turb }}\right)$ is taken as 100 : 


$$
F C_{i j, e v p}^{\text {turbine }}=P_{1}^{\text {turb }} *\left[\left(H^{H P S}-H^{M P S}\right) * F_{i j, e v p}^{M P S}\right]^{0.5}
$$

The distillation column's required size is determined as a function of the total feed flow as well as the mass fraction of ethanol in the feed $\left(x_{i j, d}^{e t o h}\right)$ :

$$
D_{i j, d}^{c o l}=a_{5}^{d i s t} *\left(F_{i j, d}^{e t o h}+F_{i j, d}^{\mathrm{H}_{2} \mathrm{O}}\right)^{0.546} * x_{i j, d}^{e t o h}+a_{6}^{d i s t} *\left(F_{i j, d}^{e t o h}+F_{i j, d}^{\mathrm{H}_{2} \mathrm{O}}\right)^{0.529}
$$

The fixed cost of the column is determined via the correlation developed using ICARUS and illustrated in Section 4.4. The parametric cost coefficients in Equation 107 are given in Table 10 of Section 4.4:

$$
F C_{i j, d}^{c o l}=P_{1}^{d i s t} *\left(D_{i j, d}^{c o l}\right)^{2}+P_{2}^{d i s t} * D_{i j, d}^{c o l}+P_{3}^{d i s t}
$$

The distillation column condenser duty $[\mathrm{kW}]$ is calculated using corresponding equations from Section 4.4. This duty is then used to calculate the required cooling water flow $\left(F_{i j, d}^{C W}\right)$ given in $[\mathrm{kg} / \mathrm{hr}]$ and corresponding operating cost for cooling water [\$/day]. For Equation 109, the heat capacity of water $\left(C_{p, H_{2} O}\right)$ is given as $4.18 \mathrm{~kJ} / \mathrm{kg}-\mathrm{K}$ :

$$
\begin{aligned}
& Q_{i j, d}^{c o n d}=a_{1}^{\text {dist } *} F_{i j, d}^{e t o h}+a_{2}^{\text {dist } *} F_{i j, d}^{\mathrm{H}_{2} \mathrm{O}} \\
& F_{i j, d}^{C W}=3600^{*} Q_{i j, d}^{c o n d} /\left(C_{p, \mathrm{H}_{2} \mathrm{O}} * \Delta T^{C W}\right) \\
& O C_{i j, d}^{C W}=24 * C^{C W} * F_{i j, d}^{C W}
\end{aligned}
$$

The required heat transfer area $\left[\mathrm{m}^{2}\right]$ of the condenser is calculated to facilitate the determination of the fixed cost for the unit via Equation 112. It is found by dividing the condenser duty $[\mathrm{kW}]$ by the overall heat transfer coefficient $\left[\mathrm{kW} / \mathrm{m}^{2}-\mathrm{K}\right]$ and log mean temperature difference $[\mathrm{K}]$ : 


$$
\begin{aligned}
& A_{i j, d}^{\text {cond }}=Q_{i j, d}^{\text {cond }} /\left(U^{\text {cond }} * \Delta T_{l m}^{\text {cond }}\right) \\
& F C_{i j, d}^{\text {cond }}=P_{1}^{\text {cond }} *\left(A_{i j, d}^{c o n d}\right)^{0.89}
\end{aligned}
$$

For this study, the parametric cost coefficient $\left(P_{1}^{\text {cond }}\right)$ in Equation 112 is taken as 2034. Similar to the condenser calculations, the duty for the rebioler $[\mathrm{kW}]$ is determined using equations developed and illustrated in Section 4.4. This duty is then used to calculate the required high pressure steam flow $[\mathrm{kg} / \mathrm{hr}]$ by dividing it by the steam enthalpy $[\mathrm{kJ} / \mathrm{kg}]$ as well as the associated operating cost [\$/day]:

$$
\begin{aligned}
& Q_{i j, d}^{r e b}=a_{3}^{d i s t *} F_{i j, d}^{e t o h}+a_{4}^{d i s t} * F_{i j, d}^{\mathrm{H}_{2} \mathrm{O}} \\
& F_{i j, d}^{H P S}=3600 * Q_{i j, d}^{r e b} / \Delta H_{v}^{H P S} \\
& O C_{i j, d}^{H P S}=24 * C^{s t m} * F_{i j, d}^{H P S}
\end{aligned}
$$

The heat transfer area $\left[\mathrm{m}^{2}\right]$ for the rebioler is determined so as to account for the fixed cost of the unit in the economic analysis. It is found by dividing the reboiler duty $[\mathrm{kW}]$ by the overall heat transfer coefficient $\left[\mathrm{kW} / \mathrm{m}^{2}-\mathrm{K}\right]$ and log mean temperature difference $[\mathrm{K}]$. This fixed cost is shown via Equation 117 and uses a similar parametric cost coefficient as the condenser. For this study $\left(P_{1}^{r e b}\right)$ is taken as 2034 :

$$
\begin{aligned}
& A_{i j, d}^{r e b}=Q_{i j, d}^{r e b} /\left(U^{r e b} * \Delta T_{l m}^{r e b}\right) \\
& F C_{i j, d}^{r e b}=P_{1}^{r e b} *\left(A_{i j, d}^{r e b}\right)^{0.89}
\end{aligned}
$$

By conducting an ethanol balance on the column, the recovered ethanol $[\mathrm{kg} / \mathrm{hr}]$ in the overhead product is found by multiplying the recovery factor of the unit $\left(X_{r e c, d}^{e t o h}\right)$ by 
the flowrate of fed ethanol $[\mathrm{kg} / \mathrm{hr}]$. This is shown in Equation 118. The subsequent water flowrate in the overhead is found as a function of the mass purity of ethanol in the stream $\left(x_{i j, \text { sieve }}^{\text {etoh }}\right)$ and is shown in Equation 119. This purity was designed to be close to the azeotropic mass fraction composition:

$$
\begin{aligned}
& F_{i j, \text { sieve }}^{\text {etoh }}=X_{\text {rec, }, d}^{\text {etoh }} * F_{i j, d}^{\text {etoh }} \\
& F_{i j, \text { sieve }}^{\mathrm{H}_{2} \mathrm{O}}=F_{i j, \text { sieve }}^{\text {etoh }} *\left(1-x_{i j, \text { sieve }}^{\text {etoh }}\right) / x_{i j, \text { sieve }}^{\text {etoh }}
\end{aligned}
$$

The water stream leaving the bottom of the column contains only trace amounts of ethanol impurities and can be recycled without expensive treatment. The flowrate of this recycled water stream $[\mathrm{kg} / \mathrm{hr}]$ is found via a water balance on the unit given by Equation 120. The credit for recycling this water stream [\$/day] is shown via Equation 121:

$$
\begin{aligned}
& F_{i j, d}^{\mathrm{H}_{2} \mathrm{O}, \mathrm{r}}=F_{i j, d}^{\mathrm{H}_{2} \mathrm{O}}-F_{i j, \text { sieve }}^{\mathrm{H}_{2} \mathrm{O}} \\
& C r_{i j, d}^{\mathrm{H}_{2} \mathrm{O}, r}=24 * \mathrm{C}^{\mathrm{H}_{2} \mathrm{O}} * F_{i j, d}^{\mathrm{H}_{2} \mathrm{O}, r}
\end{aligned}
$$

The process air cooler is used to cool the recycled water streams from both the distillation bottoms as well as the triple effect evaporator. The bay area $\left[\mathrm{m}^{2}\right]$ required for the air cooler is found using Equation 122:

$$
A_{i j, \text { air }}^{\text {cool }}=\left(F_{i j, d}^{\mathrm{H}_{2} \mathrm{O}, \mathrm{r}} * C_{p, \mathrm{H}_{2} \mathrm{O}} * \Delta T^{\text {air }}+3600 * Q_{i j, \text { evp }}^{\text {cool }}\right) /\left(U^{\text {air }} * \Delta T_{l m}^{\text {air }}\right)
$$

For Equation 122, the numerator is given in $[\mathrm{kJ} / \mathrm{hr}]$ while the overall heat transfer coefficient $\left(U^{\text {air }}\right)$ is given in $\left[\mathrm{kJ} / \mathrm{hr}-\mathrm{m}^{2}-\mathrm{K}\right]$ and the log mean temperature difference in 
[K]. The operating cost of the air cooler is based on the required power input to the draft fans. Using ICARUS and linear regression techniques, the power input [kW] was found to be directly dependent on the bay area $\left[\mathrm{m}^{2}\right]$. Using Equation 123 this air cooler operating cost is found [\$/day]. For Equation 123, $\left(a_{1}^{\text {air }}\right)$ represents the linear relation parameter for area to power input for the air cooler. The value of $\left(a_{1}^{\text {air }}\right)$ was taken as 0.1198:

$$
O C_{i j, \text { air }}^{\text {cool }}=24 *\left(a_{1}^{\text {air } * A_{i j, a i r}^{c o o l}}\right) * C^{\text {elect }}
$$

The fixed cost of the air cooler was determined using a correlation developed from obtained ICARUS costs for various bay sizes:

$$
F C_{i j, \text { air }}^{\text {cool }}=P_{1}^{\text {air }} *\left(A_{i j, \text { air }}^{\text {cool }}\right)^{2}+P_{2}^{\text {air }} * A_{i j, \text { air }}^{\text {cool }}
$$

The parametric cost coefficients $\left(P_{1}^{\text {air }}\right)$ and $\left(P_{2}^{\text {air }}\right)$ for Equation 124 were taken as 0.0033 and 358 respectively for this study.

For the molecular sieve beds, the flow of ethanol post dehydration is assumed to be equal to that entering the unit implying no product losses:

$$
F_{i j, \text { sieve }}^{\text {etoh }}=F_{i j, \text { sales }}^{\text {etoh }}
$$

The installed cost of the unit is found from NREL equipment data pricing ${ }^{29}$ which is scaled up from the year of evaluation and shown via Equation 125. For this study the parametric cost coefficient for the sieve beds was taken as 2590 :

$$
F C_{i j, \text { sieve }}=P_{1}^{\text {sieve }} *\left(F_{i j, \text { sieve }}^{\text {etoh }}+F_{i j, \text { sieve }}^{\mathrm{H}_{2} \mathrm{O}}\right)^{0.7}
$$


The total annual revenue for the process is solely based on the ethanol sales. This is obtained by summing the total ethanol flow from all routes and multiplying it by the specific volume and desired sale price. The term $O P_{\text {days }}$ is used to account for the total number of operational days for the year. The overall expression is given by Equation 127:

$$
A_{\text {sales }}=O P_{\text {days }} \sum_{i}^{I} \sum_{j}^{J} v^{\text {etoh }} * F_{i j, \text { sales }}^{\text {etoh }} * C^{\text {etoh }}
$$

The annual credit to the plant is the sum of all the daily operational credits multiplied by the number of operational days for the plant:

$$
A_{C r}=O P_{d a y s} \sum_{i}^{I} \sum_{j}^{J} C r_{i j}
$$

The total equipment fixed cost is found by summing all values for the selected processing route:

$$
F C=\sum_{i}^{I} \sum_{j}^{J} F C_{i j}
$$

The annual depreciation is found using the straight line method and is taken over the plant life (plife):

$$
A_{D}=F C / \text { plife }
$$

The total capital investment would be the sum of the fixed cost and the working capital. The working capital is considered to be between 10 to $20 \%$ of the total capital investment as shown by Peters and Timmerhaus. ${ }^{30}$ For this analysis, $15 \%$ was used:

$$
W C I=0.15^{*} T C I
$$




$$
\begin{aligned}
& T C I=F C+W C I \\
& T C I=F C I / 0.85
\end{aligned}
$$

The annualized fixed capital investment is found as a function of the interest rate and plant life ${ }^{30}$ :

$$
A_{F C}=F C I R(1+I R)^{p l i f e} /\left[(1+I R)^{p l i f e}-1\right]
$$

To account for annual operation and maintenance costs associated with the plant, a value of $7 \%$ of the fixed capital cost would be used as suggested by Peters and Timmerhaus ${ }^{30}$ :

$$
O C^{o m}=0.07^{*} F C
$$

Similarly the labor cost is found using methods described ${ }^{30}$ for a plant operating with technology and process control of average complexity:

$$
L C_{i j}=7.27 * P S_{i j} *\left(F_{i j, \text { sieve }}^{\text {etoh }}\right)^{0.23}
$$

The annual operational cost for the plant is the sum of all operational expenses minus the annual plant operational credit:

$$
A_{O C}=O C^{o m}+L C_{i j}+O P_{\text {days }} \sum_{i}^{I} \sum_{j}^{J} O C_{i j}-A_{C r}
$$

Corporate tax for the plant would be based on the gross income of the plant. The gross income would be the total annual sales less the annual operating expenses and annual depreciation:

$$
A_{\text {tax }}=\left(A_{\text {sales }}-A_{O C}-A_{D}\right) * T R^{\text {corp }}
$$


Finally the annual cash flow for the plant is the annual sales from ethanol production plus the annual credits less the operating costs, corporate taxes and annualized capital investment:

$$
A_{\text {cash flow }}=A_{\text {sales }}+A_{C r}-A_{O C}-A_{\text {tax }}-A_{F C}
$$

In most economic evaluations, profitability of technology or a proposed project is determined using certain financial metrics. Return on investment, payback period as well as other profitability indicators are used to determine the economic viability of a project. While these are useful, they would only yield favorable results in this study if end price of ethanol is known. For this study the converse problem is achieve where the metrics are in essence predetermined and the minimum ethanol price is found at zero cash flow. 


\section{EXAMPLE STUDY}

\subsection{Bioethanol Process}

The proposed biorefinery for this study would be designed to produce ethanol as the final product using conventional processing routes. The location for the facility is assumed to be in Iowa where climatic conditions favor biomass availability for parts of the year. In Iowa, it is assumed that the winter climate affects the availability of the biomass and as such alternative scheduling procedures could be investigated.

The overall objective of the study would be to investigate the optimal plant capacity of a biorefinery that minimizes the cost of ethanol to the consumer. For these economics, the cost of hydrolyzing enzyme and biomass feedstock plays a key role in the downstream cost of the ethanol. The latter is a logistics problem since many factors such as availability, labor costs, agricultural costs and many other factors can contribute to an increased value. Special attention though is directed to the cost of transportation since there is a tradeoff between the cost of this factor and the potential revenue from a unit of biomass transported. It has been shown that transportation via trucking should not exceed a 50-mile radius of the plant so as to ensure plant economic. ${ }^{31}$

The configuration of the entire biorefinery is displayed in figure 15 along with various pretreatment processing routes given by figures 16 through 19 . These processing steps were developed using procedures from literature as well as simple design principles. They represent a logical scheme of what the entire processing facility should resemble without the expected details for an actual plant. In essence the scheme is only developed to provide more detail than the usual black box approach. This approach 
would therefore not reflect the actual ethanol prices that would be expected for an established facility.

The feedstock costing for the biorefinery was obtained from literature ${ }^{7,9,14,32-34}$ and were inclusive of feed handling and transport cost. The feedstock compositions and physical properties were obtained from literature. Table 12 shows the chemical composition of each biomass source.

Table 12 Chemical compositions of biomass used.

\begin{tabular}{lccc} 
Component & Switchgrass & Poplar & Corn stover \\
\hline Glucan & 32.2 & 39.8 & 36 \\
Xylan & 20.3 & 14.8 & 19.8 \\
Galactan & - & - & 1.3 \\
Arabinan & 3.7 & 1.2 & 2.8 \\
Mannan & 0.4 & 2.4 & - \\
Klason lignin & 19.5 & 26.9 & 17.8 \\
Acid-soluble lignin & 3.7 & 2.2 & 1.9 \\
Ash & 7.1 & 1.3 & 7.2 \\
Uronic acid & 1.1 & 2.4 & - \\
Other & 12 & 9 & 13.2 \\
\hline \multicolumn{4}{c}{ Data obtained from Esteghlalian et al. }
\end{tabular}




\subsection{Pretreatment and Hydrolysis Process}

For this study, five pretreatment configurations were researched and selected for modeling:

a) Dilute acid pretreatment

b) Ammonia fiber explosion (AFEX) pretreatment

c) Lime pretreatment

d) $\mathrm{pH}$ controlled hot water pretreatment

e) Aqueous ammonia pretreatment

These pretreatment choices have great potential as the pre-processing step for ethanol production. Some are currently utilized in the bioethanol industry while others are still gaining footing. The experimental data for each processing route is also well documented in literature therefore true optimal operating conditions can be determined. This data is shown in Section 4.4 of this study.

The operating conditions as well as required equipment for each pretreatment and hydrolysis process are starkly different and as such, limitations are integrated into the model to reflect accurate as well as physically feasible results. These design conditions and equipment size limitation are shown in Table 13. Conditions with ranges indicate that they would be optimized for minimum ethanol cost. 
Table 13 Design parameters for pretreatment and hydrolysis.

\begin{tabular}{|c|c|c|c|}
\hline Pretreatment & Design parameter & value & units \\
\hline \multirow[t]{6}{*}{ Acid } & solid loading & 30 & wt\% \\
\hline & acid conc. & $0.6-1.2$ & wt\% \\
\hline & time & $0-15$ & mins \\
\hline & temperature & $140-180$ & ${ }^{\circ} \mathrm{C}$ \\
\hline & hydrolysis load & 7 & wt\% cellulose \\
\hline & enzyme load & 0.24 & $\mathrm{ml} / \mathrm{g}$ cellulose \\
\hline \multirow[t]{6}{*}{ AFEX } & solid loading & 50 & wt\% \\
\hline & time & 5 & mins \\
\hline & temperature & 100 & ${ }^{\circ} \mathrm{C}$ \\
\hline & hydrolysis load & 7 & wt\% cellulose \\
\hline & enzyme load & $0-100$ & FPU/g cellulose \\
\hline & hydrolysis time & $0-168$ & hrs \\
\hline \multirow[t]{6}{*}{ Lime } & water load & $9-10$ & kg / kg bio \\
\hline & lime load & 0.1 & kg / kg bio \\
\hline & time & 2 & hrs \\
\hline & temperature & 120 & ${ }^{\circ} \mathrm{C}$ \\
\hline & hydrolysis load & 150 & $\mathrm{~g}$ bio /kg water \\
\hline & enzyme load & $0-100$ & FPU/g cellulose \\
\hline \multirow[t]{5}{*}{ LHW } & solid loading & 16 & wt\% \\
\hline & time & $0-30$ & mins \\
\hline & temperature & 190 & ${ }^{\circ} \mathrm{C}$ \\
\hline & hydrolysis load & 7 & wt\% cellulose \\
\hline & enzyme load & 10 & FPU/g cellulose \\
\hline \multirow[t]{6}{*}{ ARP } & aq. ammonia conc. & 15 & wt\% \\
\hline & aq. ammonia flow & 313 & g/min-kg bio \\
\hline & time & $0-100$ & mins \\
\hline & temperature & 170 & ${ }^{\circ} \mathrm{C}$ \\
\hline & hydrolysis load & 7 & wt\% cellulose \\
\hline & enzyme load & 10 & FPU/g cellulose \\
\hline All & hydrolysis time & $0-168$ & hrs \\
\hline
\end{tabular}




\subsection{Fermenting Process}

There is only one option for this step since the technology is only dependent on the properties of the enzymes and not the physical operating conditions of the unit. For this study data for one type of digesting enzyme was used. This was not by choice but as a result on the dubious and cryptic nature of enzyme pricing. For the simulation and optimization of this unit the following limitations on equipment sizes and operating conditions applied are shown in Table 14.

\section{Table 14 Design parameters for fermentation process.}

\begin{tabular}{lll} 
Design parameter & value & units \\
\hline enzyme load & $0.1-2$ & dry wt protein/L \\
time & $0-120$ & $\mathrm{hrs}$ \\
temperature & 50 & ${ }^{\circ} \mathrm{C}$ \\
volume & $0-4000$ & $\mathrm{~m}^{3}$ \\
\hline
\end{tabular}

\subsection{Separation and Recovery Process}

Similar to the fermentation setup, this separation and recovery Section is limited by technology selection for this model. The configuration is displayed in Appendix A and involves the use of an ethanol stripping column followed by a distillation unit for further ethanol purification. The final unit in the ethanol purification process is a molecular sieve bed which is used to remove any remaining water in the stream. For the 
water recovery section, a multi-effect evaporating unit is used. The operating limitation and design data for this setup is given by Table 15 .

Table 15 Design parameters of separation and recovery process.

\begin{tabular}{llll} 
Equipment & Design parameter & value & units \\
\hline Stripper & pressure & 10 & $\mathrm{psig}$ \\
& size & $2-12$ & $\mathrm{ft}$ \\
& height & 35 & $\mathrm{ft}$ \\
Distillation & pressure & 50 & $\mathrm{psig}$ \\
& size & $2-12$ & $\mathrm{ft}$ \\
& height & 90 & $\mathrm{ft}$ \\
Evaporator & 1st effect & 30 & $\mathrm{psig}$ \\
& area & $0-9680$ & $\mathrm{ft}^{2} /$ effect \\
\hline
\end{tabular}

\subsection{Economic Variables}

To ensure that the evaluation of all the processing routes is complete and pragmatic, an economic evaluation is done using basic principles and literature. ${ }^{29}$ For this study a project life of ten (10) years was used with all equipment having no salvage value at the end of this life. This selected plant life is suitable since with today's economic climate for bioethanol facilities, a high rate of return is desired. A $7 \%$ interest rate is also applied along with a $20 \%$ corporate tax. For this study a number of operating cost factors would be applied given by Tables 16 through 18 . These numbers were obtained from either chemical databases such as ICIS or literature and common industrial values. 
Table 16 Plant utility costs.

\begin{tabular}{|c|c|c|}
\hline Utility & value & units \\
\hline Natural Gas & 4.4 & $\$ / M M B T U$ \\
\hline Electricity & 0.08 & $\$ / k W h$ \\
\hline Steam & 6.61 & $\$ / 1000 \mathrm{~kg}$ \\
\hline \multicolumn{3}{|l|}{ Water } \\
\hline Process & 0.001 & $\$ / m 3$ \\
\hline Cooling & 0.065 & $\begin{array}{l}\$ / \mathrm{m} 3 \\
\text { circulating }\end{array}$ \\
\hline Waste & 36 & $\$ / 1000 \mathrm{~kg}$ \\
\hline Labor & 27.60 & $\$ / h r$ \\
\hline
\end{tabular}

Table 17 Chemicals cost.

\begin{tabular}{lll} 
Chemical & value & units \\
\hline Acid & $50-94$ & $\$ /$ short ton \\
Ammonia & $500-771.64$ & $\$ / 1000 \mathrm{~kg}$ \\
Lime & $56-74$ & $\$ /$ short ton \\
\hline
\end{tabular}

Table 18 Biomass gate cost.

\begin{tabular}{lll} 
Biomass & value & units \\
\hline Corn stover & 61.6 & $\$ / 1000 \mathrm{~kg}$ \\
Switchgrass & 81.5 & $\$ / 1000 \mathrm{~kg}$ \\
Poplar & 101.6 & $\$ / 1000 \mathrm{~kg}$ \\
\hline
\end{tabular}


To account for the labor cost, the method offered in literature ${ }^{30}$ is used. For this method the labor cost was considered under average operating technology with seven main operating steps. The equipment costing was evaluated using ICARUS Process evaluator, Super Pro Designer as well as literature values. This study did not include carbon credits, taxes or any scheme that involves carbon dioxide emissions. This was directly due to the lack of maturity of this system here in the United States. Currently there is a "Cap and trade" system that is being developed here in the United States where regions are limited to the amount of carbon dioxide they can emit via permits - the cap. Those companies that reduce their emission to below the limits can sell their permits to those that require increased allowances for carbon dioxide emissions. ${ }^{35}$ 


\section{RESULTS AND DISCUSSION}

\subsection{Targeting}

For this study, the targeting applied was simply done to determine the theoretical yield of ethanol per kilogram of biomass used. By performing this targeting technique, the best suited biomass source can be elucidated therefore and initial assumption for biomass source can be made. Although this assumption may be sub optimal, it represents the potential of a particular biomass source over another. The information would also assist in the comparison of similar processing routes that use the same biomass source. Table 19 shows the results of this targeting procedure.

The economical implications of this ethanol yield per unit mass of biomass could then be used to identify the minimum contribution of biomass cost to the overall price of ethanol. This serves as the lower bound for the potential of the biomass source. This calculation is very useful since it immediately highlights what biomass sources are suitable for ethanol production for a given region. It also indicates the potential profit margin based on a desired ethanol sales price.

Table 19 Minimum biomass cost contribution.

\begin{tabular}{lccccc}
\hline Biomass & $\begin{array}{c}\text { Xylan } \\
(\%)\end{array}$ & $\begin{array}{c}\text { Glucan } \\
(\%)\end{array}$ & $\begin{array}{c}\text { Yield } \\
\text { (gal EtOH/tonne biomass) }\end{array}$ & $\begin{array}{c}\text { Cost } \\
(\$ / \mathrm{MT})\end{array}$ & $\begin{array}{c}\text { Biomass contribution } \\
\$ / \text { gal }\end{array}$ \\
\hline Corn Stover & 19.8 & 36 & 106.87 & 61.6 & 0.58 \\
Switchgrass & 20.3 & 32.2 & 100.84 & 81.5 & 0.81 \\
Poplar & 14.8 & 39.8 & 104.52 & 101.6 & 0.97 \\
\hline
\end{tabular}




\subsection{Optimization}

For the overall economical analysis of the bioethanol facility, two case studies were done. The first case study identifies the optimal bio-processing routes based on those established. Once this is done, a sensitivity analysis is performed on the three best configurations to determine the ranges of feasibility for pretreatment chemical price fluctuations.

The second case study investigated the use of biomass storage for locations that have fluctuating biomass availabilities. This was the particular reason for choosing Iowa as the location of interest for a bioethanol plant. This region experiences heavy snowfall and as such, biomass availability and steady flow is compromised. To analyze the economical implications of storage based on the monthly availability of biomass, a model is proposed to track this storage requirement and then integrated into the base models for the best configuration. 


\section{Case study I}

To solve the base case the detailed superstructure used is given by Figure 8 .

Each configuration is solved as a separate MINLP problem for faster results. These results were then compared and the optimal route established.

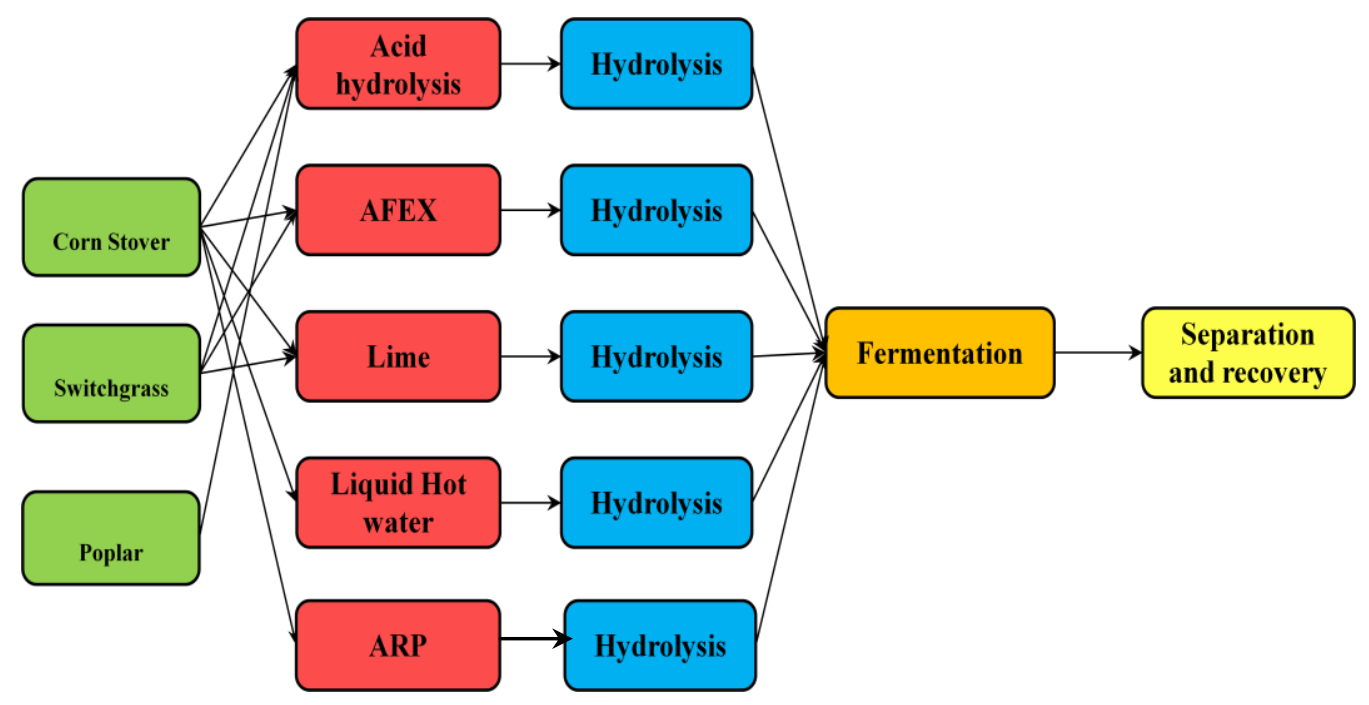

Figure 8 Superstructure for case study I.

The extensive research, simulation, modeling and optimization work showed that the AFEX pretreatment configuration using corn stover as the biomass feedstock is the optimal bio-processing route for minimum ethanol price. This minimum ethanol price is established to be $\$ 1.96 /$ gal. The other leading choices for pretreatment configuration can be seen by Figure 9. 


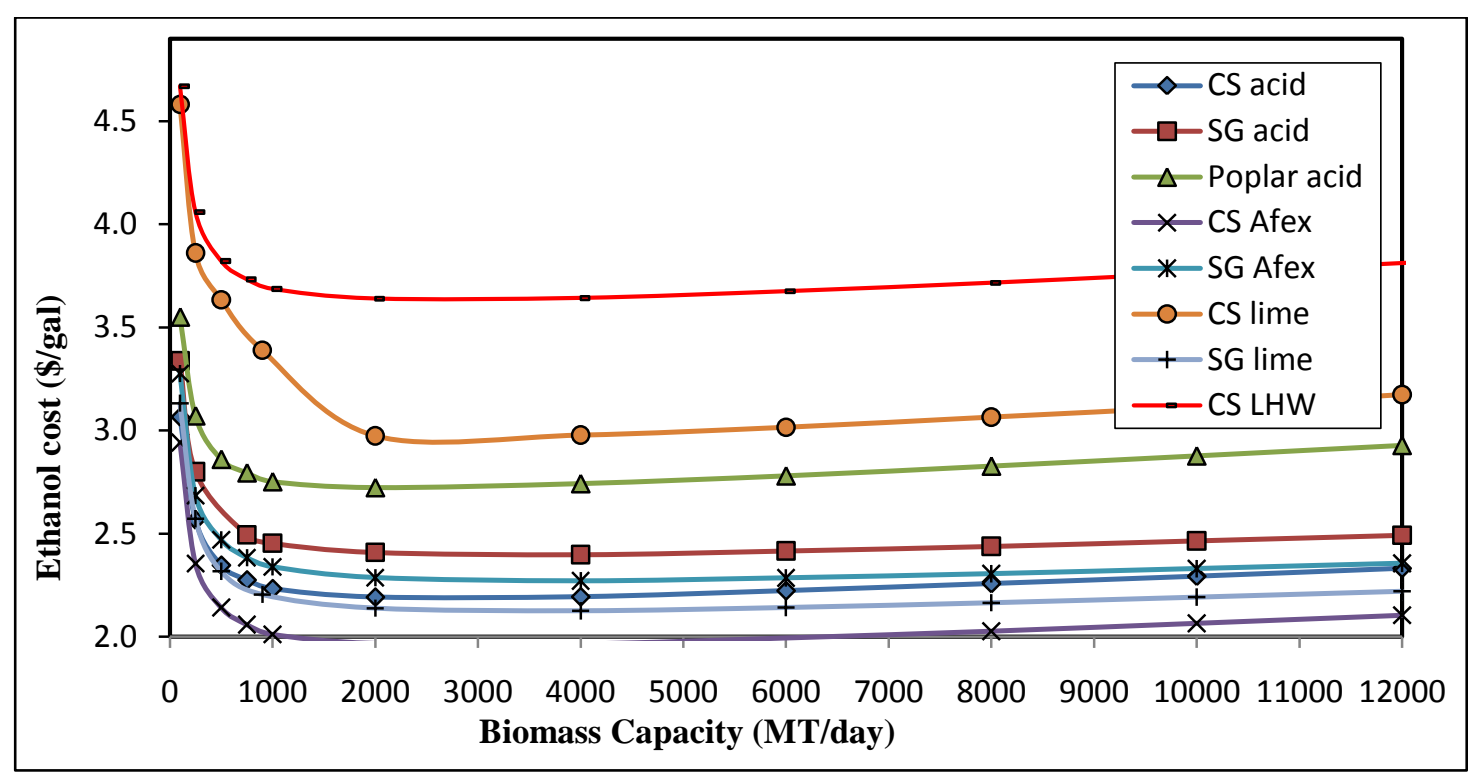

Figure 9 Effect of plant capacity on ethanol price.

It can be seen from the graph that the next optimal configuration is lime pretreatment using switchgrass as the biomass feedstock. The graph also indicates that the minimum ethanol price for each pretreatment configuration lies somewhere between 2000MT/day to 4000MT/day. Beyond 4000MT/day, the cost of ethanol starts to increase due to the effect of transportation cost. By zooming into this range, the optimization program is re-run and the results for required plant capacity for minimum ethanol price can be obtained. Table 20 shows the overall operating conditions for the optimal plant capacity for each pretreatment option. 
Table 20 Optimal conditions for selected configuration.

\begin{tabular}{|c|c|c|c|c|}
\hline & CS AFEX & SG Lime & CS Acid & SG AFEX \\
\hline Plant Cap. (MT/day) & 2788 & 3978 & 2717 & 3865 \\
\hline Xylan conv. (\%) & 58.36 & 98.42 & 88.67 & 70.53 \\
\hline Glucan conv. (\%) & 89.44 & 78.37 & 84.53 & 95.14 \\
\hline Pretreat time (mins) & 5 & 120 & 0.51 & 5 \\
\hline Acid conc. (wt\%) & - & - & 1.20 & - \\
\hline Pretreat temp. $\left({ }^{\circ} \mathrm{C}\right)$ & 100 & 120 & 180 & 100 \\
\hline Hydrolysis time (hrs) & 155.4 & 73.2 & 104.0 & 168.0 \\
\hline Fermenting time (hrs) & 120.0 & 120.0 & 120.0 & 119.2 \\
\hline \# Fermenters & 16 & 36 & 24 & 20 \\
\hline \# Stripping col. & 2 & 3 & 2 & 2 \\
\hline \# Evaporators & 11 & 24 & 16 & 12 \\
\hline \# Distillation columns & 2 & 3 & 2 & 3 \\
\hline \# Hydrolyzers & 23 & 24 & 8 & 31 \\
\hline \# Pretreatment & 1 & 4 & 1 & 1 \\
\hline $\mathrm{FCl}(\$ \mathrm{MM})$ & 129.25 & 236.38 & 136.34 & 164.77 \\
\hline EtOH Cap. (MMgal/yr) & 72.1 & 102.2 & 75.4 & 101.5 \\
\hline EtOH cost (\$/gal) & 1.956 & 2.124 & 2.184 & 2.267 \\
\hline Enzyme cost (\$/gal) & 0.412 & 0.324 & 0.941 & 0.537 \\
\hline Biomass cost (\$/gal) & 0.823 & 1.091 & 0.766 & 1.066 \\
\hline Energy cost (\$/ga) & 0.305 & 0.464 & 0.337 & 0.311 \\
\hline EtOH yield (gal/tonne bio) & 78.65 & 78.10 & 84.33 & 79.79 \\
\hline
\end{tabular}


Table 20 continued

\begin{tabular}{lcccc} 
& SG Acid & Poplar Acid & CS Lime & CS LHW \\
\hline Plant Cap. (MT/day) & 3559 & 1824 & 3274 & 2635 \\
Xylan conv. (\%) & 89.85 & 90.99 & 57.49 & 62.04 \\
Glucan conv. (\%) & 84.54 & 89.74 & 59.51 & 71.56 \\
Pretreat time (mins) & 0.41 & 0.33 & 120 & 12.38 \\
Acid conc. (wt\%) & 1.20 & 1.20 & - & - \\
Pretreat temp. ( $\left.{ }^{\circ} \mathrm{C}\right)$ & 180 & 180 & 120 & 190 \\
Hydrolysis time (hrs) & 104.2 & 117.2 & 168.0 & 48.0 \\
Fermenting time (hrs) & 120.0 & 120.0 & 120.0 & 120.0 \\
\# Fermenters & 28 & 17 & 29 & 19 \\
\# Stripping col. & 3 & 2 & 3 & 2 \\
\# Evaporators & 19 & 12 & 19 & 13 \\
\# Distillation columns & 3 & 2 & 2 & 2 \\
\# Hydrolyzers & 17 & 13 & 44 & 236 \\
\# Pretreatment & 1 & 1 & 3 & 1 \\
FCl (\$MM) & 164.65 & 101.77 & 211.44 & 281.37 \\
EtOH Cap. (MMgal/yr) & 92.8 & 52.9 & 62.4 & 58.5 \\
EtOH cost (\$/gal) & 2.396 & 2.724 & 2.959 & 3.627 \\
Enzyme cost (\$/gal) & 0.896 & 0.994 & 0.914 & 1.570 \\
Biomass cost (\$/gal) & 1.069 & 1.174 & 1.133 & 0.955 \\
Energy cost (\$/ga) & 0.367 & 0.369 & 0.595 & 0.369 \\
EtOH yield (gal/tonne bio) & 79.26 & 88.23 & 57.90 & 67.51 \\
\hline & & & & \\
\hline
\end{tabular}


The results for optimal plant capacity support many important points not intuitively highlighted without proper optimization. The optimal hydrolysis time for each route is vastly different and not always pinned to the maximum allowable. This factor highlights the tradeoff between extra residence time and cost of its corresponding cost. In some cases the reduction in required residence time can mean the negation of a single unit and less complication in process scheduling.

Another significant point to be noted is the enzyme loading required the AFEX pretreated corn stover configuration. The data for this loading at various plant capacities is shown in Figure 10.

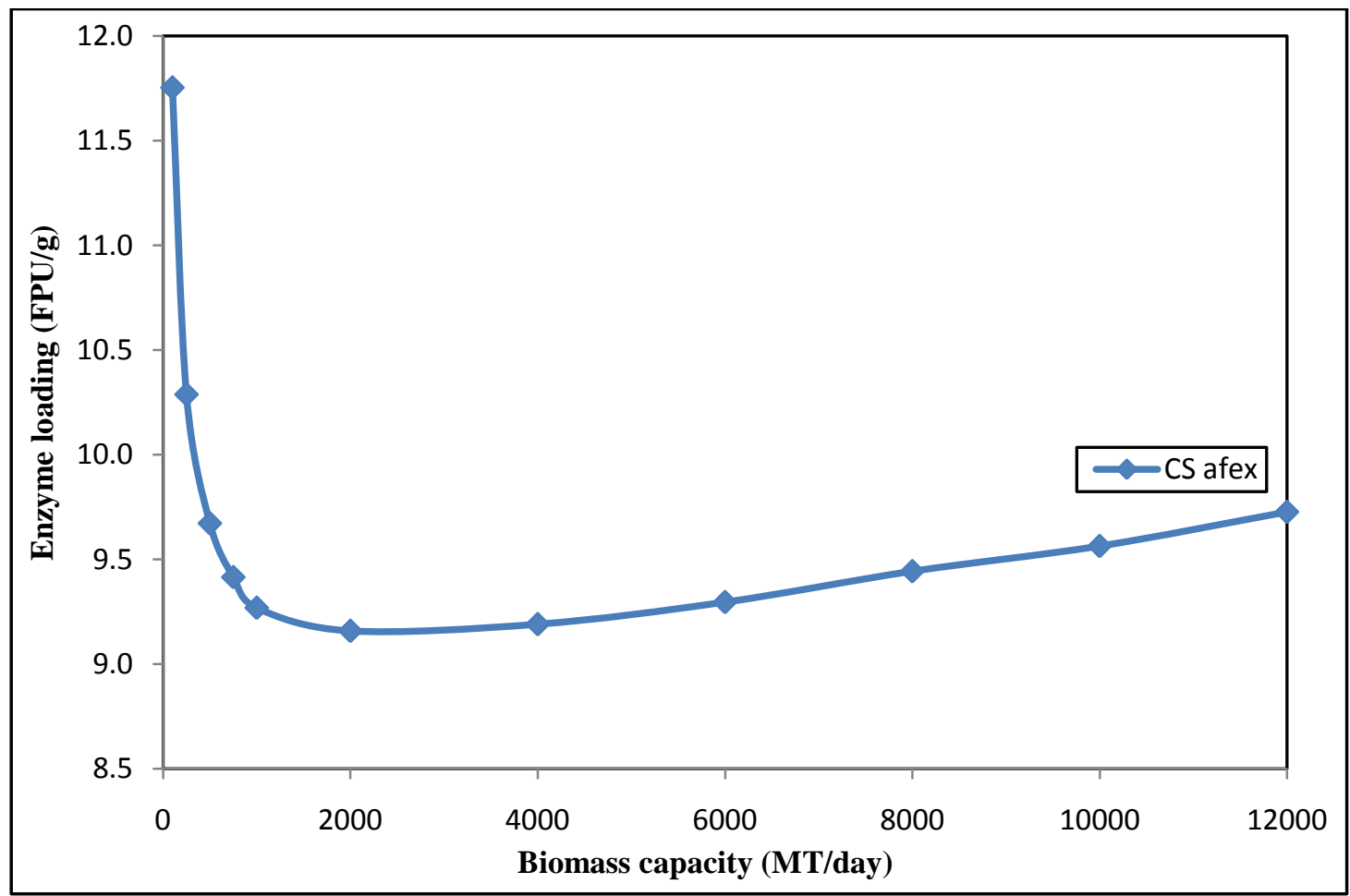

Figure 10 Effect of plant capacity on enzyme loading. 
When comparing this relationship with the corresponding graph for ethanol price, it is clear that both follow the same pathway. This similarity would suggest that the cost of ethanol production is heavily influenced by enzyme loading, a fact known too well in the industry. The graph also garners support for the use of the AFEX pretreatment configuration since its required enzyme loading is lower than other configurations.

By plotting the biomass plant capacity versus the ethanol production capacity in Figure 11, it is immediately revealed that polar has the best conversion ratio. This was not the initial expectation that was born from the targeting procedure. This factor may be due to poplar having a lower neutralizing effect on sulfuric acid than corn stover or switchgrass thereby proving to be more economically pretreated via acid hydrolysis.

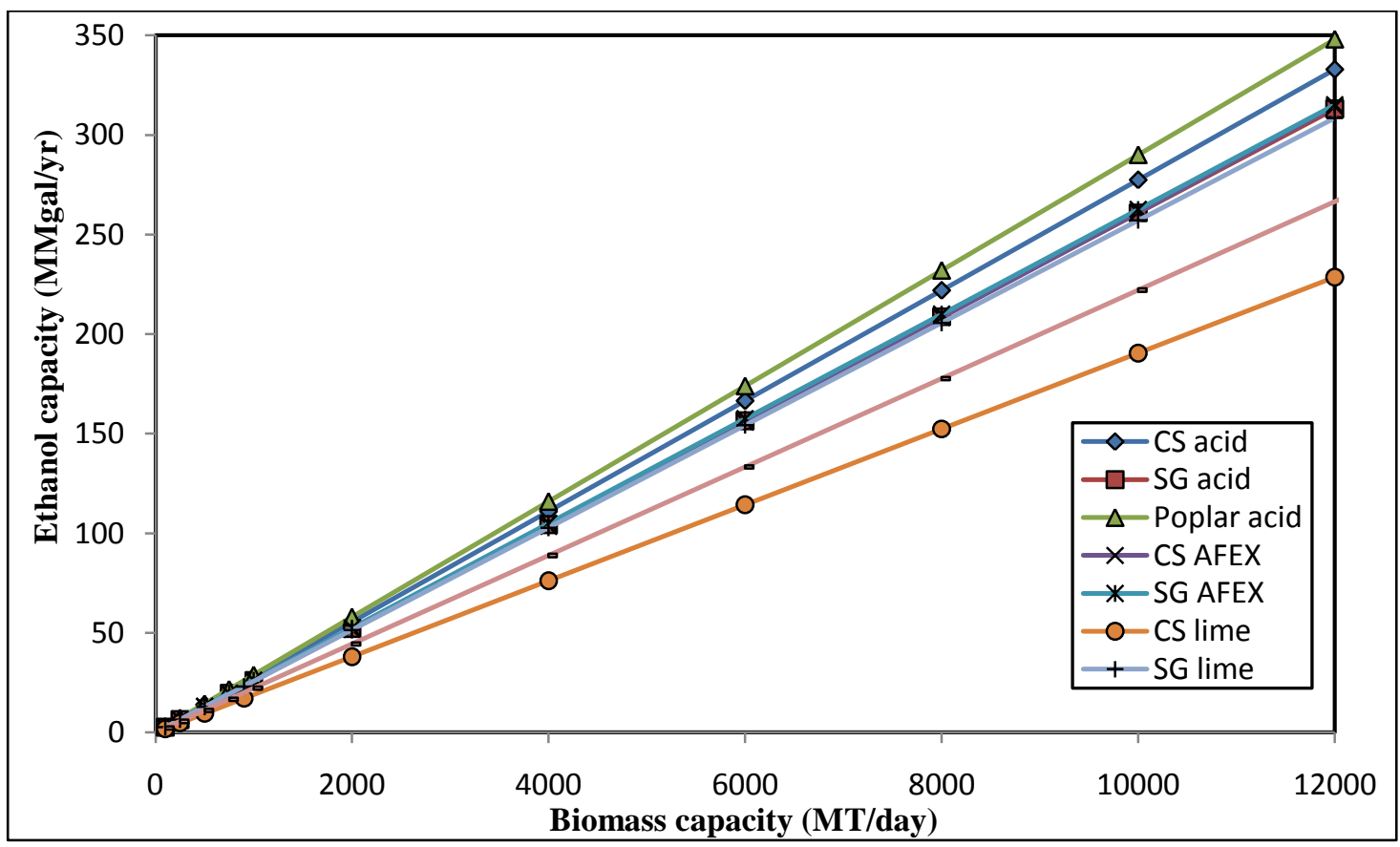

Figure 11 Effect of configuration on ethanol yield. 
Further investigation of Figure 11 reveals that although AFEX pretreated switchgrass and corn stover have the same conversion ratio, corn stover still proves to provide a dominantly lower cost of ethanol. Similar to the case with the poplar, this is as a result of the high switchgrass feedstock cost. Finally comparing both the AFEX and lime pretreated routes for switchgrass, it is easily noted that the major difference in ethanol price is due to the operating costs and fixed capital investments for both processes. This lends support for the use of the lime pretreatment process over that of AFEX in the case of switchgrass.

Sensitivity analysis

To ensure that the bioethanol process survives in present economic markets, a sensitivity analysis is done to project its ability to withstand fluctuating feedstocks and chemical prices. Figure 12 shows the upper and lower bound regions of minimum ethanol prices for three of the best configurations based on the upper and lower price of pretreatment chemical. It should be noted that the upper bound of the acid pretreatment configuration would incorporate two fluctuating chemicals - acid and lime. The latter chemical is used to neutralize the spent acid from the pretreatment section. 


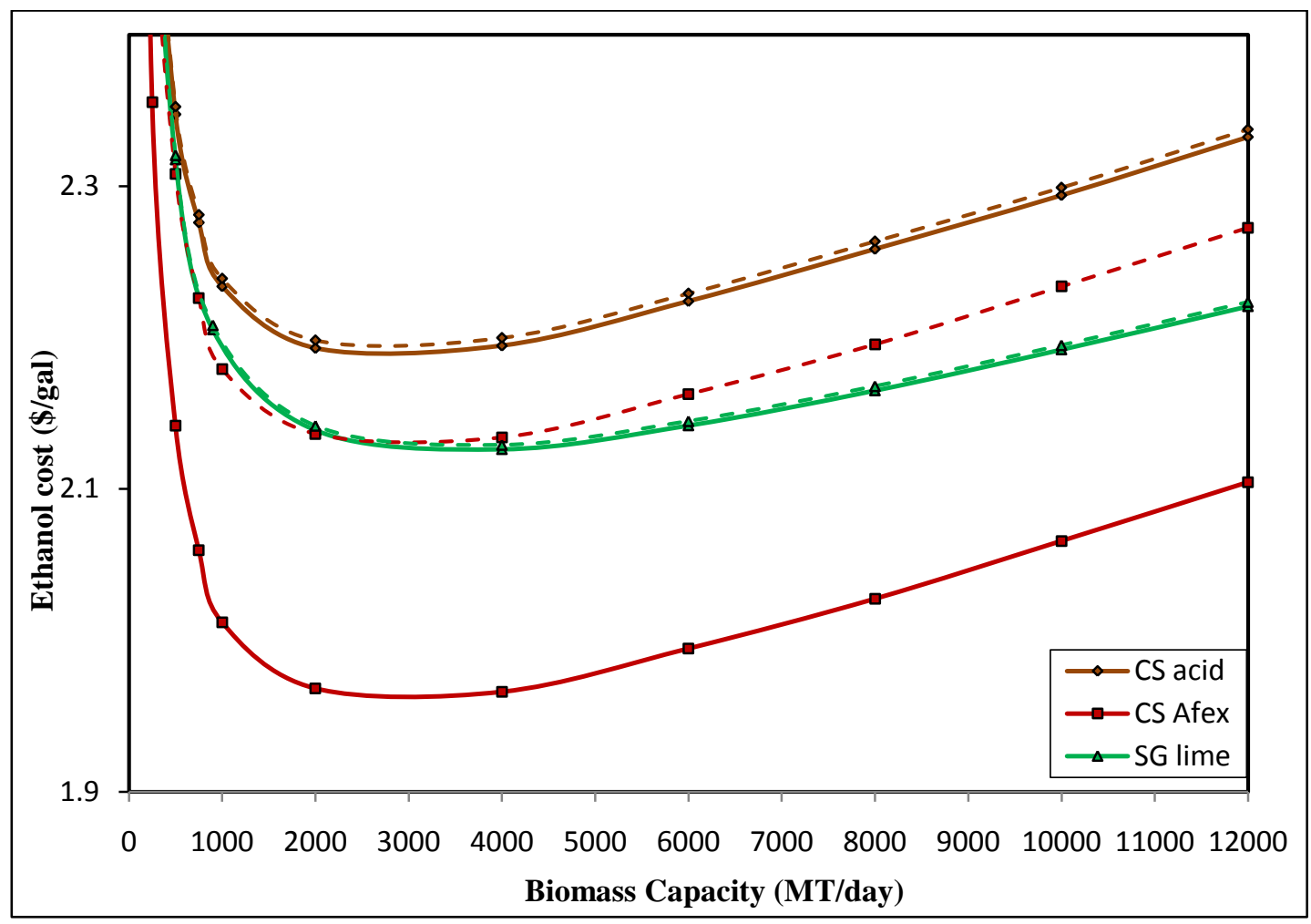

Figure 12 Effect of chemical cost on ethanol price.

An analysis of this graph indicates that the lime pretreatment configuration using switchgrass is the most stable since the price of the pretreatment chemical is fairly invariant. The highest variance in ethanol minimum price is seen with the AFEX pretreatment configuration with the acid pretreatment configuration having an intermediate variance despite the increased acid and lime chemical costs.

The sensitivity of ethanol price to biomass feedstock cost as well as hydrolyzing enzyme cost was not done since this relationship is well known in the industry and offers little additional information to this study. The theoretical targeting done in Section 6.1 already illustrates the high contribution of biomass cost to end ethanol price hence a 
quick use of this analysis can elucidate the sensitivity of ethanol prices to biomass feedstock prices.

\section{Case study II}

The premise of this case study is to offer an insight into the economics involved in the storage of biomass for later processing due to climatic changes that may hinder harvesting and biomass growth. In this analysis a simple model is proposed and integrated into the base case models for the best pretreatment configuration investigated in case study I. To illustrate the applicability of the model, some extreme cases would be used to define regions of feasibility for using storage as a bio-processing option.

\section{Model formulation}

The concept of the model is based on the simple principle involved when filling and emptying a storage vessel. To include the decomposition of the biomass over time of storage a rotting factor is included in the formulation. The model development is done for two periods of the year - the harvesting and drought or winter period. In the first period, the biomass is harvested and stored while the plant continues to operate using biomass that is stored. Hence there is an accumulation rate over time in the storage facility. During the winter period, harvested biomass supply to the storage facility is negated and stored biomass continues to be used until the start of the harvesting period of the next year. 
Storage mass balance for harvesting period

$$
\frac{d M_{s}}{d t}=\dot{m}_{H}-\dot{m}_{P}-r M_{s}
$$

In the mass balance the rotting rate is considered to be a function of the total mass stored at a given time. It is defined as the fractional loss of stored mass per month due to decomposition or polysaccharide loss due to microorganism digestion.

Given the accumulation rate:

$$
\dot{m}_{a c c}=\dot{m}_{H}-\dot{m}_{P}
$$

Equation 140 represents a first order differential equation with solution given by Equation 142 below:

$$
M_{s}=\dot{m}_{a c c} / r\left[1-\exp \left(-r t_{h a r}\right)\right]
$$

The total mass stored at the end of the harvesting period is given by Equation 142. This equation accounts for all the mass that accumulates over time as well as the amount that is lost due to decomposition.

Storage mass balance for winter period

$$
\frac{d M_{s}}{d t}=-\dot{m}_{P}-r M_{s}
$$

This mass balance is the same with the exception of the harvesting rate. Similar to Equation 140 this is a first order differential equation with solution given by Equation 144 below:

$$
M_{s}=M_{s}^{o} \exp \left(-r t_{w i n}\right)-\dot{m}_{P} / r\left[1-\exp \left(-r t_{\text {win }}\right)\right]
$$


The difference in appearance of Equations 140 and 144 is due to there being an initial mass for the winter period that must be accounted for.

\section{Ratio of harvesting to plant capacity}

To determine the ratio between the harvesting rate during the available harvesting period and the plant capacity the following analysis is applied:

$$
\begin{aligned}
& M_{s}^{o}=\dot{m}_{a c c} / r\left[1-\exp \left(-r t_{\text {har }}\right)\right] \\
& 0=M_{s}^{o} \exp \left(-r t_{\text {win }}\right)-\dot{m}_{P} / r\left[1-\exp \left(-r t_{\text {win }}\right)\right]
\end{aligned}
$$

This procedure basically says that the initial mass of stored biomass at the beginning of the winter period is equal to that stored at the end of the harvesting period. Equation 146 simply indicates that the stored biomass at the end of the winter period is zero. By simplifying the exponential terms with constants since the harvest and winter period are known:

$$
\begin{aligned}
& c_{1}=\left[1-\exp \left(-r t_{\text {har }}\right)\right] \\
& c_{2}=\left[1-\exp \left(-r t_{\text {win }}\right)\right]
\end{aligned}
$$

The relationship between the harvesting rate and plant capacity is given by:

$$
\dot{m}_{P}=c_{1}\left(1-c_{2}\right) /\left[c_{2}+c_{1}\left(1-c_{2}\right)\right] \dot{\mathrm{m}}_{\mathrm{H}}
$$

This general equation can now be used for any harvesting and winter period as well as any desired rotting rate. The equation though breaks down if the rotting rate is selected as zero due to the exponential terms used. In essence the use of a very small number 
would give the same accurate value as the formulation if the rotting rate were not incorporated into the model.

To investigate the economics of storage for the bioethanol facility, there are two scenarios for which the plant can operate. These scenarios are:

1. Operate the plant during the harvesting period only with a shut down or turn down during the winter period where there is no biomass available for ethanol production. Therefore the plant capacity is simply equal to the harvesting rate.

2. Operate the plant year round based on the operating days selected in the base case with constant storage of biomass to supply the plant with feed for the winter period.

To evaluate both scenarios fairly, certain realistic assumptions are made. Scenario 1 assumptions

1. The plant operates at the full number of harvesting days with maintenance and upgrades being performed during the shutdown or turn down period.

2. During shut down period, labor is cut to $80 \%$ of the required labor force for full capacity to allow for maintenance work and to ready the plant for restart come harvesting period. The plant utilities are also reduced to $60 \%$ of normal operating capacity. 


\section{Scenario 2 assumptions}

1. The plant operates for 329 days of the year (90\%) as outlined in the base case study.

2. Storage of biomass is done using an open field with rental rate of $\$ 224 /$ hamonth. $^{36}$

3. The average rotting rate of biomass is $5 \%$ which means that $10 \%$ of the biomass is lost over a 2 month period to account for open-air storage on the earth.

4. The base case winter period for storage would be 3 months with a remaining harvesting period of 9 months.

5. The lost biomass that decomposes is resold as compost at $90 \%$ of the original price. It should be noted that compost in Iowa can cost up to $\$ 96 /$ tonne which is significantly higher than the value used for this scenario.

Figure 13 illustrates the results of applying this model and scenarios for the economics surrounding the storage of biomass in a bioethanol facility. This graph shows that the use of storage due to biomass unavailability significantly affects the minimum ethanol selling price despite the fairly inexpensive cost of storage. It also indicates that at the base case, storage is more economical than the non-storage approach up to a specific plant capacity. This breaking point where storage is no longer considered economical is at a plant capacity of $\sim 98 \mathrm{MMgal} / \mathrm{yr}$. This capacity corresponds to a storage scheme for 3750MT/day biomass plant or for a 4500MT/day non-storage facility. 


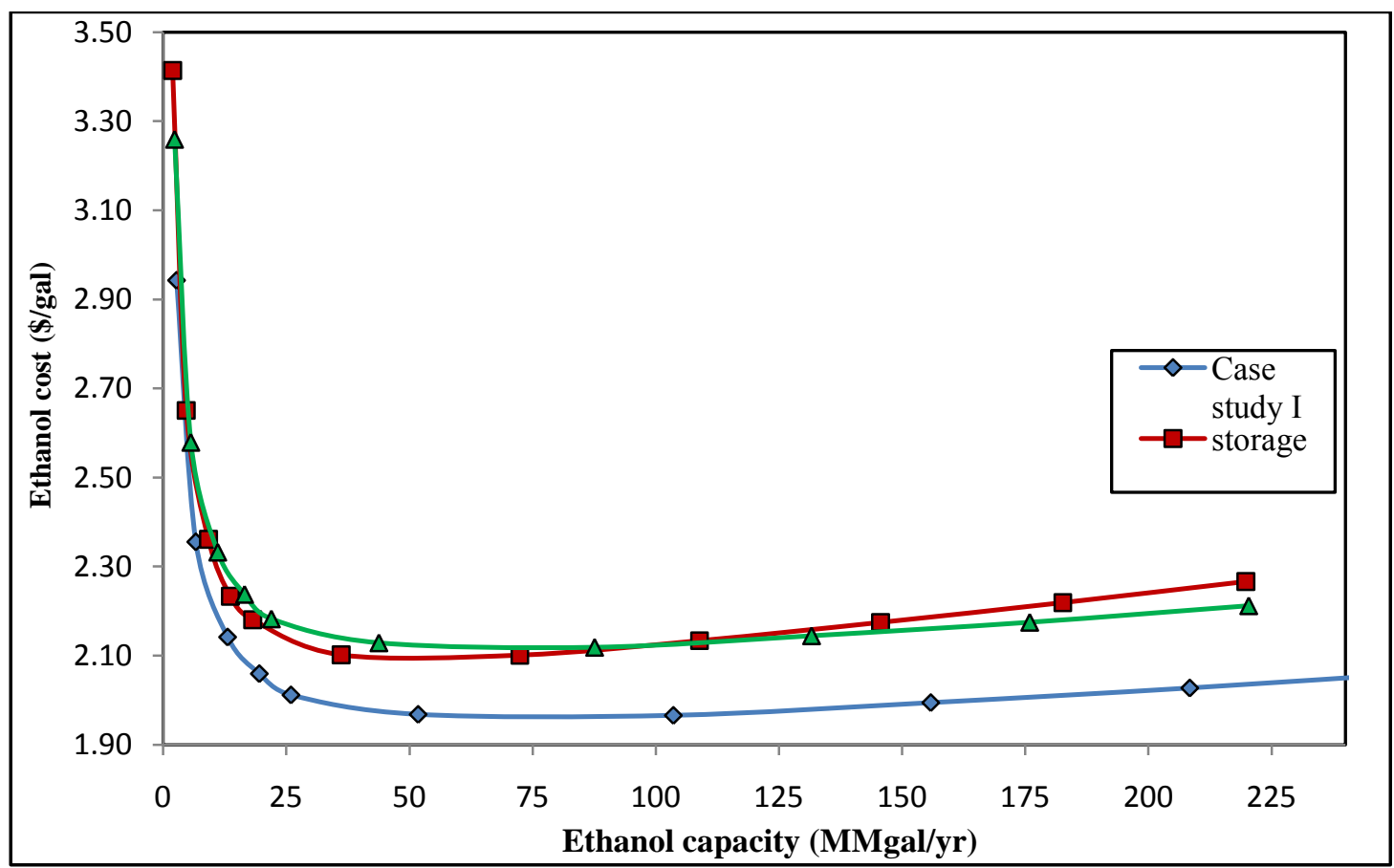

Figure 13 Effect of storage on ethanol cost.

Figure 13 shows the impact of storage cost on minimum cost of ethanol. The high storage cost sensitivity analysis was done using a cost function obtained from literature $^{29}$ that describes the use of a concrete pad for storing biomass on. It was assumed that the use of this pad reduces the decomposition rate of the biomass since it is not in contact with the earth. This reduced rate was assumed to be five fold. The conditions for which storage is always superior to non-storage would be a function of the decomposition rate and cost of storage. In reality the cost of storage would be a function of the decomposition rate since the purpose of storage would be to ensure minimal feedstock loss. It was found that the only conditions that ensure the superiority of the 
storage scheme is when the biomass decomposition rate is at $0.5 \% / \mathrm{month}$ while storage in an open field. The results for these conditions are illustrated in Figure 14.

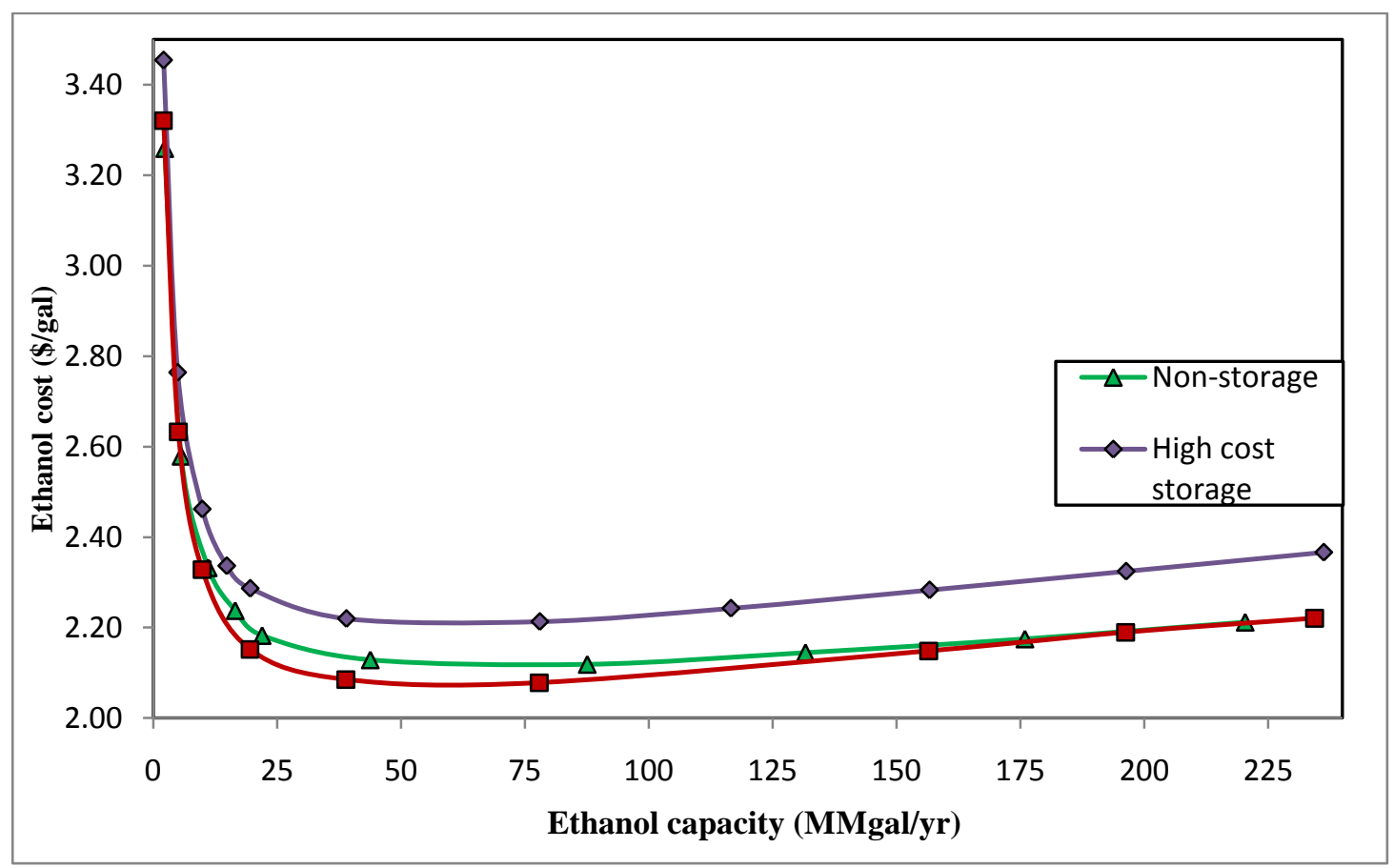

Figure 14 Optimal storage for reduced ethanol cost.

Each biomass is expected to decompose at different rates due to unique chemical compositions as well as environmental impacts. To obtain a rule of thumb for biomass storage, Figures 13 and 14 can be used to gauge the upper and lower bound for biomass storage for a particular capacity based on the physiochemical decomposition characteristics of a specified biomass. 


\section{CONCLUSIONS}

The overall study was successful in providing information on the optimization of a bioethanol facility. The data and results from the models can be used in the industry or by other researchers and design engineers as an initial screening tool for technology choice and process improvements.

The conclusion from the studies show that the AFEX pretreated configuration using corn stover is the optimal route that provides the minimum bioethanol sale price of $\$ 1.96 /$ gal. In contrast, industrial standards and literature show that the acid pretreatment configuration is preferentially used as a pretreatment choice. This is possibly as a result of the high fluctuations in ammonia price which is due to its high energy intensive process as well as its many demands in the agricultural industry. A further look at the results actually suggest that lime pretreatment of switchgrass is the more stable route that would not be severely affected by chemical price shifts. The results also indicate that the optimal plant size for minimal ethanol price is determined to be $2788 \mathrm{MT}$ biomass/day for the optimal configuration and between $2000 \mathrm{MT} /$ day and 4000MT/day for all other configurations. This is in agreement with some of the literature data and should be used as the way forward for the bioethanol industry.

Other key results from the study indicate that for each configuration choice, the yield of ethanol per unit mass of corn stover is similar to that of switchgrass which suggests that the use of switchgrass as an energy crop may not be as viable unless its price can be reduced to that of corn stover or lower. This conclusion is based on the data available for this study though industrial confidential data may show otherwise. 
In terms of biomass sources that have great potential for bioethanol production, the study reveals from the targeting approach as well as the optimization modeling that poplar shows the most promise in producing bioethanol. Its use today is unfortunately hindered by high feedstock costs as well as its availability in the United States. Provided fossil based fuel prices continue to rise, this biomass source would prove to be an economical and efficient way of producing ethanol.

The model developed for Case II is easily expandable and can be used for future examination of potential storage schemes for biomass in different climatic regions. Despite the simplicity of the model, its economic value lies in its ability to link biomass availability, decomposition rate and storage cost together in one single relationship. Using this model, Case Study II showed that storage of biomass with a simultaneous reduction in plant capacity is a more economical way of producing bioethanol in areas that have reduced biomass availabilities. This storage scheme is limited to plant capacities less than $3750 \mathrm{MT} /$ day above which non-storage is more economical. The results of this case study also show that the use of a storage scheme is moderately dependent on the decomposition rate as well as storage cost. This decomposition rate once linked to the cost of storage can be used to properly identify the limiting conditions for a biomass storage scheme. Based on assumed conditions and cost of storage, the optimal scenario for any storage scheme would be $0.5 \% /$ month decomposition rate while stored open to the atmosphere.

This study analyzed as many operational variables that influence the economics of a bioethanol plant though unfortunately did not incorporate all. In the future this 
optimization model can be expanded to include more experimental data such that a more definitive conclusion can be drawn about the economical optimality of a specific bioprocessing configuration. Future models can also integrate safety metrics that affect the location and equipment layout of the plant, thereby offering a complete optimization of not just processing but plant layout as well. Other interesting problems that can be solved from the model are to determine optimal plant locations within the United States such that an optimal ethanol distribution network can be established. 


\section{LITERATURE CITED}

1. Sissine F. CRS Report for Congress. Energy Independence and Security Act of 2007 http://energy.senate.gov/public/_files/RL342941.pdf.

2. Huber GW. Breaking the Chemical and Engineering barriers to Lignocellulosic Biofuels 2007; http://www.ecs.umass.edu/biofuels/Images/Roadmap2-08.pdf.

3. Bouton J, Bransby D, Conger B, McLaughlin S, Ocumpaugh W, et al. Developing Switchgrass as a Bioenergy Crop Perspectives on new crops and new uses. 1998:p. 35

4. Guffey FD, Wingerson RC. Fractionation of lignocellulosic biomass for fuelgrade ethanol production. 2002; . Available at: http://www.osti.gov/energycitations/servlets/purl/807155-kbdGYV/native/.

5. McLaughlin SB, Adams-Kszos L. Development of switchgrass (Panicum virgatum) as a bioenergy feedstock in the United States. Biomass and Bioenergy. 2005;28(6):515-535.

6. McLaughlin SB, Kiniry JR, Taliaferro CM, Ugarte DD. Projecting yield and utilization potential of switchgrass as an energy crop. Advances in Agronomy 2006;90:267-297.

7. Morrow WR, Griffin WM, Matthews HS. Modeling switchgrass derived cellulosic ethanol distribution in the United States. Environmental Science \& Technology. 2006;40(9):2877-2886.

8. Cardona CA, Sánchez ÓJ. Fuel ethanol production: Process design trends and integration opportunities. Bioresource Technology. 2007;98(12):2415-2457. 
9. Gunderson CA, Davis E, Jager Y, West TO, Perlack RD, et al. Exploring Potential U.S. Switchgrass Production for Lignocellulosic Ethanol 2008; http://www.osti.gov/bridge/servlets/purl/936551-xk7e8M/.

10. Balan V, Bals B, Chundawat SP, Marshall D, Dale BE. Lignocellulosic biomass pretreatment using AFEX. Methods in Molecular Biology. 2009;581:61-77.

11. Nlewem KC, Thrash Jr ME. Comparison of different pretreatment methods based on residual lignin effect on the enzymatic hydrolysis of switchgrass. Bioresource Technology. 2010;101(14):5426-5430.

12. Balat $\mathrm{M}$, Balat $\mathrm{H}$. Recent trends in global production and utilization of bioethanol fuel. Applied Energy. 2009;86(11):2273-2282.

13. Chang V, Nagwani M, Holtzapple M. Lime pretreatment of crop residues bagasse and wheat straw. Applied Biochemistry and Biotechnology. 1998;74(3):135-159.

14. Perrin R, Vogel K, Schmer M, Mitchell R. Farm-scale production cost of switchgrass for biomass. Bioenergy Research. 2008;1(1):91-97.

15. Teymouri F, Laureano-Perez L, Alizadeh H, Dale BE. Optimization of the ammonia fiber explosion (AFEX) treatment parameters for enzymatic hydrolysis of corn stover. Bioresource Technology. 2005;96(18):2014-2018.

16. Esteghlalian A, Hashimoto AG, Fenske JJ, Penner MH. Modeling and optimization of the dilute-sulfuric-acid pretreatment of corn stover, poplar and switchgrass. Bioresource Technology. 1998;59(2-3):129-136. 
17. Chang VS, Burr B, Holtzapple MT. Lime pretreatment of switchgrass. Applied Biochemistry and Biotechnology. 1997;63-5:3-19.

18. Ladisch MR, R.Weil J, Inventors; Purdue Research Foundation Office of Technology Transfer, assignee. Processes for treating cellulosic material. . US patent 5846787. 1994.

19. Steele B, Raj S, Nghiem J, Stowers M. Enzyme recovery and recycling following hydrolysis of ammonia fiber explosion-treated corn stover. Applied Biochemistry and Biotechnology. 2005;124(1):901-910.

20. Alkasrawi M, Eriksson T, Börjesson J, Wingren A, Galbe M, et al. The effect of Tween-20 on simultaneous saccharification and fermentation of softwood to ethanol. Enzyme and Microbial Technology. 2003;33(1):71-78.

21. Moniruzzaman M, Dien BS, Skory CD, Chen ZD, Hespell RB, et al. Fermentation of corn fibre sugars by an engineered xylose utilizing Saccharomyces yeast strain. World Journal of Microbiology \& Biotechnology. $1997 ; 13(3): 341-346$.

22. Zondervan E, Nawaz M, de Haan AB, Woodley JM, Gani R. Optimal design of a multi-product biorefinery system. Computers \& Chemical Engineering. 2011; In Press, Corrected Proof.

23. Kumar A, Sokhansanj S. Switchgrass (Panicum vigratum, L.) delivery to a biorefinery using integrated biomass supply analysis and logistics (IBSAL) model. Bioresource Technology. 2007;98(5):1033-1044. 
24. El-Halwagi MM, Process Integration Amsterdam; Elsevier Academic Press. 2006.

25. Alizadeh H, Teymouri F, Gilbert T, Dale B. Pretreatment of switchgrass by ammonia fiber explosion (AFEX). Applied Biochemistry and Biotechnology. 2005;124(1):1133-1141.

26. Kim S, Holtzapple MT. Lime pretreatment and enzymatic hydrolysis of corn stover. Bioresource Technology. 2005;96(18):1994-2006.

27. Kim TH, Kim JS, Sunwoo C, Lee YY. Pretreatment of corn stover by aqueous ammonia. Bioresource Technology. 2003;90(1):39-47.

28. Mosier N, Hendrickson R, Ho N, Sedlak M, Ladisch MR. Optimization of pH controlled liquid hot water pretreatment of corn stover. Bioresource Technology. 2005;96(18):1986-1993.

29. Kazi. FK, J. Fortman RA, Hsu. D. Techno-Economic Analysis of Biochemical Scenarios for Production of Cellulosic Ethanol. 2010; http://www.nrel.gov/docs/fy10osti/46588.pdf.

30. Max S. Peters, Timmerhaus KD. Plant Design and Economics for Chemical Engineers. 5th ed: New York: McGraw-Hill; 2003.

31. Mahmudi H, Flynn P. Rail vs truck transport of biomass. Applied Biochemistry and Biotechnology. 2006;129(1):88-103.

32. Sokhansanj S, Mani S, Turhollow A, Kumar A, Bransby D, et al. Large-scale production, harvest and logistics of switchgrass (Panicum virgatum L.): current 
technology and envisioning a mature technology. Biofuels Bioproducts \& Biorefining. 2009;3(2):124-141.

33. Huang H-J, Ramaswamy S, Al-Dajani W, Tschirner U, Cairncross RA. Effect of biomass species and plant size on cellulosic ethanol: A comparative process and economic analysis. Biomass and Bioenergy. 2009;33(2):234-246.

34. Brechbill SC, Tyner WE, Ileleji KE. The economics of biomass collection and transportation and Its supply to Indiana cellulosic and electric utility facilities. Bioenergy Research. 2011;4(2):141-152.

35. EPA. Cap and Trade: Essentials. 2011; http://www.epa.gov/capandtrade/documents/ctessentials.pdf.

36. Maker AD. Cash Rentals Rates for Iowa. 2011; http://www.extension.iastate.edu/publications/fm1851.pdf. 
APPENDIX A

PROCESS FLOW DIAGRAMS

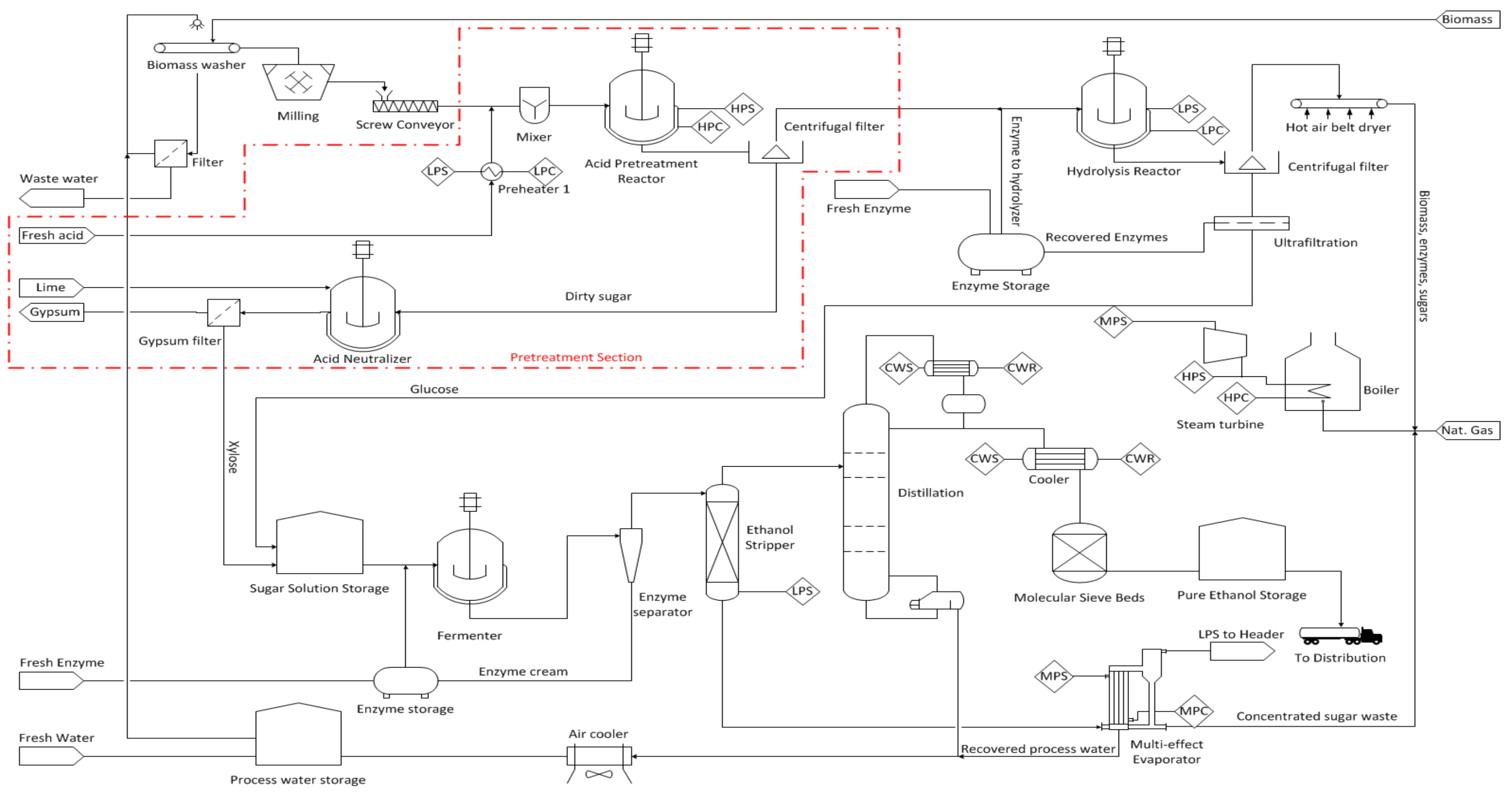

Figure 15 Overall bioethanol production plant configuration. 


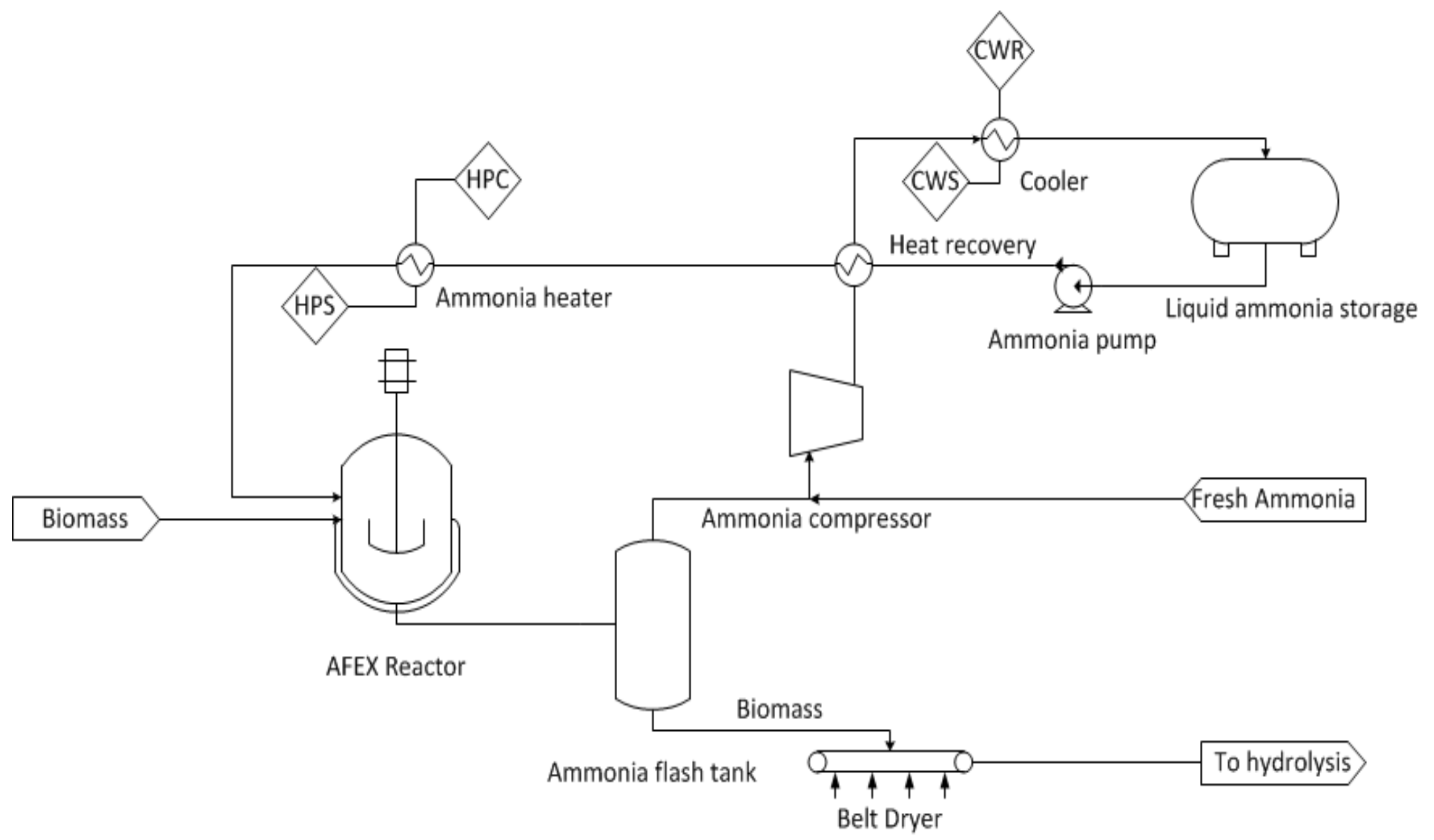

Figure 16 Ammonia fiber explosion pretreatment. 


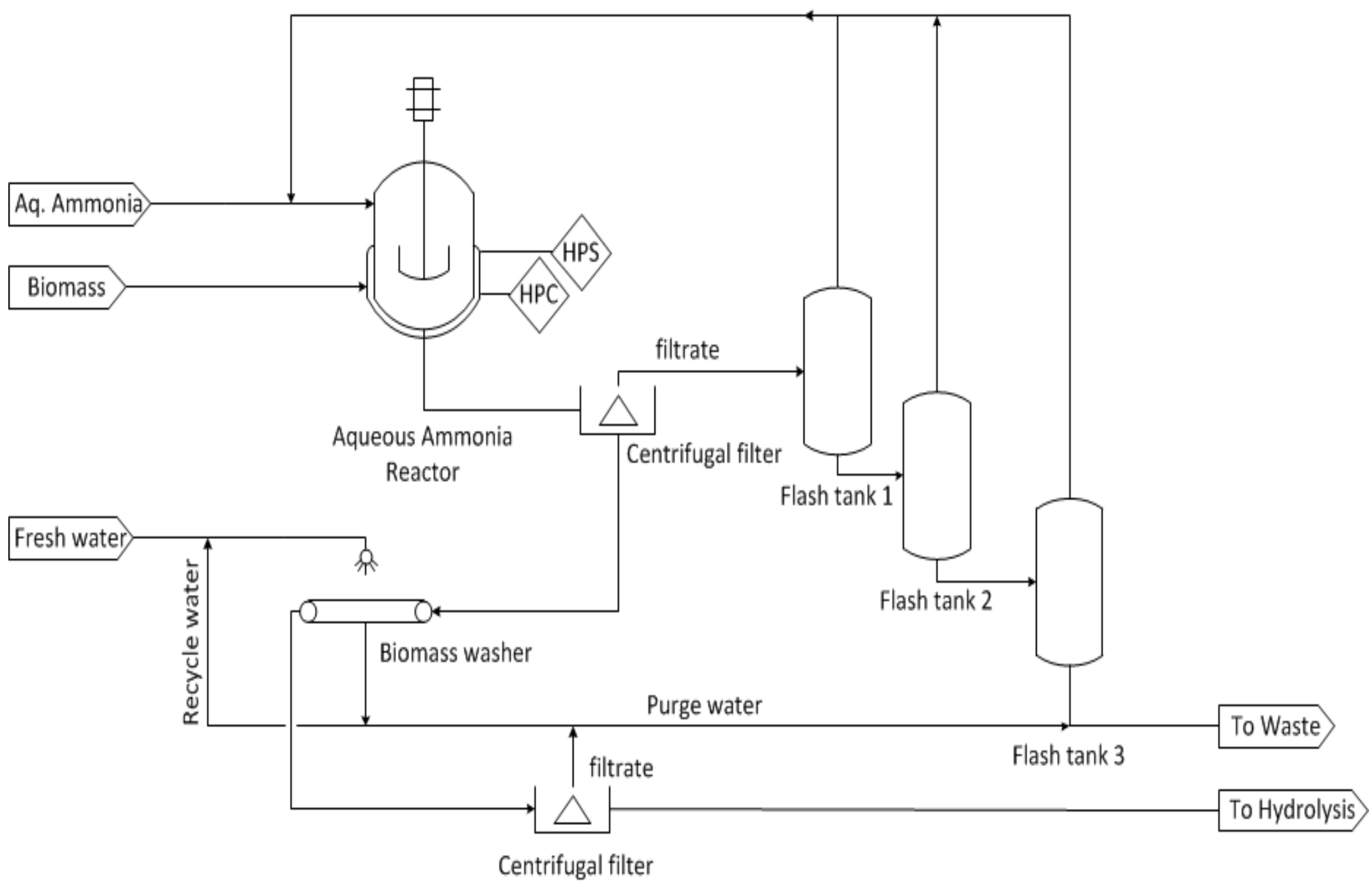

Figure 17 Aqueous ammonia recirculation and percolation pretreatment. 


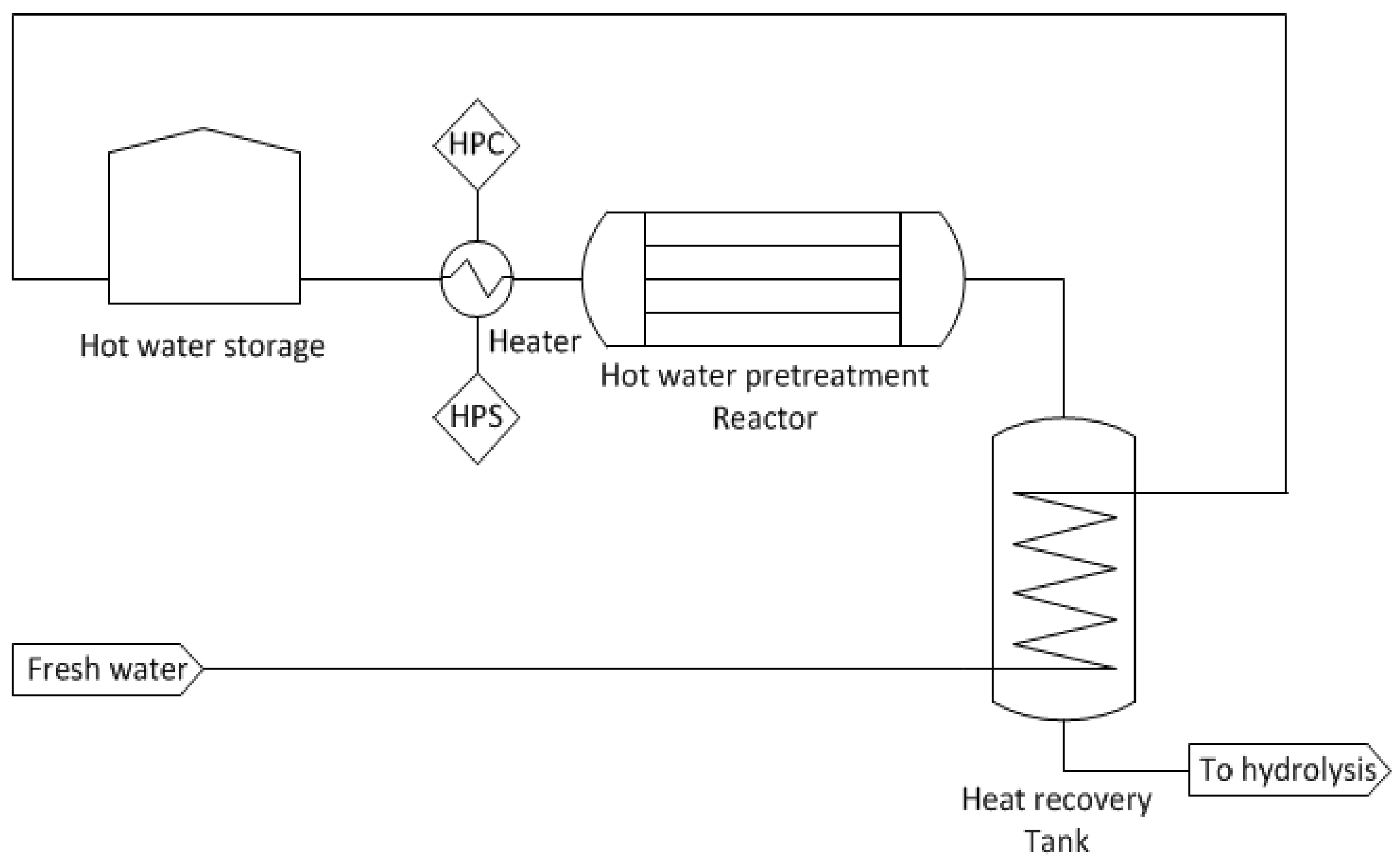

Figure $18 \mathrm{pH}$ controlled hot water pretreatment. 


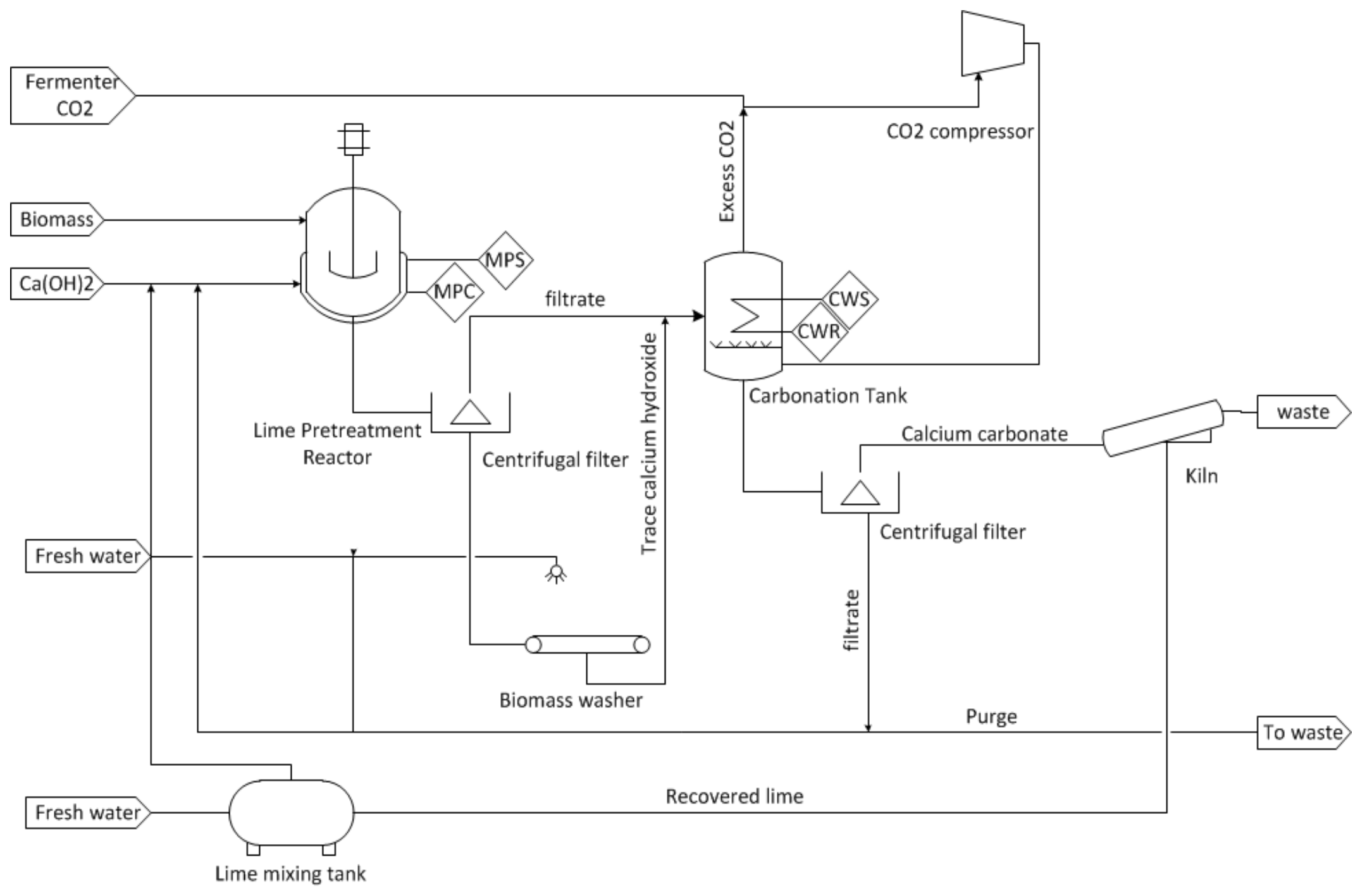

Figure 19 Lime pretreatment. 


\section{APPENDIX B}

\section{OPTIMIZATION PROGRAM}

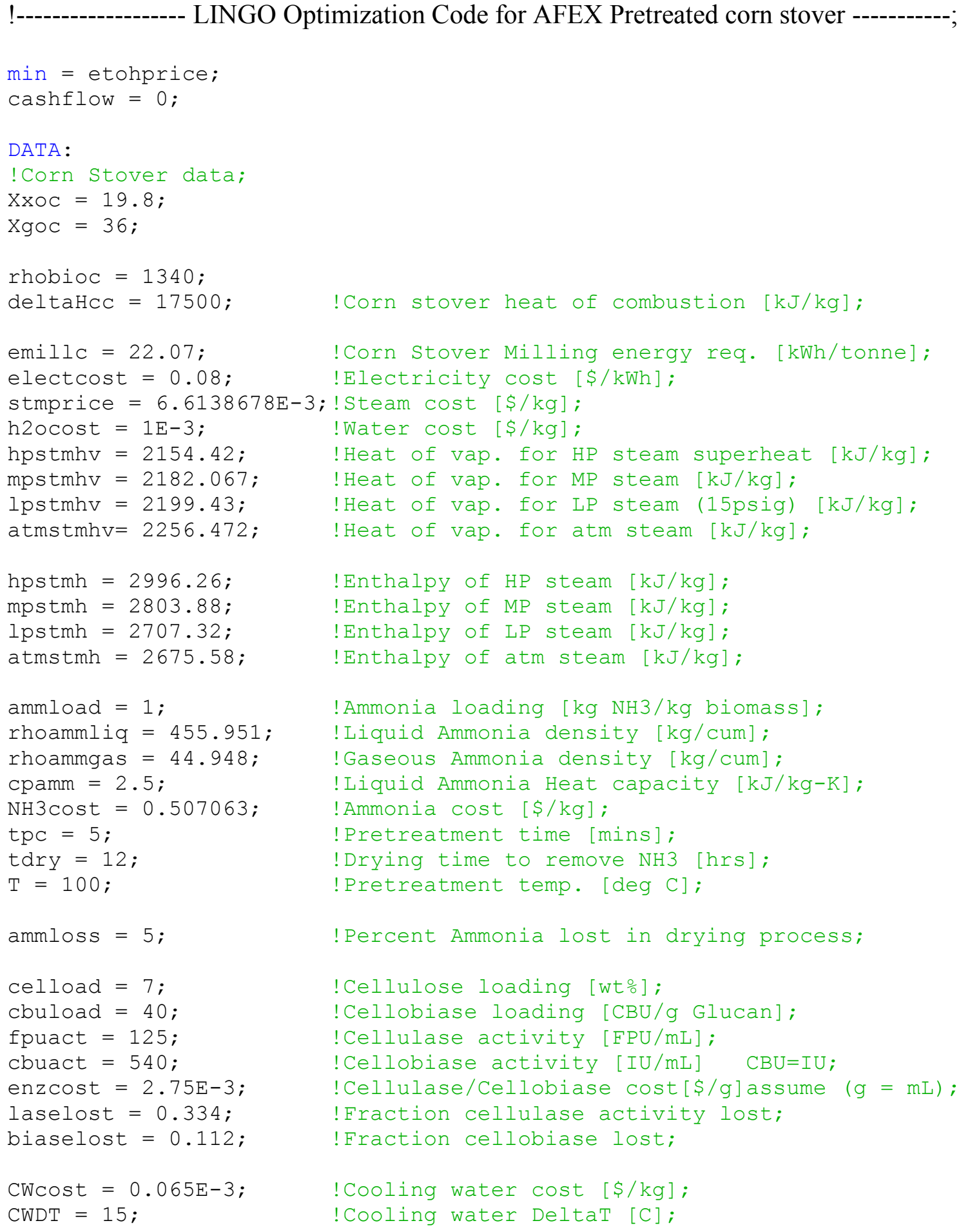




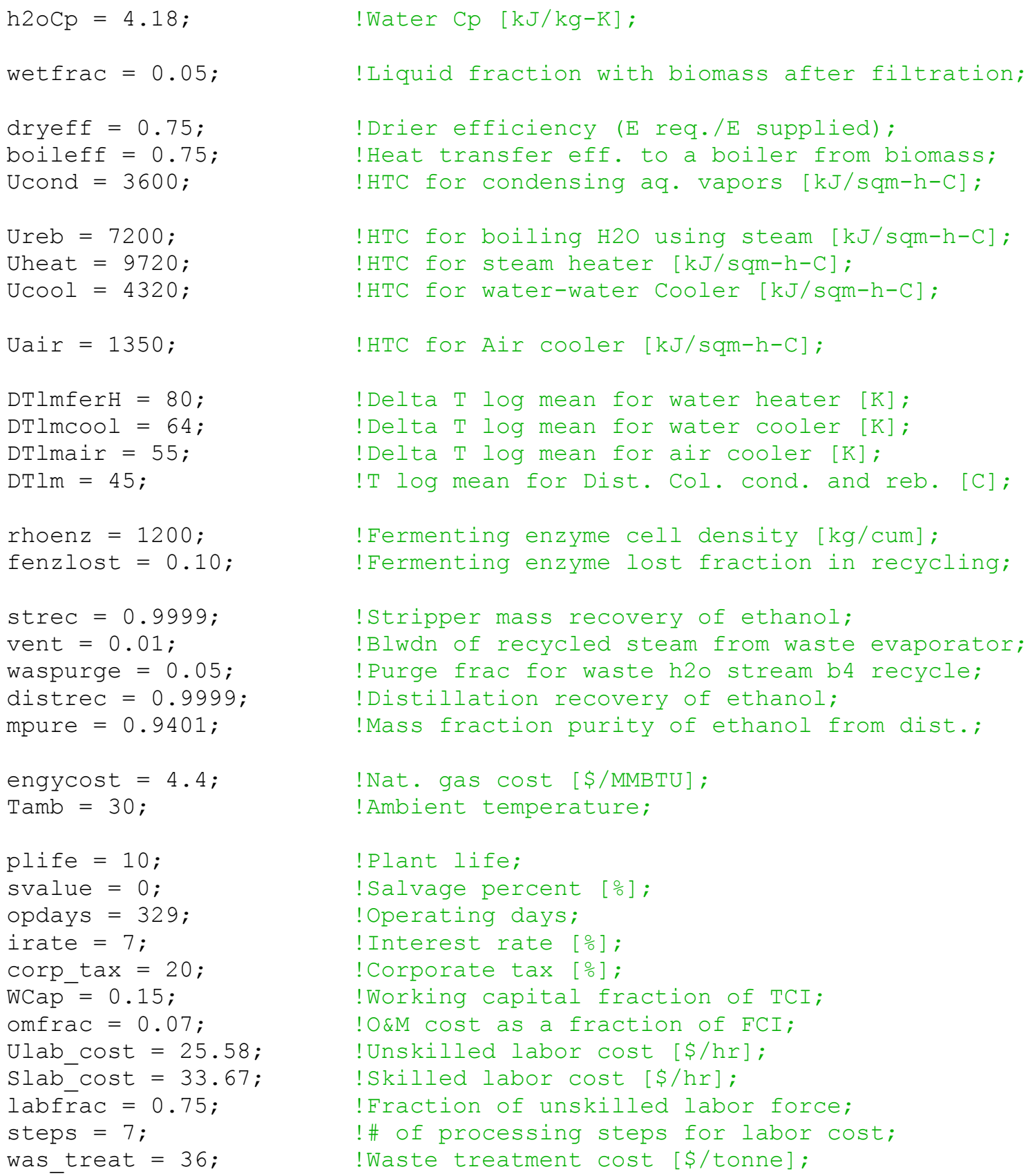

!Enzyme concentration [g dry cell wt/L liquid]; !Hydrolysis cellulase loading [FPU/g Glucan]; !Hydrolysis time [hrs]; !Fermentation time [hrs];

!No. of Fermenters at the max vol.(4000 cum); !No. of Stripper columns req.; 


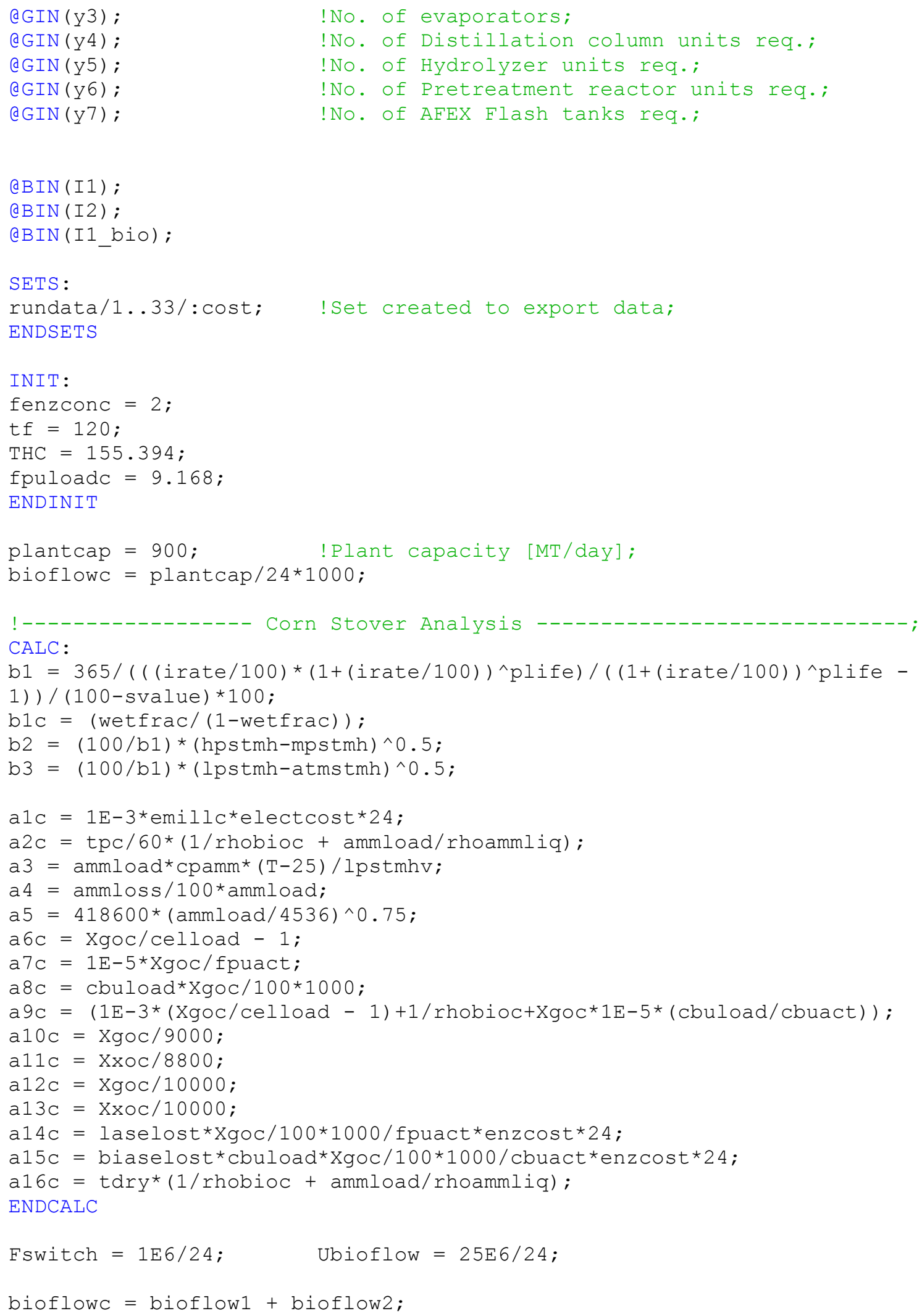




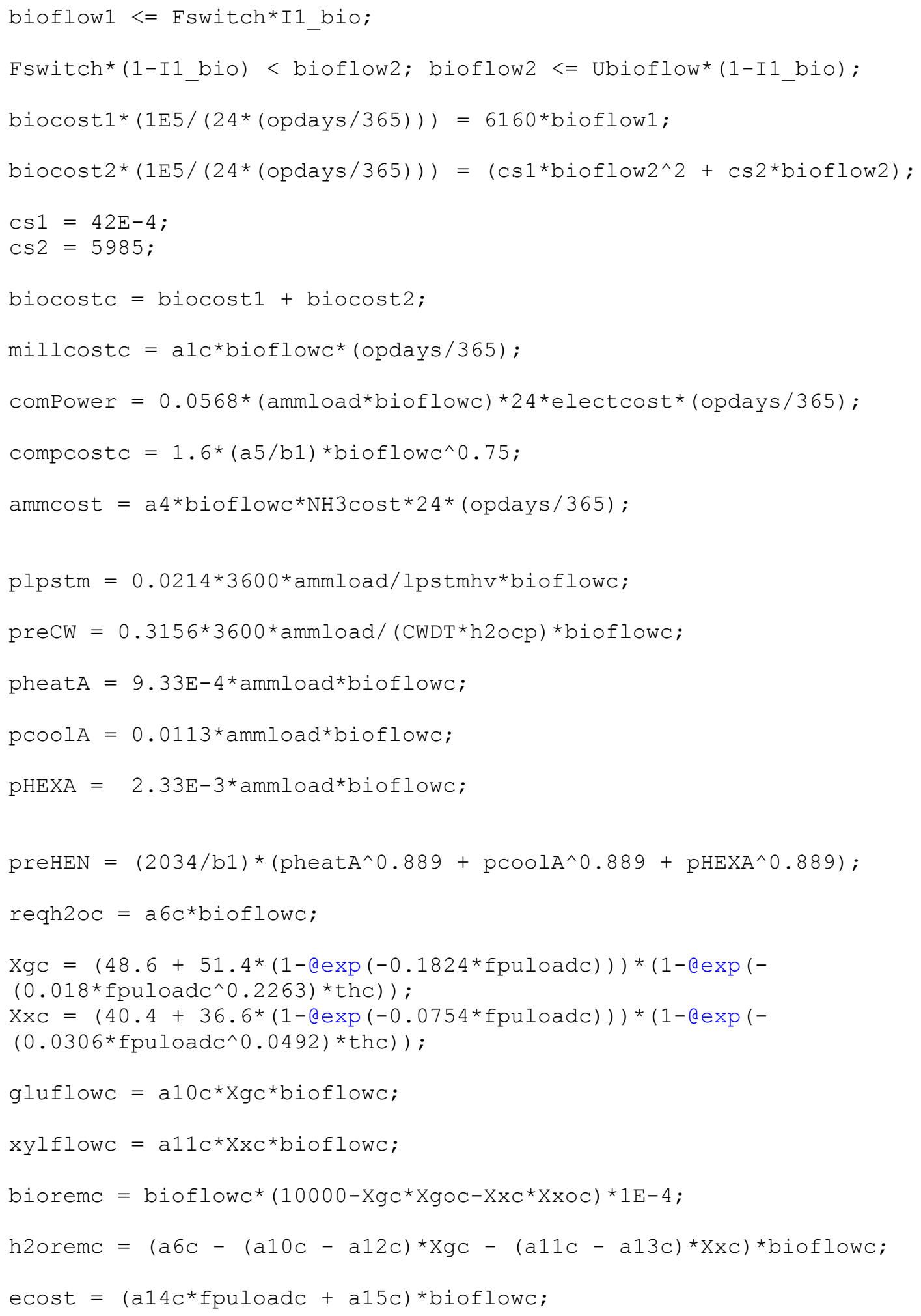




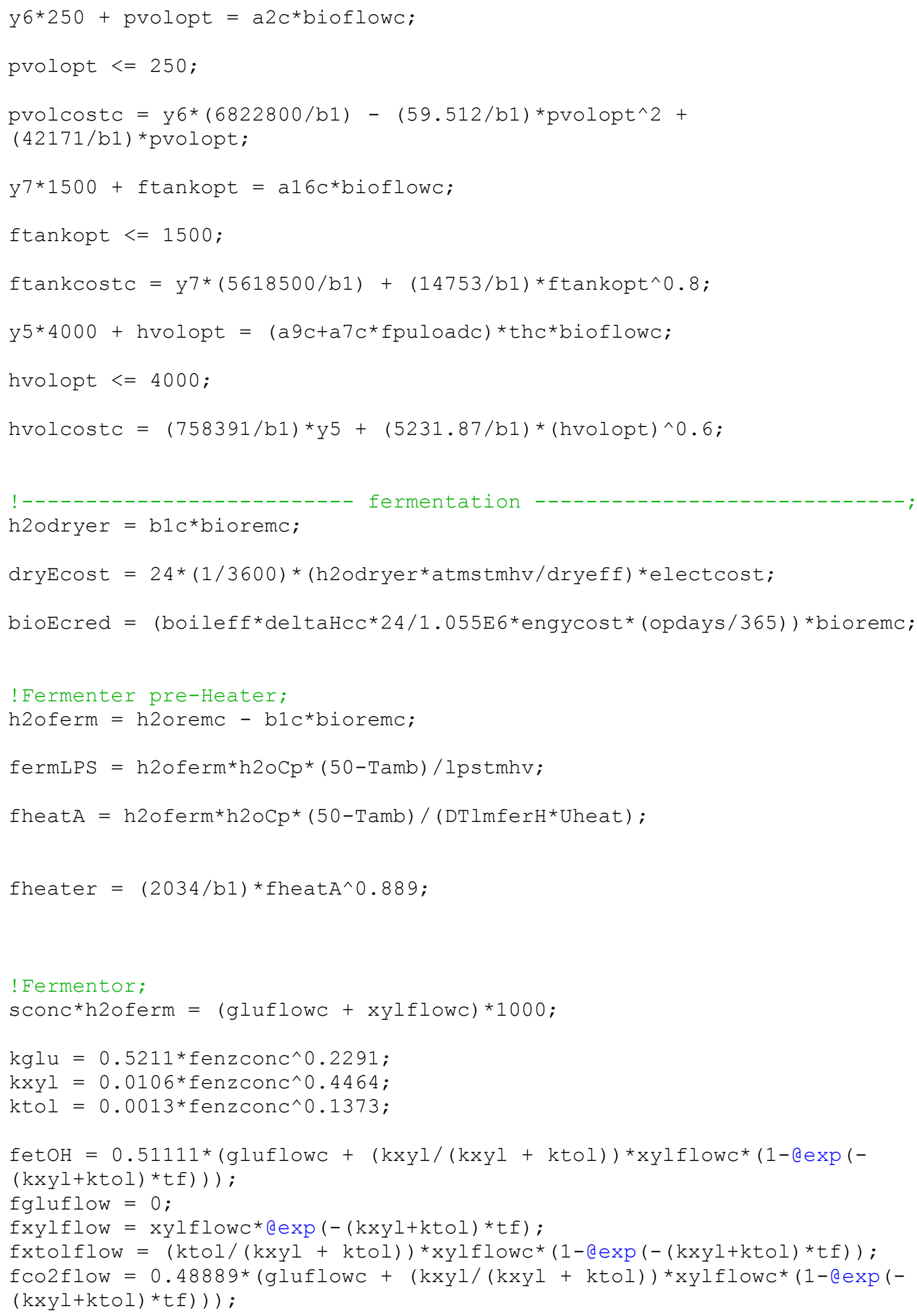




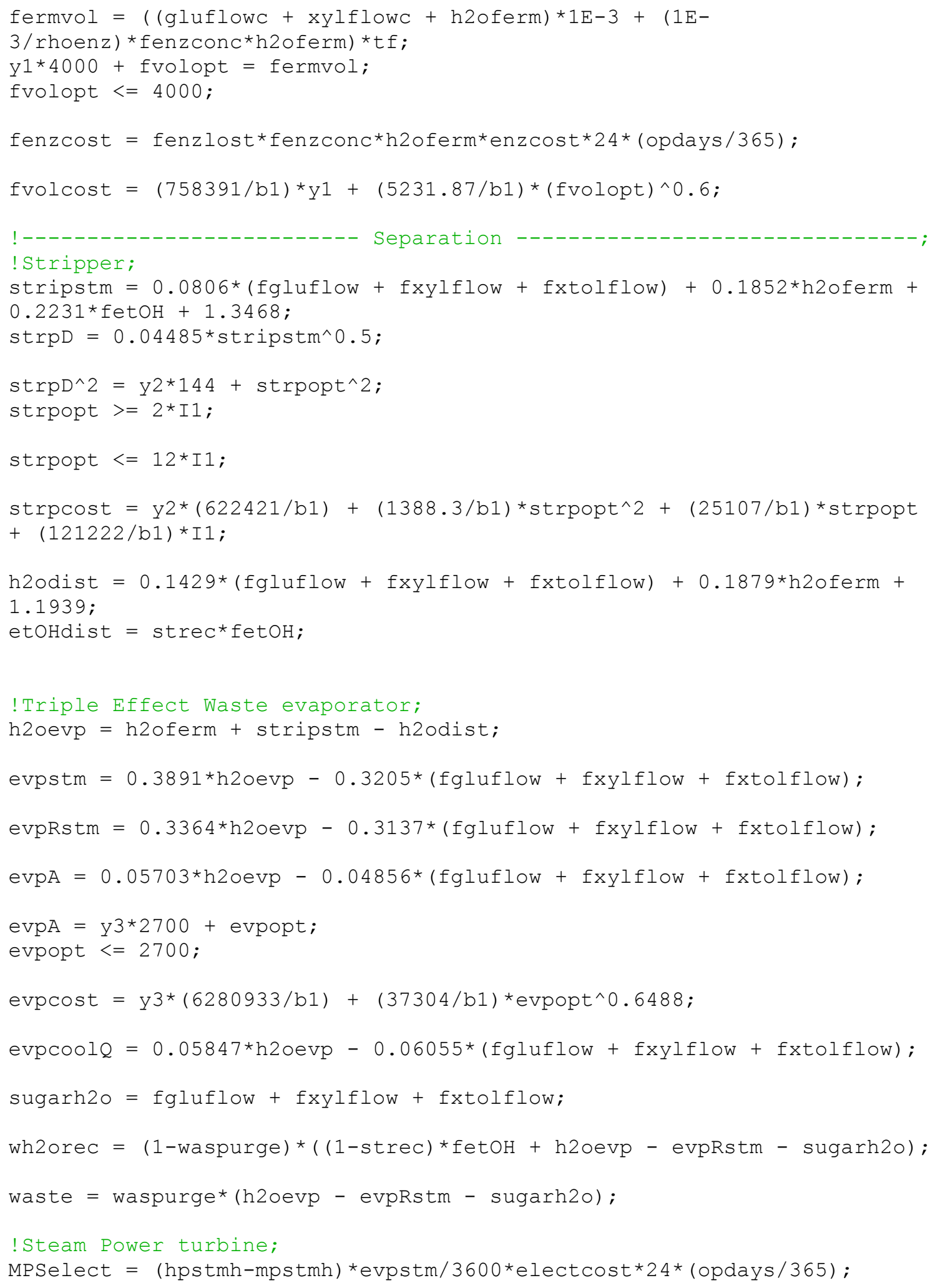




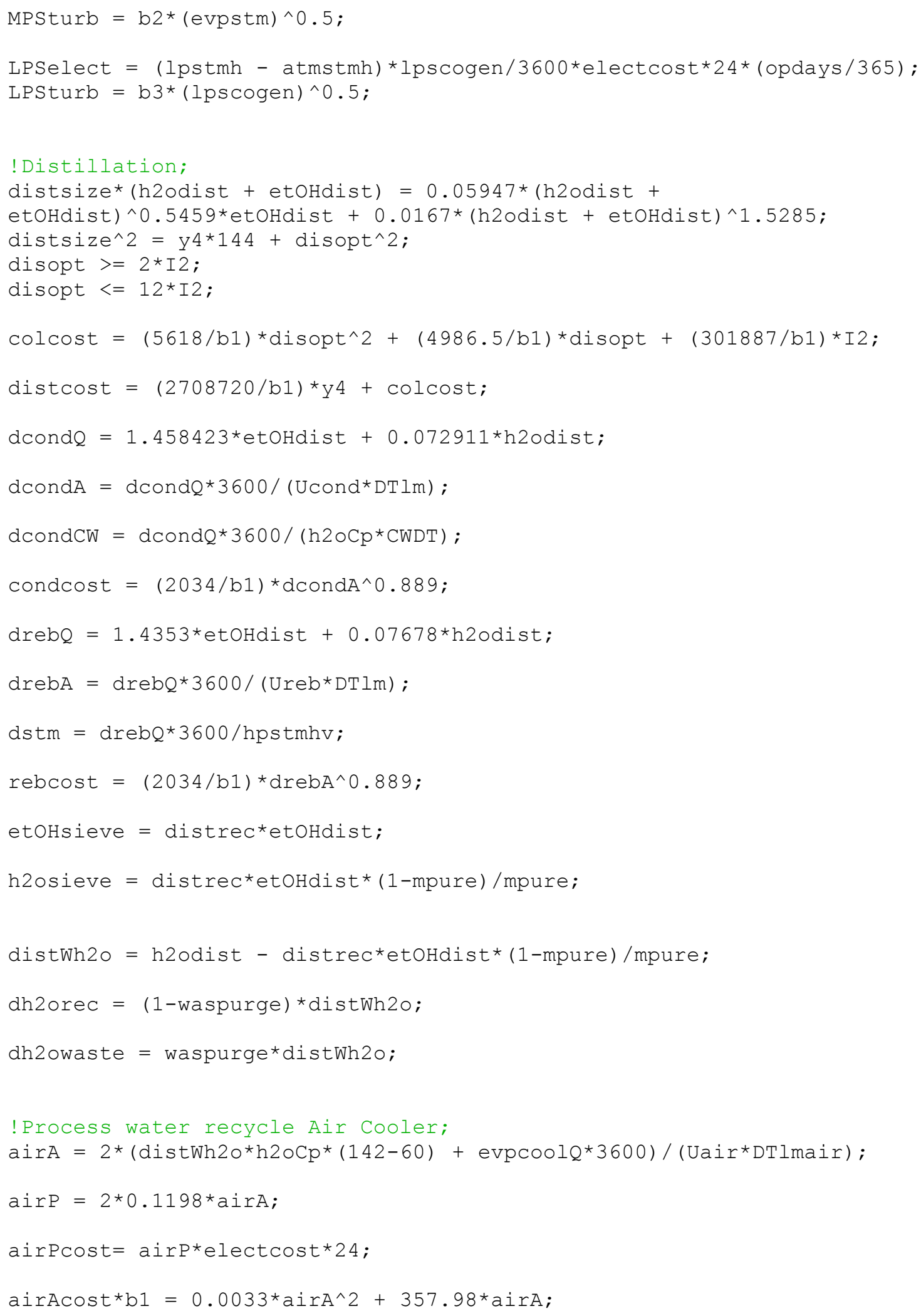




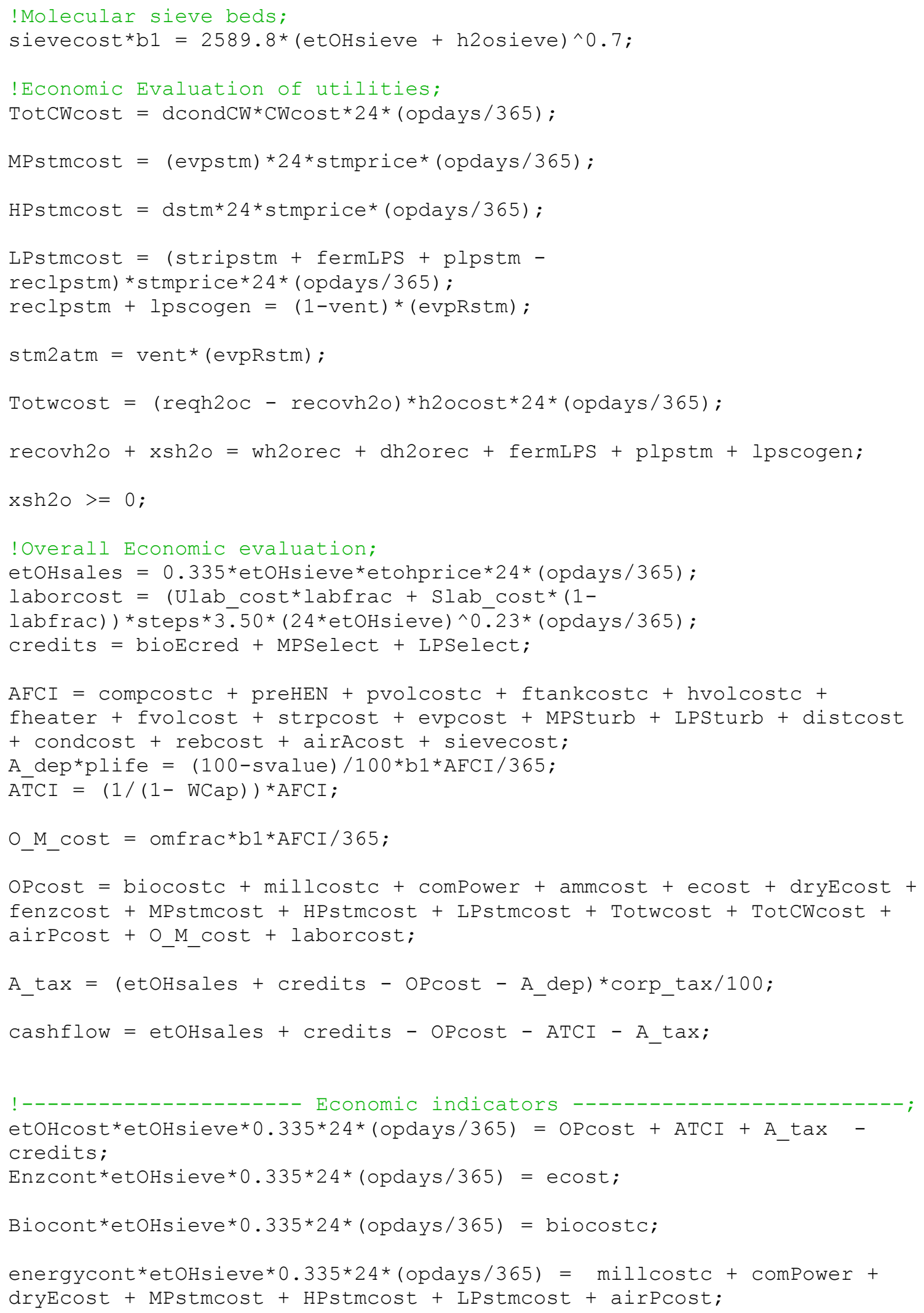




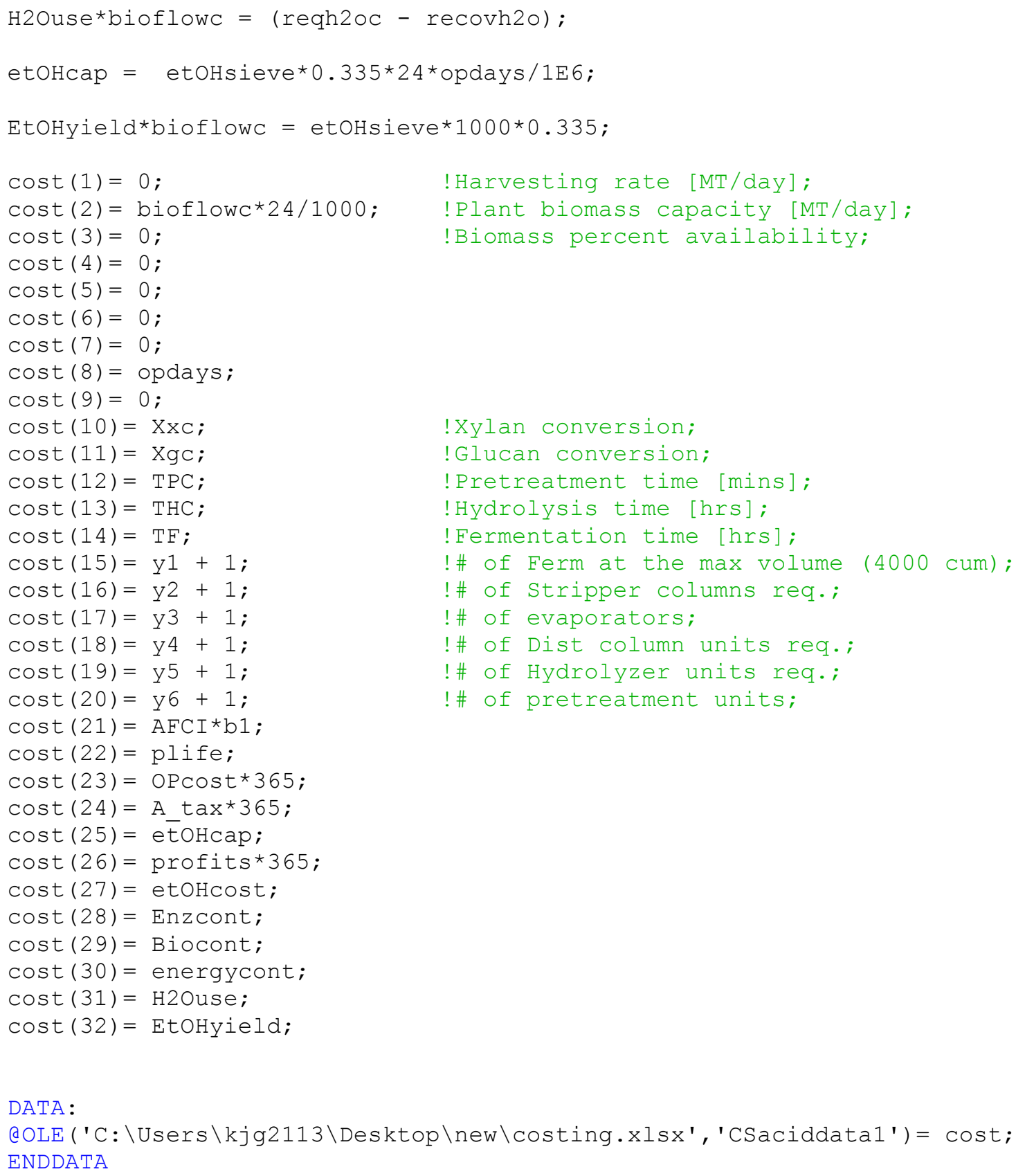




\section{VITA}

Kerron Jude Gabriel was born and grew up in Coryal, Trinidad and Tobago. He received a Bachelor of Science Degree in chemical engineering from the University of the West Indies in 2006 and began work as a Process Systems Engineer at Bechtel Engineering in Pointe a Pierre, Trinidad. He joined the graduate program in the Department of Chemical Engineering in Texas A\&M University in August 2009 and completed his master's degree in August 2011.

Mr. Gabriel may be reached at the Department of Chemical Engineering, Texas A\&M University, College Station TX 77843-3122. His email is kgabriel@neo.tamu.edu. 